\title{
Physiological and genetic mechanism(s) of cold acclimation in Rhododendron
}

Chon Chong Lim

West Virginia University

Follow this and additional works at: https://researchrepository.wvu.edu/etd

\section{Recommended Citation}

Lim, Chon Chong, "Physiological and genetic mechanism(s) of cold acclimation in Rhododendron" (1999). Graduate Theses, Dissertations, and Problem Reports. 1037.

https://researchrepository.wvu.edu/etd/1037

This Dissertation is protected by copyright and/or related rights. It has been brought to you by the The Research Repository @ WVU with permission from the rights-holder(s). You are free to use this Dissertation in any way that is permitted by the copyright and related rights legislation that applies to your use. For other uses you must obtain permission from the rights-holder(s) directly, unless additional rights are indicated by a Creative Commons license in the record and/ or on the work itself. This Dissertation has been accepted for inclusion in WVU Graduate Theses, Dissertations, and Problem Reports collection by an authorized administrator of The Research Repository @ WVU.

For more information, please contact researchrepository@mail.wvu.edu. 


\title{
Physiological and Genetic Mechanism(s) of Cold Acclimation in Rhododendron
}

\author{
Chon Chong Lim, B.Sc., M.Sc.
}

\author{
Dissertation submitted to the College of \\ Agriculture, Forestry and Consumer Sciences \\ at West Virginia University \\ in partial fulfillment of the requirements \\ for the degree of
}
Doctor of Philosophy in Agricultural Sciences

\author{
Rajeev Arora, Ph.D., Chair \\ Bradford C. Bearce, Ph.D. \\ Jonathan R. Cumming, Ph.D. \\ Stephen L. Krebs, Ph.D. \\ Daniel G. Panaccione, Ph.D. \\ Department of Horticulture \\ Division of Plant and Soil Sciences
}

\author{
Morgantown, West Virginia \\ 1999
}

Keywords: Cold Acclimation, Dehydrin, Genetics, Ion-Leakage, Juvenility, Molecular Marker, Rhododendron, Woody Plants

Copyright 1999 Chon C. Lim 


\section{ABSTRACT}

\section{PHYSIOLOGICAL AND GENETIC MECHANISM(S) OF COLD ACCLIMATION IN RHODODENDRON.}

\section{Chon-Chong Lim}

An in vitro laboratory protocol for assessing cold hardiness $(\mathrm{CH})$ in rhododendrons based on electrolyte-leakage was developed. The raw leakage data were transformed into percentadjusted injury, which showed high correlation with injury data based on visual observations. The percent-adjusted injury data - fitted to the Gompertz function coupled with the Jackknife method - allowed for reliable and statistically sound estimations of Rhododendron leaf freezingtolerance (LFT). Utilizing this method, $\mathrm{T}_{\max }$ values for Rhododendron cultivars, species, and populations were determined and ranked relatively. Our observation of a continuous distribution of LFT in $\mathrm{F}_{2}$ and backcross (BC) populations derived from a $R$. catawbiense $\mathrm{x} R$. fortunei cross suggested that as few as three genes with strong additive effects were controlling variation in $\mathrm{CH}$. Differences in mid-winter freezing tolerance (FT) were primarily due to differences in acclimating ability among the progenies and were independent of non-acclimated FT. A 25-kDa dehydrin correlated with LFT differences among cold-acclimated $\mathrm{F}_{2}$ segregants. Moreover, its expression increased as LFT increased with both chronological age and developmental phasechange of wild and cultivated plants. The presence or absence of the 25-kDa dehydrin may serve as a genetic marker for 'super' $\mathrm{CH}$ in Rhododendron. Rhododendron seedlings (in $\mathrm{F}_{1}, \mathrm{~F}_{2}$ and $\mathrm{BC}$ populations segregating for $\mathrm{T}_{\max }$ ) increased their yearly average LFT by about $5-6{ }^{\circ} \mathrm{C}$ during the period of juvenile growth. This change in $\mathrm{CH}$ is likely the reflection of an increased ability to cold acclimate, however, the degree of $\mathrm{CH}$ increment in individual progenies varied yearly. Bulked segregant analysis (a PCR-RAPD-based technique) was used to identify molecular markers in Rhododendron progenies segregating for $\mathrm{CH}$. No markers were found to be associated with super cold-hardy genes, however a putative marker linked with low $\mathrm{CH}$ bulk was detected. The data from a nutritional study showed no correlation between nutrient status and seasonal CH of Rhododendron. 


\section{DEDICATIONS}

To my parents, Lim Mok Hai and Chee Sow

Chan for instilling within me the value of a good education

To my wife, Lim Chwee Chee for her

relentless support and encouragement in the past several years of hardship

Also, in memory of my late grandmother-inlaw, Lee Yem Cheong who left us this past February 


\section{ACKNOWLEDGEMENTS}

This journey to the pinnacle of my academic career represents the realization of a lifetime dream. I have aspired to this high and honorable degree because of the support, encouragement and advice of so many valuable people.

I would like to acknowledge the assistance provided by my dissertation committee, particularly Dr. Rajeev Arora who assumed the leadership role on my committee. His suggestions and support have been invaluable to me. Dr. Steve Krebs, I thank for his enormous contribution to two of my chapters and the long journey he had to travel from Ohio to WV each time I call for a committee meeting. I thank Dr. Brad Bearce for his advice on "rhodies" cultivation and I particularly enjoy his stories during those long road trips to national conferences. I thank Dr. Dan Panaccione and Dr. Jonathan Cumming for their support and willingness to help at all times. Every student should have such support from this group of professionals.

I would like to acknowledge several administrative personnel, particularly Associate Provost Rosemary Haggett who (as the former dean of the college) have always offered her helping hands. Associate Dean Kerry Odell who allowed me to attend the graduation ceremonies ahead of time. Dr. Barton Baker for his support of my graduate studies.

I would be remiss if I did not express my appreciation to several individuals who have assisted me in various technical means in order to complete this huge project. Dr. Townsend, my statistician and teacher who provided the very foundation upon which this dissertation is built. My thanks to the greenhouse crew, particularly to Sue Myers and Gail Sikorsky for their "green' hands and keeping my plant material alive. My special thanks to Hatice Gulen, my lab collaborator during my last year here who brought warmness into the cold hardiness lab. My thanks to Mohd. Salleh Daim for his help in evaluating the Rhododendron LFT. I would also like to express my appreciation to Dr. Bob Marquard and Eric Davis of the Holden Arboretum for sharing their RAPD techniques. I am indebted to Dr. Bhumbla for his advice on leaf nutrient analysis and Joan Wright for performing the leaf nutrient analysis on the ICP. Last but not least I want to thank Gloria Nestor for putting parts of my posters together in single pieces.

I want to thank my fellow "cohorts" for their support over the past fours years. Donna Ballard and Marlene Cross who are always there to help out whenever I needed assistance during my doctoral program. I could not have asked for a better company to squeeze into our tiny office space.

Most of all, I want to thank my children -Tian and Jacquelina- and my wife -Chwee Chee- for allowing me to be absence in the family scene the past couple of years. Your unconditional love and encouragement had permitted me to persist through difficult times and rise to top at the end. Also, I want to thank my parents -Lim Mok Hai and Chee Sow Chan-for they are my greatest source of my education.

This work is definite a reflection of hard work, persistence, perseverance, sacrifices, love, passion and most of all the collective generosity of so many people that allowed me to string together into a so called dissertation. 


\section{TABLE OF CONTENTS}

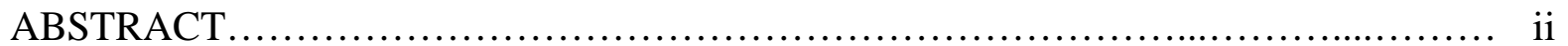

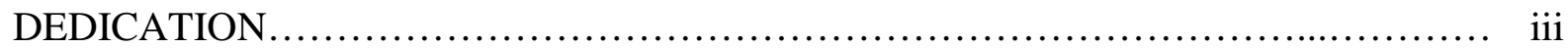

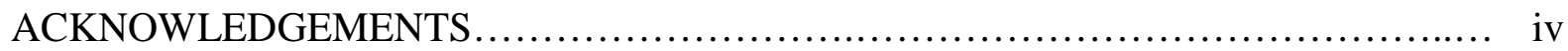

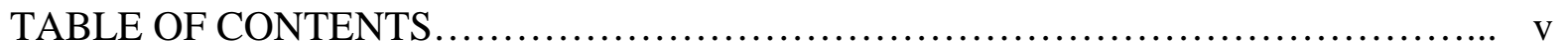

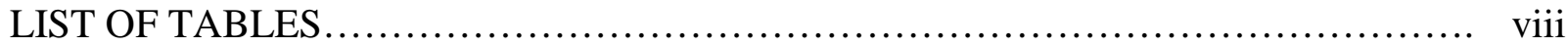

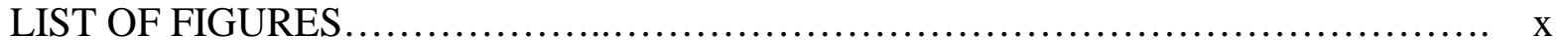

LIST OF ABBREVIATIONS...................................................... xii

CHAPTER ONE: INTRODUCTION_........................................... 1

Literature review.......................................................... 2

Nature of freezing in woody plants.................................. 3

Supercooling versus equilibrium freezing........................ 3

Assessment of injury.................................................. 4

Electrolyte-leakage method and quantitative measure of cold hardiness................................................... 4

Response curve fitting and statistical analysis .................... 5

Cold acclimation .................................................. 6

Rhododendron as experimental source.......................... 6

Genetics of freezing tolerance.................................. 7

Bulked segregant analysis and RAPD markers.............. 8

Biochemical changes......................................... 9

Dehydrin........................................... 9

Other factors influencing cold acclimating ability.................. 11

Juvenility........................................... 12

Nutrient status........................................ 12

Research objectives...................................................... 14

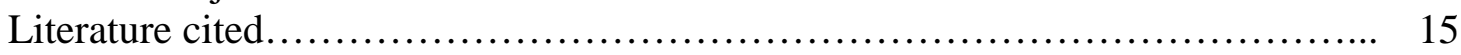

Organization of the remaining chapters..................................... 24

CHAPTER TWO: DEVELOPMENT OF AN IN VITRO PROTOCOL TO ESTIMATE LEAF FREEZING-TOLERANCES IN RHODODENDRON.......................... 25

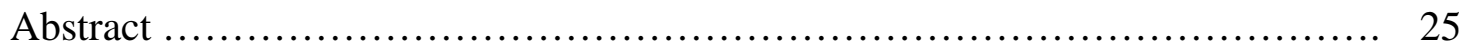

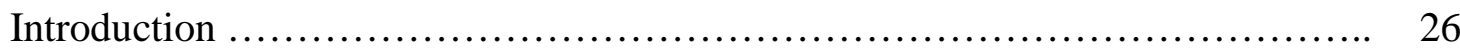

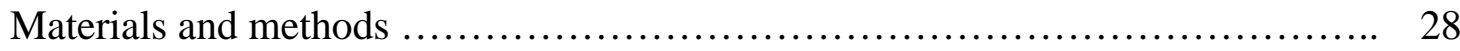

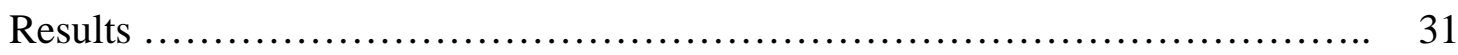

Discussion ................................................................. 32

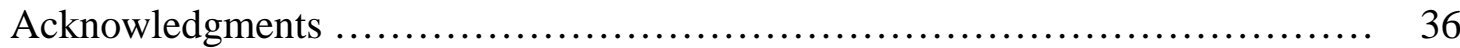

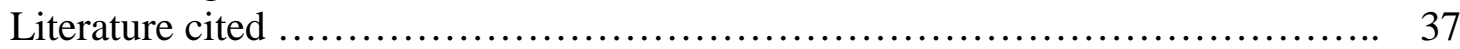


CHAPTER THREE: FREEZING-TOLERANCE IN RHODODENDRON

POPULATIONS: GENETICS................................................... 46

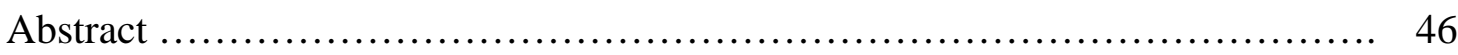

Introduction .......................................................... 47

Materials and methods ...................................................... 49

Results and discussion................................................... 51

Conclusions........................................................... 56

Acknowledgments .................................................. 57

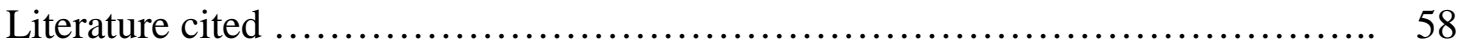

CHAPTER FOUR: DEHYDRIN AND ITS ASSOCIATION WITH RHODODENDRON

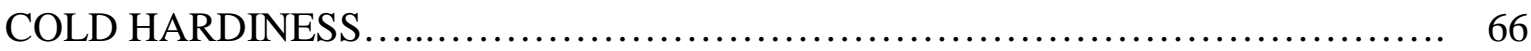

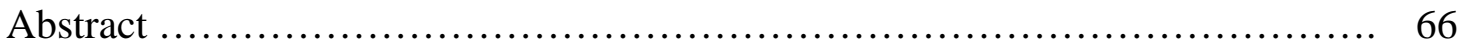

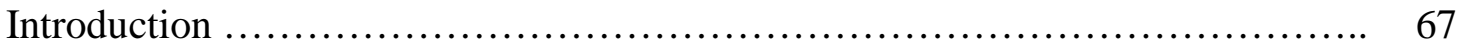

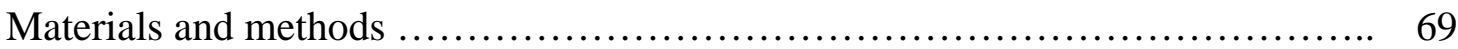

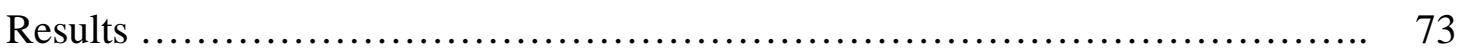

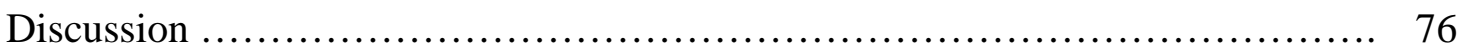

Acknowledgments .................................................. 80

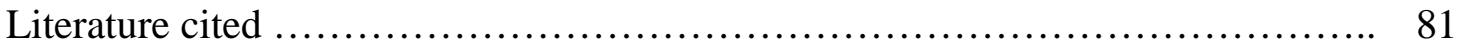

CHAPTER FIVE: PLANT AGE INFLUENCES LEAF FREEZING-TOLERANCE IN

RHODODENDRON POPULATIONS ........................................ 91

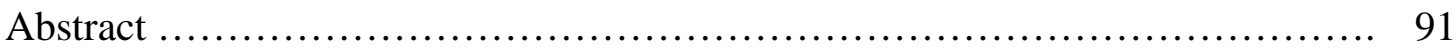

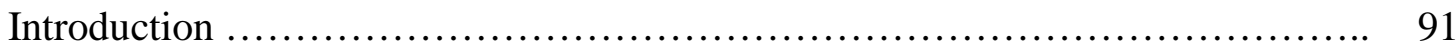

Materials and methods .................................................... 92

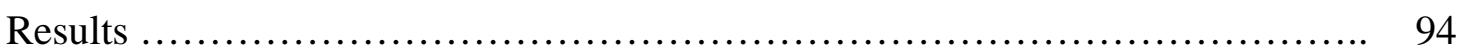

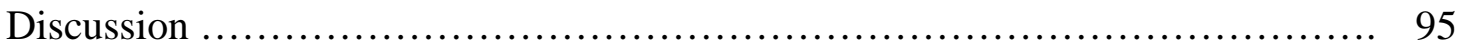

Acknowledgments ........................................................ 96

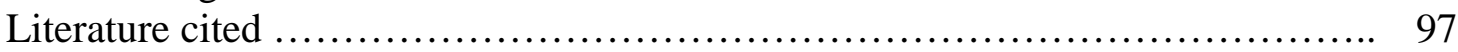

CHAPTER SIX: DETECTING MOLECULAR MARKERS FOR COLD HARDINESS IN RHODODENDRON POPULATIONS BY BULKED SEGREGANT

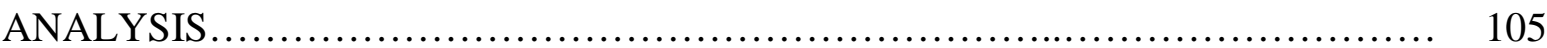

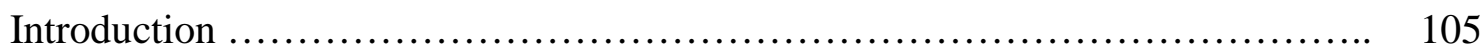

Materials and methods ................................................. 106

Results .................................................................. 109

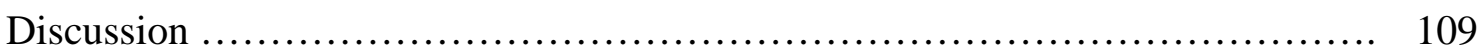

Acknowledgments .................................................. 112

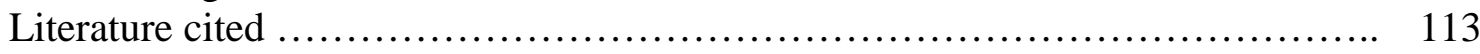


CHAPTER SEVEN: LEAF FREEZING-TOLERANCE OF RHODODENDRON AND ITS RELATION TO THE TISSUE NUTRIENT STATUS....................... 116

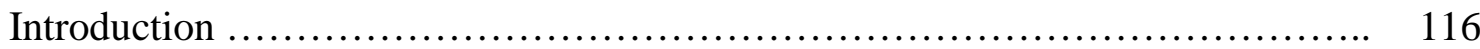

Materials and methods .................................................. 117

Results ................................................................ 118

Discussion ................................................................ 120

Acknowledgments ................................................... 121

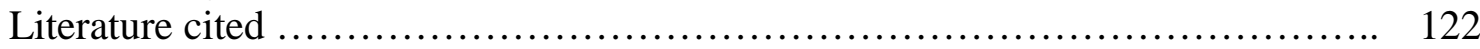

CHAPTER EIGHT: SUMMARY AND CONCLUSIONS ........................... 127

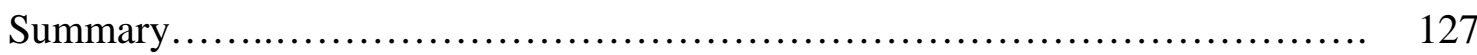

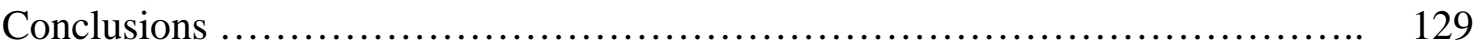

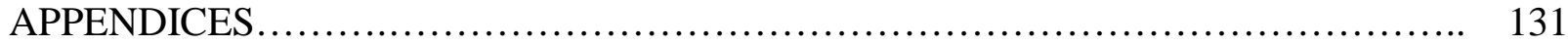

APPENDIX A: A 27-KILODALTON LEAF PROTEIN IN NON-ACCLIMATED AND

DEACCLIMATED TISSUES OF RHODODENDRON IS RELATED TO A FAMILY OF ABA STRESS RIPENING/ WATER DEFICIT STRESS INDUCIBLE

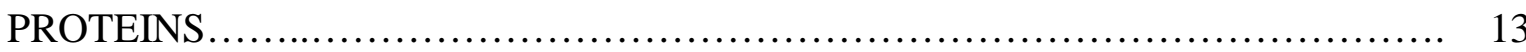

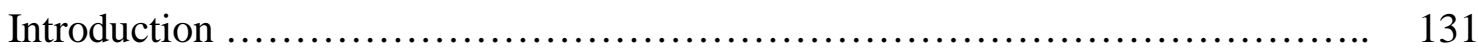

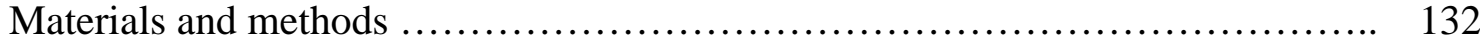

Results ................................................................. 133

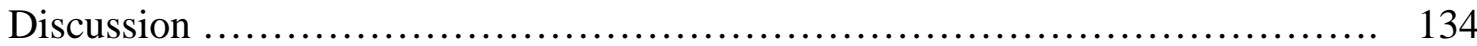

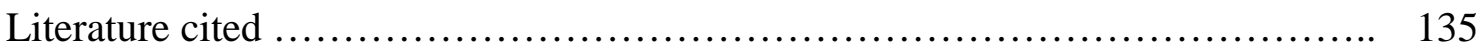

APPENDIX B: LIST OF OTHER RELATED ARTICLES $\ldots \ldots \ldots \ldots \ldots \ldots \ldots \ldots \ldots \ldots \ldots . . \ldots \ldots$

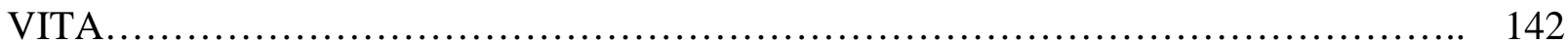

APPROVAL OF EXAMINING COMMITTEE................................. 145 


\section{LIST OF TABLES}

\section{CHAPTER TWO}

Table 1. Example of ion-leakage data calculations and transformation for $R$.

'Vulcan's flame' leaf tissues in December 1995.

Table 2. Empirical calculations used in the determination of freezing tolerance.....

Table 3. Partial correlation coefficients derived from the Error Sum of Squares for the comparison of three different freeze-thaw injury estimates with visual estimates

Table 4. Comparison of two asymmetric functions to GLM using F-test for lack of fit.

Table 5. Partial correlation coefficients derived from the Error Sum of Squares for comparison of four freezing tolerance quantitative expression with visual $\mathrm{LT}_{50}$

Table 6. Leaf freezing tolerance $\left(\mathrm{T}_{\max } ;{ }^{\circ} \mathrm{C}\right)$ of five Rhododendron cultivars .........

\section{CHAPTER THREE}

Table 1. Leaf-freezing tolerance $\left(\mathrm{T}_{\max }\right)$ of three Rhododendron populations.......

\section{CHAPTER FOUR}

Table 1. Leaf freezing-tolerance $\left(\mathrm{T}_{\max }\right)$ and corresponding levels of a $25 \mathrm{kD}$ dehydrin in a Rhododendron population segregating for FT

Table 2. Leaf freezing-tolerance $\left(\mathrm{T}_{\max }\right)$ and corresponding levels of a $25 \mathrm{kD}$ dehydrin in Rhododendron plants varying in physiological and chronological age

\section{CHAPTER FIVE}

Table 1. Average cold acclimated leaf freezing-tolerance $\left(\mathrm{T}_{\max }\right)$ in Rhododendron parents and populations segregating for freezing tolerance

Table 2. Significant increment in leaf freezing-tolerance $\left(\mathrm{T}_{\max }\right)$ in Rhododendron

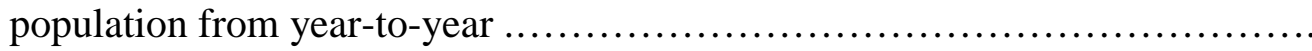

Table 3. Leaf freezing-tolerance $\left(\mathrm{T}_{\max }\right)$ differences between juvenile and mature plants of natural Rhododendron maximum populations

\section{CHAPTER SIX}

Table 1. Leaf freezing-tolerance $\left(\mathrm{T}_{\max },{ }^{\circ} \mathrm{C}\right)$ of Rhododendron progenies used for bulking

\section{CHAPTER SEVEN}

Table 1. Seasonal macronutrient concentrations (\% dry weight) in leaves of Rhododendron cultivars and corresponding leaf freezing-tolerance levels

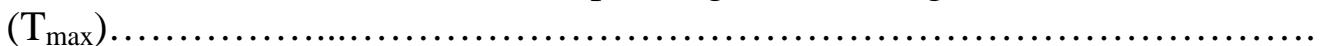


Table 2. Macronutrient concentrations (\% dry weight) in leaves of $R$. catawbiense, $R$. fortune $i$ and $R$. 'Ceylon' in February 1998 and corresponding

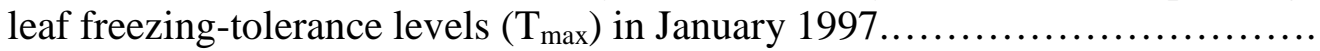

Table 3. Seasonal micronutrient concentrations $(\mathrm{mg} / \mathrm{L})$ in leaves of Rhododendron cultivars and corresponding leaf freezing-tolerance levels $\left(\mathrm{T}_{\max }\right)$

Table 4. Micronutrient concentrations (mg/L) in leaves of $R$. catawbiense, $R$. fortunei and $R$. 'Ceylon' in February 1998 and corresponding leaf freezing-

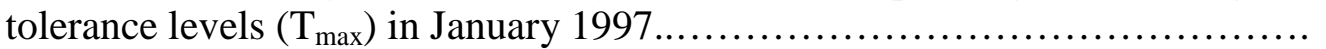

\section{APPENDIX A}

Table 1. Total amino acid composition of RhDA27.......................... 136

Table 2. Partial amino acid sequence of RhDA27 and its comparison with two closely related proteins.

Table 3. Three partial amino acid sequences of Rhododendron RhDA27 when arranged with other closely related proteins 


\section{LIST OF FIGURES}

\section{CHAPTER TWO}

Fig. 1. A SAS program for finding the best starting parameters of the Gompertz

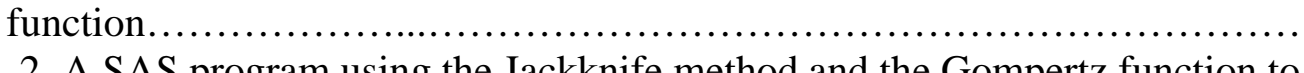

Fig. 2. A SAS program using the Jackknife method and the Gompertz function to

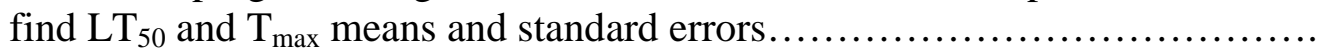

Fig. 3. Determinations of $\mathrm{LT}_{50}$ and $\mathrm{T}_{\max }$ (quantitative expressions of freezing tolerance) by employing the Gompertz function fitted to \%-adjusted injury data and by interpolating the mean of three data points per treatment temperature $\left(\mathrm{LT}_{50}\right.$ only)

Fig. 4. Seasonal fluctuations of leaf freezing tolerance $\left(\mathrm{T}_{\max } ;{ }^{\circ} \mathrm{C}\right)$ of five Rhododendron cultivars

\section{CHAPTER THREE}

Fig. 1. Percent-injury as a function of freezing temperatures in $R$. 'Ceylon' leaf tissues

Fig. 2. Leaf-freezing tolerance $\left(\mathrm{T}_{\max }\right)$ distributions at cold-acclimated state of three Rhododendron populations

ig. 3. Leaf-freezing tolerance $\left(\mathrm{T}_{\max }\right)$ distributions at non-acclimated state of a $\mathrm{F}_{2}$

Rhododendron population

Fig. 4. Relationships between the components of cold hardiness in $\mathrm{F}_{2}$ progenies....

Fig. 5. Regressions of floral bud freeze-tolerance on leaf freeze-tolerance (LFT) in Rhododendron species accessions (large and small; 37 plants total), analysis of data presented by Sakai et al. 1986 .

\section{CHAPTER FOUR}

Fig. 1. Group 1 plants: (A) SDS-PAGE profiles of total soluble proteins from cold-acclimated leaves. (B) Anti-dehydrin immunoblots of parents, $F_{1}$ and bulks of $\mathrm{F}_{2}$ progenies.

Fig. 2. Group 1 plants: (A) Anti-dehydrin immunoblots of 9 individual $F_{2}$ progenies. (B) Regression analysis of LFT on dehydrin O.D. in the population comprised of parents, $F_{1}$, and nine $F_{2}$ progenies.

Fig. 3. Group 2 plants: Wild populations of $R$. maximum. (A) SDS-PAGE profiles of total soluble leaf proteins extracted from cold-acclimated state. (B) Antidehydrin immunoblots of juvenile seedlings and mature plants

Fig. 4A, B. Group 3 plants: $R$. 'Hawaii', R. 'Swansdown' and $R$. 'Pink Parasol' cultivars. (A) SDS-PAGE profiles of total soluble leaf proteins extracted from cold-acclimated state. (B) Anti-dehydrin immunoblots of ramets (rootedcuttings) and ortets (stock plants).... 


\section{CHAPTER FIVE}

Fig. 1. Cold hardiness $\left(\mathrm{T}_{\max }\right)$ distribution of a $\mathrm{F}_{2}$ population: $(\mathrm{A})$ December 1996;

(B) December 1997.

Fig. 2. Changes in cold hardiness $\left(\mathrm{T}_{\max }\right)$ of individual $\mathrm{F}_{2}$ progeny from December 1996 to 1997.

Fig. 3 Cold hardiness $\left(\mathrm{T}_{\max }\right.$ ) distribution of a BC population: (A) December 1996;

(B) December 1997; (C) December 1998.

102

Fig. 4. Changes in cold hardiness $\left(\mathrm{T}_{\max }\right)$ of individual $\mathrm{F}_{2}$ progeny from December 1996 to 1997 and 1996 to 1998

Fig. 5. Relationship between the cold hardiness $\left(\mathrm{T}_{\max }\right)$ of individual $\mathrm{BC}$ progeny in successive years: (A) 1996 vs. 1997; (B) 1997 vs. 1998.....

\section{CHAPTER SIX}

Fig. 1. DNA profiles of individual $\mathrm{F}_{2}$ progenies after PCR amplification with primer No. 29. Lane 9 was loaded with a 100 base pair (bp) ladder

\section{APPENDIX A}

Fig. 1. SDS-PAGE profile of soluble leaf proteins from non-acclimated, coldacclimated and deacclimated tissues of Rhododendron cultivars

Fig. 2. SDS-PAGE analysis of Rotofor fractions (3-20) containing soluble leaf proteins from deacclimated tissues of R. 'Vulcan's Flame'. 


\section{LIST OF ABBREVIATIONS}

$\begin{array}{ll}\text { BC } & \text { Backcross } \\ \text { CA } & \text { Cold acclimation } \\ \text { CAS } & \text { Cold-acclimation specific } \\ \text { CH } & \text { Cold hardiness } \\ \text { EC } & \text { Electrical conductance } \\ \text { FT } & \text { Freezing-tolerance } \\ \text { GLM } & \text { General Linear Model } \\ \text { ICP } & \text { Inductively-coupled plasma atomic emission spectrometer } \\ \text { IEF } & \text { Iso-electric focusing } \\ \text { LEA } & \text { Late embryogenesis abundant } \\ \text { LFT } & \text { Leaf freezing-tolerance } \\ \text { LN2 } & \text { Liquid nitrogen } \\ \text { LSD } & \text { Least significant difference } \\ \text { LT } & \text { Lethal temperature causing 50\% injury } \\ \text { NA } & \text { Non-acclimated } \\ \text { NLIN } & \text { Non-linear } \\ \text { OD } & \text { Optical density } \\ \text { PCR } & \text { Polymerase chain reaction } \\ \text { RAPD } & \text { Randomly amplified polymorphic DNA } \\ \text { T } m a x & \text { Temperature at maximum rate of injury } \\ \text { TTC } & \text { Tripheny tetrazolium chloride }\end{array}$




\section{CHAPTER ONE}

\section{INTRODUCTION}

Cold temperatures are a major environmental constraint in plant distribution and productivity. Severe cold temperatures can cause dramatic crop damages and huge economic losses. Freezing weather in December 1998 caused an estimated \$634 million in damages to California crops, according to the California Department of Food and Agriculture. Among agricultural commodities that suffered the greatest losses were oranges, lemons, avocados, grapefruits and nursery stocks (totaling over \$602 million). The combined losses for vegetable crops were estimated at more than $\$ 7.6$ million. However, these damages incurred by California seem modest when compared to the Florida freeze damages in 1983 and 1985 where the citrus industry alone suffered losses amounting to $\$ 2.0$ and $\$ 1.2$ billion (unadjusted for inflation), respectively, according to the National Climatic Data Center (Billion Dollar U.S. Weather Disasters 1980-1998). The citrus industry had previous episodes of freezing damage in 1962 (\$500 million), 1981 and 1982 (Yelenosky 1985 and references within). The frequent enormous damages incurred by the state of Florida caused its world leadership role in citrus production to slip to Brazil (Riemenschneider 1983). There are sizeable (10-50\%) losses of ornamental and fruit crops in West Virginia due to the indirect effects of low temperature stresses. Freezing injury can have serious consequences for the growth and productivity of sensitive species, but plants native to regions with freezing temperatures have developed mechanisms to survive such stress.

The ability of the plant to minimize cold injury is mainly attributed to the plant's ability to cold acclimate. How plants cold acclimate is not well understood either physiologically or genetically. There has been worldwide and considerable research devoted to cold acclimation (CA) processes in plants. However, development of cultivars with marked improvements in cold hardiness $(\mathrm{CH})$ has remained elusive due to the complex biology associated with cold tolerance in plants. $\mathrm{CH}$ is a complex multigenic trait. Different varieties of crop plants vary in their tolerance to cold. It is the interaction between genetic and environmental factors that determines 
the plant's ability to withstand a given cold temperature stress. Hence, it is not surprising that classical plant breeding has had limited success in improving $\mathrm{CH}$ of crop plants.

The major emphasis of this study is to develop a better understanding of CA in plants. A better understanding of how plants respond to freezing conditions would eventually lead to better strategies to reduce crop damages. There has been significant research conducted on herbaceous plants because they are the most vulnerable to temperature fluctuations. However, herbaceous freezing tolerance (FT) in mid-winter conditions is minimal at best when compared to woody perennials. The acclimating ability of woody perennials is generally greater than that in herbaceous plants. However, the dormancy and deciduous nature of some woody perennials make them a less appropriate choice of study due to the extended period of dormancy. Also, the superimposition of cold acclimation and dormancy development in woody perennials makes it difficult to study physiological/ molecular events associated with these two phenological processes. Unlike woody deciduous perennials, broad-leaved evergreens can withstand severe cold temperatures and yet retain their leaves. Therefore, research into evergreen woody perennials and understanding the basis of its CA processes are of great interest scientifically and importance economically.

\section{LITERATURE REVIEW}

The amount of research literatures on plant FT is numerous, with over a thousand of citations. Therefore this review does not attempt to integrate all aspects of plant's response to low temperature stress. Most plant FT reviews are focused on specific areas of low-temperature plant physiology/ molecular biology (Steponkus 1984; Guy 1990; Chen 1994; Hughes and Dunn 1996; Thomashow 1999). Refer to Levitt (1980) and Weiser (1970) for a review of the early literature. Similarly, this review will focus on several key areas of research interest within plant CA. 


\section{Nature of freezing in woody plants}

Tremendous variability exists within and between plant species in their tolerance to cold stress. Woody plants generally can tolerate colder temperatures than herbaceous plants can, whereas tropical plants practically have no ability to endure the slightest freeze. Freeze-thaw injury to plants is a fairly complex process. During freeze-thaw cycle, several potentially injurious stresses occur at the cellular level including sub-freezing temperature, mechanical stress due to presence of ice in the tissue, freeze-induced dehydration and resultant high internal solute concentration (Wisniewski and Arora 1993). Generally, it is believed that the formation of extracellular ice and freeze-induced dehydration are the main cause of freezing injury where the plasma membrane is disrupted (Gordon-Kamm and Steponkus 1984; Iswari and Palta 1989). The strategy used for ice nucleation by a plant species determines whether the plant tolerates or avoids the cytoplasmic desiccation associated with freezing (see below). In contrast to extracellular freezing, intracellular ice formation is always lethal (non-reversible injury) to the cell simply because of the physical shearing of intracellular membranes and other structures. In acclimated tissue, cell dehydration is fully reversible to a characteristic threshold where cell injury is only apparent as solutes leak across the plasma membrane and the cell experiences loss of turgor (Palta and Weiss 1993). The development of FT as plants acclimate is associated with changes in the physical properties and composition of the plasma membrane. Plants rarely experience fast intracellular freezing in nature as plants cool slowly, usually only a few degrees per hour in the most extreme situations, and thaw at an equally slow rate (Levitt 1980; Steffen et al. 1989). Cooling and thawing rates are also important in the design and conduct of in vitro freeze tests to measure FT in the laboratory (Levitt 1980; Steffen et al. 1989).

\section{Supercooling versus equilibrium freezing. There are two primary} mechanisms that plants utilize to survive freeze stress: "supercooling" and "equilibrium freezing." Most plants seldom freeze at the freezing points of tissue water, but supercool a few degrees below this point due to the lack of ice nucleating sites. However, certain tissues, such as xylem ray parenchyma and bud tissues, of many woody species exhibited what is called "deep supercooling" and have exploited this as a primary strategy to avoid cytoplasmic desiccation 
during freezing. However, the protection cannot exceed $-38^{\circ} \mathrm{C}$, the homogenous nucleation temperature of water. The ability of woody tissues to supercool varies among species, and in those that have evolved this strategy, this species-specific threshold temperature limits their geographic distribution to regions where this minimal temperature is not exceeded (Burke et al. 1976).

A second method, used primarily by native or cold hardy plants in the temperate regions, is equilibrium freezing. When atmospheric temperatures drop below $0^{\circ} \mathrm{C}$, ice formation in plant tissues occurs first at locations having the least negative osmotic potential. Ice normally forms first in the large vessels of the xylem in leaves and stems, in sub-stomatal cavities, and intercellular spaces (Levitt 1980). Once ice forms it will spread throughout the vessel and into the intercellular spaces of other tissues. However, the ice crystal can not penetrate an intact plasma membrane to inoculate the cytoplasm. This creates a gradient in the chemical potential of water (water potential) between the extracellular and intracellular compartments that draws water out of the cytoplasm. Severe freeze-induced dehydration can have numerous effects that result in cellular damage such as denaturation of proteins and precipitation of various molecules (Thomashow 1998)

\section{Assessment of injury}

Estimation of the freezing injury of plant tissues in the laboratory is generally based on the use of controlled freeze-thaw treatments and evaluation of the injury using visual estimates. Many laboratory protocols have been developed for estimating the viability of stressed tissues, including visible rating, triphenyl tetrazolium chloride (TTC) reduction and electrolyte or phenolic leakage (Harber and Fuchigami 1986; Wisniewski and Arora 1993). Most of the time, two protocols are needed in concert to produce reliable estimates (Palta et al. 1978).

\section{Electrolyte-leakage method and quantitative measure of cold}

hardiness. Measurement of electrolyte leakage following a freeze-thaw stress imposed on excised tissues, i.e. leaf discs (Harber and Fuchigami 1986), has been widely used to estimate 
freezing injury. However, some discrepancies have been found in laboratory procedures when compared to field data (Pellett et al. 1986). Therefore, all freeze-thaw experiments in the laboratory must consider the freeze-thaw rate, duration of freezing and ice nucleation near subzero $\left(-1^{\circ} \mathrm{C}\right)$ temperature. A quick freeze-thaw rate or long duration of freezing could result in more drastic conditions than plant tissues normally experience in nature (Steffen et al. 1989; Anisko and Lindstrom 1996). Ice nucleation close to $0^{\circ} \mathrm{C}$ is initiated to prevent plant tissues from supercooling (Steffen et al. 1989). Electrolyte leakage is usually expressed as the percent ratio of ion leakage from freeze-injured to the total ions in the tissue. The temperature giving an index of 50\% ion leakage (and sometime injury) is termed as $\mathrm{LT}_{50}$ value (Burr et al. 1990). Most reports use $\mathrm{LT}_{50}$ as a measure of relative FT (Palta et al. 1978; Sakai et al. 1986; Arora et al. 1992; Sutinen et al. 1992). When working with woody plants, however, even the lowest treatment temperature employed in the experimental protocol often fails to reach the $\mathrm{LT}_{50}$ level (Zatylny et al. 1996). Alternatively, others have used the point of maximum rate of freezing injury/ the point of inflection $\left(\mathrm{T}_{\max }\right)$ as a measure of FT (von-Fircks and Verwijst 1993; Anisko and Lindstrom 1995).

\section{Response curve fitting and statistical analysis. In many cases} researchers rely on empirical mathematical models to predict plant response as a function of time and environmental stress. When using any computerized simulation for estimating any plant response, the accuracy of predictions will depend on the appropriateness of the mathematical function (Hopper et al. 1996). Plant response to temperature stress is characterized by an asymmetric sigmoid function (von-Fircks and Verwijst 1993). However, simple straight line or interpolation techniques (Holt and Pellett 1981; Sutinen et al 1992) have been used to determine the $\mathrm{LT}_{50}$. Some reports have used functions such as Probit analysis (Andrews and Morrison 1992), which is inappropriate because of its symmetric sigmoid function. Most reports use lethal temperatures that cause $50 \%$ injury to the cells or tissues $\left(\mathrm{LT}_{50}\right)$ as a measure of relative $\mathrm{CH}$. In most cases, LT $_{50}$ values are based on single point estimates (Sakai et al. 1986; Hummer et al. 1995) and no statistical analysis can be performed because variances or standard errors cannot be provided (Anisko and Lindstorm 1996). Labor intensiveness, limited plant material and/or high experimental costs are most likely the cause for the lack of complete replication of in vitro 
freeze-thaw experiments. Therefore, there is a need to develop reliable laboratory protocols under controlled conditions that produce relative injury estimates and enable comparison among cultivars with reproducible results (Wagner 1994).

\section{Cold acclimation}

In order to cope with cold stress, plants have evolved adaptive mechanisms that are temperature regulated and involve acclimation processes that can be reversed. During early fall, hardy plants will not survive subfreezing temperatures any better than tender plants. However, hardy plants grown under cool fall temperatures will cold acclimate. The term "cold acclimation" is most often used to illustrate the outcome of the myriad biochemical and physiological processes associated with the increase in cold tolerance (Guy 1990; Raulston and Tripp 1995). CA in perennial plants is induced by environmental signals including low temperature and/or short photoperiod (Fuchigami et al. 1971; Gray 1997). Sub-lethal freezing temperatures later in the acclimation process may induce a second phase in the acclimation process leading to maximal expression of FT. The rate of cold tolerance induction during CA is dependent on temperature and species (Alberdi and Corcuera 1991). CA is the result of modifications of structure and function that a plant tissue undergoes to minimize the damage during low temperature (Alberdi and Corcuera 1991). The perennial plants are most freezing tolerant in midwinter and can survive very low atmospheric temperatures. In field environments, there is considerable yearly variation in cold tolerance (Fowler and Gusta 1979; Fowler et al. 1983). A return to temperatures above freezing and increasing daylength in the spring promotes plant growth, breaks dormancy and eventually results in a complete dehardening of hardy plants.

\section{Rhododendron as experimental source. A unique feature of many} temperate-zone rhododendrons is their ability to withstand severe low temperatures as broadleaved evergreens. Within the genus, this ability varies widely. Sakai et al. (1986) found that many species in the Ponticum subsection (R. brachycarpum and $R$. maximum) are leaf-hardy to $-60^{\circ} \mathrm{C}$ and bud-hardy to $-30^{\circ} \mathrm{C}$; whereas cold-tender species, such as $R$. barbatum and $R$. griersonianum, show both leaf and bud damage at temperatures approaching $-18^{\circ} \mathrm{C}$. Most 
environmental stresses such as cold, heat, water and light stress have varying degrees of impact on the growth of Rhododendron. However, freezing stress is recognized as the major factor limiting the distribution of Rhododendron (Iwaya-Inoue and Kaku 1983; Nilsen 1992). Relative injury of Rhododendron cultivars may vary from year to year depending on the severity of the winter season and the level of bud and leaf $\mathrm{CH}$ (Holt and Pellett 1981). Some information can be obtained on midwinter $\mathrm{CH}$ capabilities of various Rhododendron species and cultivars (Holt and Pellett 1981; Sakai et al. 1986; Wagner 1994), but it has been mostly based on sampling from a single source or period at a particular location (Pellett et al. 1986). Breeders of Rhododendron are particularly interested in the plants' $\mathrm{CH}$; however, breeding selection is limited by the lack of severe or test winters. Breeding efficiency has been improved in programs in which mass selection and multiple site testing are used to increase $\mathrm{CH}$ (Uosukainen and Tigerstedt 1988). Since the CA process appears to be evolutionarily conserved, a Rhododendron population can serve as a model for elucidating the mechanism of plant CA. These studies can provide new insights into the genetics and physiological mechanisms of cold tolerance and will aid the efforts to breed new cold-resistant Rhododendron cultivars.

Genetics of freezing-tolerance. A wide variation in the genetic potential to acclimate occurs in plants. Wild species of potatoes develop only modest tolerance, to about $6^{\circ} \mathrm{C}$; winter cereals and most field crops are more hardy and develop tolerance to temperatures in the range of $-20^{\circ} \mathrm{C}$; in the extreme, some woody perennials seem to have no low-temperature limits for survival. Crosses between compatible parents of differing $\mathrm{CH}$ often produce progeny displaying a continuous range between the parental extremes (Guy 1990). A continuous pattern, as opposed to discrete groupings of hardiness types, suggests that genetic control at this level of FT is multigenic (Guy 1990; Hayes et al. 1993; Stone et al. 1993; Teutonico et al. 1995; Arora et al. 1998). However, reciprocal crosses between $F_{1}$ and parents usually exhibited inconsistent patterns of maternal CH inheritance (Dorsey and Bushnell 1925; Harris 1965; Wilner 1965; Quamme 1978; Sutka 1981; Hummel et al. 1982). Studies of overwintering cereal crops and potatoes suggest that $\mathrm{CH}$ is a complex, quantitatively inherited trait with additive and dominance components (Sutka 1981; Stone et al. 1993). Genetic studies in woody plants suggest that the gene action for FT is also inherited in an additive manner (Watkins and Spangelo 1970; Fejer 
1976; Tibbits et al. 1991). Although $\mathrm{CH}$ genes are multivariate, a study with potato indicates that relatively few genes are responsible for this trait (Stone et al. 1993). Similarly, a study with pea indicates that as few as three additive genes are responsible for the $\mathrm{CH}$ trait (Liesenfeld et al. 1986). Screening large populations derived from two different cold hardy parents would provide some insights on how the gene action of $\mathrm{CH}$ is transmitted.

Woody plants have several physiological traits that confound $\mathrm{CH}$ research. Woody perennials of temperate zone undergo dormancy (onset and release) and $\mathrm{CH}$ (cold acclimation and deacclimation) transitions simultaneously during their annual life cycle (Rowland and Arora 1997). This makes it difficult to associate physiological/molecular changes with one or the other phenological event (Arora et al. 1992; Arora et al. 1997; Rowland and Arora 1997). One approach to understand the freeze tolerance mechanisms in woody plants is through studying the inheritance and genetics of cold tolerance of broad-leaved evergreens. Since Rhododendron can survive and withstand severe cold winter as a broadleaf evergreen, complications with dormancy can be avoided. Genes expressed in leaves during $\mathrm{CA}$ are crucial for conferring $\mathrm{CH}$ and alterations in metabolic activity due to seasonal changes seem to be genetically controlled (Weiser 1970). Previous studies have been biased by comparing cold hardy and sensitive plants of different genetic backgrounds, whereas a study comparing individual plants from a segregating population of hardy $\mathrm{x}$ less-hardy species offers an ideal system to investigate the genetic control of $\mathrm{CH}$.

Bulked segregant analysis and RAPD markers. Reports have shown bulked segregant analysis can be utilized to better understand segregation of genes within a population (Barua et al. 1993; Kochert 1994). This technique can be applied to CH studies by pooling DNA samples from a group of hardy plants and a group of less hardy plants of a segregating population from a single cross. Hence, the two resultant bulked DNA samples differ only in the region that determines $\mathrm{CH}$, assuming there are no complex linkages. These two bulks can then be screened for differences using randomly amplified polymorphic DNA (RAPD) primers. The RAPD technique relies on the differential enzymic amplification of small DNA fragments by PCR primed from arbitrary oligonucleotide primers. RAPD assays provide an efficient way of identifying new loci and require only small amounts of DNA and no radioactivity. Bulked 
segregant analysis allows for the rapid screening of many loci and identification of segregating markers (Michelmore et al. 1991). A marker for $\mathrm{CH}$ or a freezing sensitive trait would be of great benefit to Rhododendron breeders in screening young plants for the desired trait.

Biochemical changes. During acclimation to freezing temperatures, the plant undergoes several metabolic changes (Levitt 1980). A common hypothesis has been that increased FT is associated with the accumulation of specific metabolites (cryoprotectants) that protect the cell during a freeze-thaw cycle, but it has proven very difficult to determine which of these metabolic changes are critical to the acquisition of FT. For example, it has been difficult to discern which of these changes are simply adaptations to growth at low temperatures as opposed to being responsible for increased FT. Most studies have attempted to correlate acclimation (or developmental changes in tolerance) with metabolic changes. Sarhan et al. (1997) showed that $\mathrm{CA}$ in winter wheat is associated with an increase in the amount of mRNA, polysomes, and tRNA required for protein synthesis. Although the accumulation of soluble proteins during CA has been shown to occur in many plants species, it was regarded as a general response and not universal (Guy 1990). Some of the proteins that are induced during CA include wcs 120 protein (Sarhan et al. 1997), cryoprotectins (Sieg et al. 1996), anti-freeze proteins (Griffith et al. 1997) and late embryogenesis abundant (LEA) proteins (Close et al. 1993). Most of these proteins have the unique property of remaining soluble after boiling and are hydrophilic in nature. One class in particular, LEA group II proteins, is also induced during water-stress, ABA-treatment or osmotic stress. These proteins have been termed "dehydrins". When subjected to freezing, plant cells lose water to extracellular ice and undergo desiccation stress. Hence, it is conceivable that CA mechanisms should involve a component of dehydration-tolerance and may involve expression of dehydrins.

Dehydrin. Dehydrins (also known as group II LEA family of proteins) are proteins that are induced in response to plant stresses possessing a dehydration component, such as salt, water, or freezing stress (Close 1996). Dehydrins are glycine-rich, hydrophilic and remain water soluble even when heated close to the boiling point (Close et al. 1989). Dehydrins are the products of a gene family varying in molecular weight and $\mathrm{p}$ (isoelectric points). Sequences of dehydrin 
cDNAs differ but share one or more copies of a consensus sequence - a 15 residue, amphipathic $\alpha$-helix-forming domain (K-segment) — that is highly conserved in higher and lower plants (Close et al. 1993; Close 1997). Dehydrins occur in seeds and vegetative parts of plants, including barley, wheat, maize, rice, potato, soybean, cotton, almonds, grapes, ferns, mosses, algae, and also in bacteria (Close et al. 1993). During the CA process, dehydrins and dehydrin-like proteins and/or their transcripts accumulate in a wide array of plant tissues (Lång et al. 1989; Neven et al. 1993; Welin et al. 1994; Wisniewski et al. 1996) and have been cellularly localized in the cytosol and nucleus (Neven et al. 1993; Egerton-Warburton et al. 1997; Danyluk et al. 1998; Wisniewski et al. 1999).

A functional role for dehydrins in FT is suggested, in part, by their hydrophilic nature (thereby protecting macromolecular structures from desiccation) and in vitro cryoprotectant properties (Lin and Thomashow 1992; Close 1996; Ingram and Bartels 1996; Wisniewski et al. 1999). Since plant cells undergo dehydration during freezing stress due to the presence of ice in extracellular spaces (Levitt 1980), the cellular responses invoking desiccation-tolerance should conceivably be involved in FT mechanisms. A number of studies have established a positive correlation between dehydrin accumulation and $\mathrm{CH}$ phenotype among selected genotypes (Danyluk et al. 1994; Muthalif and Rowland 1994; Robertson et al. 1994; Cai et al. 1995; Arora et al. 1997; Artlip et al. 1997). Recently, a direct relationship between dehydrin-like proteins and FT was demonstrated by the ability of constitutively regulated cor proteins (some of which are dehydrins) in Arabidopsis to confer FT without prior acclimation (Jaglo-Ottosen et al. 1998). It has also been postulated that dehydrins may act as ion-sequesters (Palva and Heino 1998) or as molecular chaperones (Campbell and Close 1997; Close 1997) under stressful conditions, thereby stabilizing proteins and membranes via hydrophobic interactions.

Accumulation of dehydrin protein and transcripts during CA has been amply documented in a number of herbaceous species (Guy et al. 1994; Close 1997; Thomashow et al. 1998 and references within), where the FT of cold-acclimated tissues typically does not exceed $-15^{\circ} \mathrm{C}$. Investigations of dehydrin expression and its association with CA in woody perennials, which exhibit significantly higher CA ability and FT than herbaceous plants, are comparatively scarce. Several studies with herbaceous plants have reported that dehydrins accumulate in response to any environmental stress that has a dehydration component, including drought, low temperature 
and salinity (Close et al. 1993). Thus far, studies of woody perennials have used deciduous species to document CA and dehydrin profiles in overwintering tissues such as xylem, bark, and floral buds (Arora and Wisniewski 1994; Muthalif and Rowland 1994; Salzman et al. 1996; Artlip et al. 1997; Welling et al. 1997). In deciduous peach trees, freeze-hardiness of bark tissues was positively correlated with the accumulation of a $60 \mathrm{kDa}$ dehydrin protein (Arora and Wisniewski 1994). The results of these studies are in general agreement with findings from herbaceous plants, indicating that dehydrins accumulate during the acclimation period. Unlike herbaceous plant model systems such as Arabidopsis (Jaglo-Ottosen et al. 1998), no cause and effect relationship has yet been established for woody perennials. Isolation of genes encoding these proteins could be used to manipulate traits such as $\mathrm{CH}$ by over-expressing or underexpressing the appropriate genes.

Other factors correlating cold acclimating ability. During CA, the levels of growth regulators change; ABA commonly increases (Chen and Gusta 1983; Li, 1991) while gibberellin decreases. The growth promoting effect of gibberellin is negatively associated with FT (Carter and Brenner 1985), whereas the quiescence or dormancy caused by ABA is positively associated with tolerance (Heino et al. 1990; Chandler and Robertson 1994; Robertson et al. 1994; Robertson et al. 1995; Wilen et al. 1995; Wilen et al. 1996). However, in another experimental system, the cell suspensions of peach, the addition of ABA failed to induce CA when cultured for 5 days at $24^{\circ} \mathrm{C}$ (Arora and Wisniewski 1995). Besides growth regulators, the water content of plant tissue was found to be inversely related to FT (Levitt 1980). CA promotes both water-loss from the tissue and accumulation of starch (Sasaki et al. 1996) and proteins that are not osmotically active. The loss of water has obvious adaptive advantages because there would be less water to freeze, less ice to accommodate, and less physical expansion in the intercellular spaces - thus reducing cell rupture. Osmotic concentration also increases with CA. The major changes in osmotic potential are due to changes in sugars, and there is a good correlation between sugar content and FT (Hamman et al. 1996; Sasaki et al.1996; Savitch et al.1997). Sugars may depress the freezing point of the tissue, act as a nutrient and energy reserve, alter phase properties of membranes in the dry state and act as a cryoprotectant to preserve protein structure and function during low temperature stress (Olien and Clark 1995; Crowe et 
al.1998). Lipids also accumulate in many species during acclimation and fatty acids tend to be more unsaturated (Uemura et al. 1995). In many cases, the increase in lipids is associated with a proliferation of cellular membranes (Uemura and Steponkus 1994). An inverse relationship between rate of respiration (growth) and FT is also observed. However, this may be dependent on the stage of acclimation and seems to be a complex relationship. Low temperature acclimation of seedlings and plants requires photosynthesis, and therefore light and $\mathrm{CO}_{2}$, presumably to support the accumulation of sugars, proteins and other solutes.

Juvenility. Although it is generally believed that juvenility influences woody plants' $\mathrm{CH}$, the notion is largely anecdotal. For example, Pellett (1998) observed that seedlings of Phellodendron sachalinense were easily killed by frosty weather in the Fall while mature plants suffered no visible damage. Juvenility and the associated phase-change to maturity have strong influences on morphogenesis, tissue differentiation, and plant development (Hackett 1985; Zimmerman et al. 1985). Although phase change has been associated with a number of morphological, physiological, and biochemical alterations in plants (Zimmerman et al. 1985; Hackett et al. 1990; Hand et al. 1996), little is known about its effect on stress tolerance. A systematic investigation of the relationship between juvenility, aging and $\mathrm{CH}$ has yet to be undertaken.

Nutrient status. Healthy plants contain predictable concentrations of essential elements. These elements are required for normal growth and development. Plants require major elements in greater quantities than secondary elements. Micronutrients are required in smallest amounts and can become toxic if in excess. Since plants require nutrients in order to grow, develop and complete their life cycle, any nutrient shortages can adversely affect the overall function of the plant and may influence adaptive traits such as stress tolerance. It may be speculated that increased nutrition increases the total soluble salts in the plant cells, which then lowers the freezing point a few degrees and helps protect the plant during a freezing event.

Some nutrients have been known to be associated with plant $\mathrm{CH}$, particularly calcium. Calcium has been shown to protect plant membranes in the event of cold stress. Calcium is known to stabilize cell membranes by bridging phosphate and carboxylate groups of phophoslipids and proteins (Marschner 1995). The injury caused to tissues by freeze-thaw was 
alleviated by calcium (Arora and Palta 1988). Calcium chloride $\left(\mathrm{CaCl}_{2}\right)$ and calcium nitrate $\left[\mathrm{Ca}\left(\mathrm{NO}_{3}\right)_{2}\right]$ fertilizer increased $\mathrm{CH}$ of 'Anjou' pear trees, and reduced the incidence of fruit disorders (Raese 1996). Also, Durner and Gianfagna (1988) have shown that fall calcium cyanamide application increases peach flower bud resistance to low-temperature stress. Calcium and protein phosphorylation, or perhaps a coupling of the two, play an important role during the acquisition of FT. Cold shock elicits an immediate rise in cytosolic free calcium concentration in both chilling-resistant Arabidopsis and chilling-sensitive tobacco that has suggested that calcium influx plays a major role in the cold shock response and that an intracellular calcium source also might be involved (Knight et al. 1996). It may play a similar role in CA. Chemical treatments to block calcium channels, antagonize calmodulin action, or inhibit protein kinases markedly inhibited the cellular capacity to develop cold-induced FT in cell-suspension cultures of the alfalfa (Monroy et al. 1993). The addition of a calcium ionophore to cells caused the influx of calcium and induced the expression of two cas (cold acclimation-specific) genes at $25^{\circ} \mathrm{C}$ (Monroy and Dhindsa 1995). A sequence of signaling events occurs early during CA and leads to the expression of specific cold regulated genes and the development of FT. No studies, however, have been found that correlate level of nutrients or calcium with $\mathrm{CH}$ in Rhododendron. 


\section{RESEARCH OBJECTIVES}

There is much to learn about the CA process in evergreen woody perennials. This study was undertaken to gain fundamental understanding of the physiological and genetic aspects of $\mathrm{CH}$ of Rhododendron. We chose Rhododendron as our plant material because of its unique ability to withstand severe cold temperatures, which varies drastically within the genus. Following are the primary objectives for undertaking this study. First, to develop an in vitro method of measuring Rhododendron $\mathrm{CH}$ based on LFT. Second, using a reliable and reproducible in vitro $\mathrm{CH}$ determination methodology, to study FT distribution of Rhododendron progenies segregating for $\mathrm{CH}$ in order to gain understanding of $\mathrm{CH}$ gene action in Rhododendron. Third, to study the association of "dehydrin" expression with CA in wide array of Rhododendron populations differing/segregating for CA ability. Fourth, identify "molecular markers" or "DNA tags" that are linked to $\mathrm{CH}$ genes in Rhododendron. Lastly, to investigate the association between leaf tissue nutrient status and $\mathrm{CH}$ in Rhododendron. In addition, two other studies were undertaken as part of this dissertation. Objectives of these studies were as follows. One, to examine the effect of plant age (physiological or chronological) on CA ability in Rhododendron. Two, to characterize a protein (RhDA27) associated with deacclimation in Rhododendron. 


\section{LITERATURE CITED}

Alberdi M, Corcuera LJ (1991) Cold acclimation in plants. Phytochemistry 30:3177-3184

Andrews CJ, Morrison MJ (1992) Freezing and ice tolerance tests for winter brassica. Agron J $84: 960-962$

Anisko T, Lindstrom OM (1995) Applying the Richards function in freezing tolerance determination with electrolyte and phenolic leakage techniques. Physiol Plant 95:281-287

Anisko T, Lindstrom OM (1996) Survival of water-stressed Rhododendron subjected to freezing of fast or slow cooling rates. HortSci 31:357-360

Arora R, Palta JP (1988) In vivo perturbation of membrane-associated calcium by freeze-thaw stress in onion bulb cell: simulation of this perturbation in extra-cellular $\mathrm{KCl}$ and alleviation by calcium. Plant Physiol 85:622-628

Arora R, Wisniewski ME (1994) Cold acclimation in genetically related (sibling) deciduous and evergreen peach (Prunus persica [L.] Batsch) II. A 60-kilodalton bark protein in cold acclimated tissues of peach is heat stable and related to the dehydrin family of proteins. Plant Physiol 105:95-101

Arora R, Wisniewski ME (1995) Ultrastructural and protein changes in cell suspension cultures of peach associated with low temperature-induced cold acclimation and abscisic acid treatment. Plant Cell Tissue Organ Cult 40:17-24

Arora R, Wisniewski ME, Scorza R (1992) Cold acclimation in genetically related (sibling) deciduous and evergreen peach (Prunus persica [L.] Batsch) I. Seasonal changes in cold hardiness and polypeptides of bark and xylem tissues. Plant Physiol 99:1562-1568

Arora R, Rowland LJ, Panta GR (1997) Chill-responsive dehydrins in blueberry: are they associated with cold hardiness or dormancy transitions? Physiol Plant 101:8-16

Arora R, Rowland LJ, Panta GR, Lim CC, Lehman JS, Vorsa N (1998) Genetic control of cold hardiness in blueberry. In: Li PH, Chen THH (eds) Plant cold hardiness: molecular biology, biochemistry, and physiology. Plenum Press, New York, pp. 99-106

Artlip TS, Callahan AM, Bassett CL, Wisniewski ME (1997) Seasonal expression of a dehydrin gene in sibling deciduous and evergreen genotypes of peach (Prunus persica [L.] Batsch). Plant Mol Biol 33:61-70

Barua UM, Chalmers KJ, Hackett CA (1993) Identification of RAPD markers linked to a Rhynchosporium secalis resistance locus in barley using near-isogenic lines and bulked segregant analysis. Heredity 71:177-184 
Burke MJ, Gusta LV, Quamme HA, Weiser CJ, Li PH (1976) Freezing and injury in plants. Annu Rev Plant Physiol 27:507-528

Burr KE, Tinus RW, Wallner SJ, King RM (1990) Comparison of three cold hardiness tests for conifer seedlings. Tree Physiol 6:351-369

Cai QY, Moore GA, Guy CL, (1995) An unusual Group 2 LEA gene family in citrus responsive to low temperature. Plant Mol Biol 29:11-23

California Agricultural Statistics Service (December 31, 1998) December Freeze Causes \$634 Million Loss to California State Crops. P.O. Box 1258 Sacramento, CA 95812

Campbell SA, Close TJ (1997) Dehydrins: Genes, proteins, and associations with phenotypic traits. New Phytologist 137:61-74

Carter JV, Brenner ML (1985) Plant growth regulators and low temperature stress. Encyclopedia of Plant Physiology. New Series 11: 418-443

Chandler PM, Robertson M (1994) Gene expression regulated by abscisic acid and its relation to stress tolerance. Annu Rev Plant Physiol Plant Mol Biol 45:113-141

Chen THH (1994). Plant adaptation to low temperature stress. Can J Plant Path 6:231-6

Chen THH, Gusta LV (1983) Abscisic acid-induced freezing resistance in cultured plant cells. Plant Physiol.73:71-75

Close TJ (1996) Dehydrins: emergence of a biochemical role of a family of plant dehydration proteins. Physiol Plant 97:795-803

Close TJ (1997) Dehydrins: a commonalty in the response of plants to dehydration and low temperatures. Physiol Plant 100:291-296

Close TJ, Kortt AA, Chandler PM (1989) A cDNA-based comparison of dehydration-induced proteins (dehydrins) in barley and corn. Plant Mol Biol 13:95-108

Close TJ, Fenton RD, Yang A, Asghar A, DeMason DA, Crone DE, Meyer NC, Moonana F (1993) Dehydrin: the protein. Curr Topics Plant Physiol 10:104-118

Crowe JH, Carpenter JF, Crowe LM (1998) The role of vitrification in anhydrobiosis. Annu Rev Physiol 60: 73-103

Danyluk J, Houde M, Rassart EÂ, Sarhan F (1994) Differential expression of a gene encoding an acidic dehydrin in chilling sensitive and freezing tolerant Gramineae species. FEBS Lett $344: 20-24$ 
Danyluk J, Perron A, Houde M, Limin A, Fowler B, Benhamou N, Sarhan F (1998) Accumulation of an acidic dehydrin in the vicinity of the plasma-membrane during coldacclimation of wheat. Plant Cell 10:623-638

Dorsey JM, Bushnell J (1925) Plum investigation. II. The inheritance of hardiness. Univ of Minn Agric Expt Stn Techn Bull 32:1-24

Durner EF, Gianfagna TJ (1988) Fall ethephon application increases peach flower bud resistance to low-temperature stress. J Amer Soc Hort Sci 113:404-406

Egerton-Warburton LM, Balsamo RA, Close TJ (1997) Temporal accumulation and ultrastructural localization of dehydrins in Zea mays L. Physiol Plant 101:545-555

Fejer SO (1976) Combining ability and correlations of winter survival, electrical impedance and morphology in juvenile apple trees. Can J Plant Sci 56:303-309

Fowler DB, Gusta LV (1979) Selection for winter survival in wheat: I. Identification of genotype variability. Crop Sci 19:769-772

Fowler DB, Lumin AE, Gusta LV (1983) Breeding for winterhardiness in wheat. In: Fowler DB, Gusta LV, Slinkard AE, Hobin BA (eds) New frontiers in winter wheat production. University of Saskatchewan, Saskatoon, Canada, pp. 136-184

Fuchigami LH, Weiser CJ, Evert DR (1971) Induction of cold acclimation in Cornus stolonifera Michx. Plant Physiol 47:98-103

Gordon-Kamm WJ, Steponkus PL (1984) Lamellar-to-hexagonal II. phase transitions in the plasma membrane of isolated protoplasts after freeze-induced dehydration. Proc Natl Acad Sci USA 81:6373-6377

Gray GR, Chauvin LP, Sarhan F (1997) Cold acclimation and freezing tolerance. A complex interaction of light and temperature. Plant Physiol 114:467-74

Griffith M, Antikainen M, Hon WC (1997) Antifreeze proteins in winter rye. Physiol Plant 100:327-32

Guy CL (1990) Cold acclimation and freezing stress tolerance: role of protein metabolism. Annu Rev Plant Physiol Plant Mol Biol 41:187-223

Guy CL, Anderson JV, Haskell DV, Li QB (1994) CAPS, cors, dehydrins, and molecular chaperones; their relationship with low temperature responses in spinach. In Cherry JH (ed) Biochemical and cellular mechanisms of stress tolerance in plants, Springer-Verlag, Berlin, pp. 479-499

Hackett WP (1985) Juvenility, maturation, and rejuvenation in woody plants. Hort Rev 7:109155 
Hackett WP, Murray JR, Woo HH, Stapfer RE, Geneve R (1990) Cellular, biochemical and molecular characteristics related to maturation and rejuvenation in woody species. In Rodriguez R (ed) Plant aging: basic and applied approaches. Plenum Press, New York, pp. $147-152$

Hamman RA, Dami IE, Walsh TM, Stushnoff C (1996) Seasonal carbohydrate changes and cold hardiness of Chardonnay and Riesling grapevines. Amer J Enol Viticult 47: 31-36

Hand P, Besford RT, Richardson CM, Peppitt SD (1996) Antibodies to phase related proteins in juvenile and mature Prunus avium. Plant Growth Regulat 20:25-29

Harber RM, Fuchigami LH (1986) The relationship of ethylene and ethane production to tissue damage in frozen Rhododendron leaf discs. J Amer Soc Hort Sci 111:434-436

Harris RE (1965) The hardiness of progeny from reciprocal Malus crosses. Can J Plant Sci 45:159-161

Hayes PM, Blake T, Chen THH, Tragoonrung S, Chen F, Pan A, Liu B (1993) Quantitative trait loci on barley (Hordeum vulgare L.) chromosome 7 associated with components of winter hardiness. Genome 36:66-71

Heino P, Sandman G, Lang V, Nordin K, Palva KT (1990) Abscisic acid deficiency prevents development of freezing tolerance in Arabidopsis thaliana (L) Heynh. Theor Appl Genet 79:801-806

Holt MA, Pellett NM (1981) Cold hardiness of leaf and stem organs of Rhododendron cultivars. J Amer Soc Hort Sci 106:608-612

Hopper DA, Hammer PA, Wilson JR (1996) Comparison of two simulation-based methods for modeling plant growth. HortSci 31:25-28

Hughes MA, Dunn MA (1996) The molecular biology of plant acclimation to low temperature. J Exp Bot 47:291-305

Hummel RL, Ascher PD, Pellett HM (1982) Inheritance of photoperiodically induced cold acclimation response in Cornus sericea L., Red Osier Dogwood. Theor Appl Genet 62:385394

Hummer K, Fuchigami LH, Peters V, Bell A (1995) Cold hardiness in Rubus. Fruit Var J 49:5258

Ingram J, Bartels D (1996) The molecular basis of dehydration tolerance in plants. Annu Rev Plant Physiol Plant Mol Biol 47:377-403 
Iswari S, Palta JP (1989) Plasma membrane ATPase as a site of functional alteration during cold acclimation and freezing injury. In: Li PH (ed) Low temperature stress physiology in crops. CRC Press, Boca Raton, FL, pp. 123-128

Iwaya-Inoue M, Kaku S (1983) Cold hardiness in various organs of Rhododendron species and the supercooling ability of flower buds as the most susceptible organ. Cryobiology $20: 310-317$

Jaglo-Ottosen KR, Gilmour SJ, Zarka DG, Schabenberger O, Thomashow MF (1998) Arabidopsis CBF1 overexpression induces cor genes and enhances freezing tolerance. Science 280:104-106

Knight H, Trewavas AJ, Knight MR (1996) Cold calcium signaling in Arabidopsis involves two cellular pools and a change in calcium signature after acclimation. Plant Cell 8:489-503

Kochert G (1994) RFLP technology. In: Phillips RL, Vasil IK (eds) DNA based markers in plants. Kluwer Academic Publishers, Netherlands, pp. 8-38

Lång V, Heino P, Palva ET (1989) Low temperature acclimation and treatment with exogenous abscisic acid induce common polypeptides in Arabidopsis thaliana (L.) Heynh. Theor Appl Genet 77:729-734

Levitt J (1980) Responses of plants to environmental stresses. Vol 1, 2nd ed, Academic Press, Orlando, FL, 497 p.

Li PH (1991) Mefluidide - induced cold hardiness in plants. Crit Rev Plant Sci 9:497-517

Liesenfeld DR, Auld DL, Murray GA, Swensen JB (1986) Transmittance of winterhardiness in segregated populations of peas. Crop Sci 26:49-54

Lin C, Thomashow MF (1992) A cold-regulated Arabidopsis gene encodes a polypeptide having potent cryoprotective activity. Biochem Biophys Res Commun 183:1103-1108

Marschner H (1995) Mineral nutrition of higher plants. Academic Press Ltd., London, 292 p.

Michelmore RW, Paran I, Kesseli RV (1991) Identification of markers linked to diseased-resistance genes by bulked segregant analysis: a rapid method to detect markers in specific genomic regions by using segregating population. Proc Natl Acad Sci USA $88: 9828-9832$

Monroy AF, Dhindsa RS (1995) Low-temperature signal transduction: induction of cold acclimation-specific genes of alfalfa by calcium at $25^{\circ} \mathrm{C}$. Plant Cell 7: 321-331

Monroy AF, Castonguay Y, Laberge S, Sarhan F, Vezina LP, Dhindsa RS (1993) A new coldinduced alfalfa gene is associated with enhanced hardening at subzero temperature. Plant Physiol 102: 873-879 
Muthalif MM, Rowland LJ (1994) Identification of dehydrin-like proteins responsive to chilling in floral buds of blueberry (Vaccinium section Cyanococcus). Plant Physiol 104:1439-1447

National Climatic Data Center Research Customer Service Group (January 7, 1999) Billion Dollar U.S. Weather Disasters 1980-1998. Asheville, NC 28801

Neven LG, Haskell DW, Hofig A, Li QB, Guy CL (1993) Characterization of a spinach gene responsive to low temperature and water stress. Plant Mol Biol 21:291-305

Nilsen ET (1992) Thermonastic leaf movements: a synthesis of research with Rhododendron. Bot J Linn Soc 110:205-233

Olien CR, Clark JL (1995) Freeze-induced changes in carbohydrates associated with hardiness of barley and rye. Crop Sci 35:496-502

Palta JP, Weiss LS (1993) Ice formation and freezing injury: an overview on the survival mechanisms and molecular aspects of injury and cold acclimation in herbaceous plants. In: Li PH, Christersson L (eds) Plant cold hardiness. CRC Press, Boca Raton, FL, pp. 143-176

Palta JP, Levitt J, Stadelmann EJ (1978) Plant viability assay. Cryobiology 15:249-255

Palva ET, Heino P (1998) Molecular mechanisms of plant cold acclimation and freezing tolerance. In: Li PH, Chen THH (eds) Plant cold hardiness: molecular biology, biochemistry, and physiology. Plenum Press, New York, pp. 1-14

Pellett H (1998) Breeding of cold hardy woody landscape plants. In: Li PH, Chen THH (eds) Plant cold hardiness: molecular biology, biochemistry, and physiology. Plenum Press, New York, pp. 317-324

Pellett H, Moe S, Mezitt W (1986) Flower bud hardiness of Rhododendron Taxa. ARS Journal Oct. 1986:203-205

Quamme HA (1978) Breeding and selecting temperate fruit crops for cold hardiness. In Li PH, Sakai A (eds) Plant cold hardiness and freezing stress: mechanisms and crop implications. Academic Press, New York pp. 313-332

Raese JT (1996) Calcium nutrition affects cold hardiness, yield, and fruit disorders of apple and pear trees. J Plant Nutr 19:1131-1151

Raulston JC, Tripp KE (1995) Exploring the complexities of plant hardiness. J Amer Rhodo Soc 49:227-230

Riemenschneider CH (1983) World supply and demand for citrus and citrus products. Citrograph 68:243-245 
Robertson AJ, Reaney MJT, Wilen RW, Lamb N, Abrams SR, Gusta LV (1994) Effects of abscisic acid metabolites and analogs on freezing tolerance and gene expression in bromegrass (Bromus inermis Leyss) cell cultures. Plant Physiol 105: 823-830

Robertson AJ, Ishikawa M, Gusta LV (1995) The effect of prolonged abscisic acid treatment on the growth, freezing tolerance and protein patterns of Bromus inermis (Leyss) cell suspensions cultured at either 3 or $25^{\circ} \mathrm{C}$. J Plant Physiol 145: 137-142

Rowland LJ, Arora R (1997) Proteins related to endodormancy (rest) in woody perennials. Plant Sci 126:119-144

Sakai A, Fuchigami L, Weiser CJ (1986) Cold hardiness in the genus Rhododendron. J Amer Soc Hort Sci 111:273-280

Salzman RA, Bressan RA, Hasegawa PM, Ashworth EN, Bordelon BP (1996) Programmed accumulation of LEA-like proteins during desiccation and cold acclimation of overwintering grape buds. Plant Cell Environ 19:713-720

Sarhan F, Ouellet F, Vazquez-Tello A (1997) The wheat wcs120 gene family: a useful model to understand the molecular genetics of freezing tolerance in cereals. Plant Physiol 101:439-45

Sasaki H, Ichimura K, Oda M (1996) Changes in sugar content during cold acclimation and deacclimation of cabbage seedlings. Ann Bot 78: 365-369

Savitch LV, Gray GR, Huner NPA (1997) Feedback-limited photosynthesis and regulation of sucrose-starch accumulation during cold acclimation and low-temperature stress in a spring and winter wheat. Planta 201:18-26

Sieg F, Schroder W, Schmitt JM (1996) Purification and characterization of a cryoprotective protein (cryoprotectin) from the leaves of cold-acclimated cabbage. Plant Physiol 111:215-21

Steffen KL, Arora R, Palta JP (1989) Relative sensitivity of photosynthesis and respiration to freeze-thaw stress in herbaceous species. Importance of realistic freeze-thaw protocols. Plant Physiol 89:1372-1379

Steponkus PL (1984) Role of the plasma membrane in freezing injury and cold acclimation. Annu Rev Plant Physiol 35: 543-584

Stone JM, Palta JP, Bamberg JB, Weiss LW, Harbage JF (1993) Inheritance of freezing resistance in tuber-bearing Solanum species: evidence for independent genetic control of nonacclimated freezing tolerance and cold acclimation capacity. Proc Natl Acad Sci USA 90:7869-7873

Sutinen ML, Palta JP, Reich PB (1992) Seasonal differences in freezing stress resistance of needles of Pinus nigra and Pinus rensinosa: evaluation of the electrolyte leakage method. Tree Physiol 11:241-254 
Sutka J (1981) Genetic studies of frost resistance in wheat. Theor Appl Genet 59:145-152

Teutonico RA, Yandell B, Satagopan JM, Ferreira ME, Palta JP, Osborn TC (1995) Genetic analysis and mapping of genes controlling freezing tolerance in oilseed Brassica. Mol Breeding 1:329-339

Thomashow MF (1990) Molecular genetics of cold acclimation in higher plants. Adv Genet 28:99-131

Thomashow MF (1998) Role of cold-responsive genes in plant freezing tolerance. Plant Physiol 118:1-7

Thomashow MF (1999) Plant cold acclimation: freezing tolerance genes and regulatory mechanisms. Annu Rev Plant Physiol Plant Mol Biol 50: 571-599

Thomashow MF, Stockinher EJ, Gilmour SJ (1998) Regulation of plant gene expression in response to low temperature. In: Li PH, Chen THH (eds) Plant cold hardiness: molecular biology, biochemistry, and physiology. Plenum Press, New York, pp. 29-34

Tibbits WN, Potts BM, Savva MH (1991) Inheritance of freezing resistance in interspecific F1 hybrids of Eucalyptus. Theor Appl Genet 83:126-135

Uemura M, Steponkus PL (1994) A contrast of the plasma membrane lipid composition of oat and rye leaves in relation to freezing tolerance. Plant Physiol 104: 479-496

Uemura M, Joseph RA, Steponkus PL (1995) Cold acclimation of Arabidopsis thaliana - effect on plasma membrane lipid composition and freeze-induced lesions. Plant Physiol 109:15-30

Uosukainen M, Tigerstedt PMA (1988) Breeding of frosthardy rhododendrons. J Agr Sci Fin 60:235-254

von-Fircks HA, Verwijst T (1993) Plant viability as a function of temperature stress. Plant Physiol 103:125-130

Wagner I (1994) Measurement of frost resistance in Rhododendron-hybrids. Acta Hort 364:169-174

Watkins R, Spangelo LPS (1970) Components of genetic variance for plant survival and vigor of apple trees. Theor Appl Genet 40:195-203

Weiser CJ (1970) Cold resistance and injury in woody plants. Science 169:1296-1278

Welin BV, Olson Å, Nylander M, Palva ET (1994) Characterization and differential expression of $d h n / l e a / r a b$-like genes during cold acclimation and drought stress in Arabidopsis thaliana. Plant Mol Biol 26:131-144 
Welin BV, Olson A, Palva ET (1995) Structure and organization of two closely related lowtemperature-induced dhn/lea/rab-like genes in Arabidopsis thaliana L Heynh. Plant Mol Biol 29:391-395

Welling A, Kaikuranta P, Päivi R (1997) Photoperiodic induction of dormancy and freezing tolerance in Betula pubescens. Involvement of ABA and dehydrins. Physiol Plant 100:119125

Wilner J (1965) The influence of maternal parent on frost-hardiness of apple progenies. Can J Plant Sci 45:67-71

Wisniewski M, Arora R (1993) Adaptation and response of fruit trees to freezing temperatures. In Biggs AR (ed) Cytology, histology and histochemistry of fruit tree diseases. CRC Press, Boca Raton, FL pp. 299-320

Wisniewski M, Close TJ, Artlip T, Arora R (1996) Seasonal patterns of dehydrins and 70-kDa heat-shock proteins in bark tissues of eight species of woody plants. Physiol Plant 96:496505

Wisniewski M, Webb R, Balsamo R, Close TJ, Yu X-M, Griffith M (1999) Purification, immunolocalization, cryoprotective, and antifreeze activity of PCA60: a dehydrin from peach (Prunus persica). Physiol Plant 105:600-608

Yelenosky G (1985) Cold hardiness in citrus. Hort Rev 7:201-238

Zatylny AM, Proctor JTA, Sullivan JA (1996) Assessing cold hardiness of red raspberry genotypes in the laboratory and field. J Amer Soc Hort Sci 121: 495-500

Zimmerman RH, Hackett WP, Pharis RP (1985) Hormonal aspects of phase change and precocious flowering. Encyclopedia of Plant Physiology. New Series 11: 79-115 


\section{ORGANIZATION OF THE REMAINING CHAPTERS}

The rest of this dissertation is divided into three segments. First, chapters two to four are full-length published articles. Second, chapters five to seven are concise articles that have yet to be published plus a summary and conclusions chapter. Lastly, in the appendix, there is another brief chapter that was not including in the original proposal of study and part of the serendipity results stemming from other lab research. A list of other related published articles is also included in the appendix. 


\title{
CHAPTER TWO \\ DEVELOPMENT OF AN IN VITRO PROTOCOL TO ESTIMATE \\ LEAF FREEZING-TOLERANCES IN RHODODENDRON
}

published as:

Comparing Gompertz and Richards Functions to Estimate

Freezing Injury in Rhododendron using Electrolyte Leakage.

J Amer Soc Hort Sci (1998) 123:246-252

Chon C. Lim ${ }^{1}$, Rajeev Arora ${ }^{1}$ and Edwin C. Townsend ${ }^{2}$

${ }^{1}$ Division of Plant and Soil Sciences

${ }^{2}$ WVAFES, Office of Statistics

West Virginia University, Morgantown, WV 26506

\begin{abstract}
Seasonal patterns in freezing tolerance (FT) of five Rhododendron cultivars that vary in FT were estimated. Electrolyte leakage was used, and raw leakage data were transformed to percent leakage, percent-injury, and percent-adjusted injury. These data were compared with visual estimates of injury. Percent-adjusted injury was highly correlated (0.753) to visual estimates. Two asymmetric sigmoid functions-Richards and Gompertz-were fitted to the seasonal percent-adjusted injury data for all cultivars. Two quantitative measures of leaf freezing-tolerance- $-\mathrm{LT}_{50}$ and $\mathrm{T}_{\max }$ (temperature at maximum rate of injury) — were estimated from the fitted sigmoidal curves. When compared to the General Linear Model, the Gompertz function had a better fit (lower mean error sum of squares) than Richards. Correlation analysis of all freezing tolerance estimates made by Gompertz and Richards with visual $\mathrm{LT}_{50}$ revealed similar closeness (0.77-0.79). However, the Gompertz function and $\mathrm{T}_{\max }$ were selected as the criteria for comparison of relative freezing tolerance among cultivars due to the better data fitting
\end{abstract}


of Gompertz function (than Richards) and more descriptive physiological representation of $\mathrm{T}_{\max }$ (than $\mathrm{LT}_{50}$ ). Based on the $\mathrm{T}_{\max }\left({ }^{\circ} \mathrm{C}\right)$ values at maximum cold acclimation of respective cultivars, we ranked $R$. 'Autumn Gold' and $R$. 'Grumpy Yellow' in the relatively tender group, $R$. 'Vulcan's Flame' in intermediate group and $R$. 'Chionoides' and $R$. 'Roseum Elegans' in the hardy group. These relative rankings are consistent with midwinter bud hardiness values reported by nurseries.

\section{INTRODUCTION}

Measurement of electrolyte leakage following a freeze-thaw stress has been widely used to estimate freezing injury and tolerance of various plant tissues. Some discrepancies however, have been found in laboratory estimates of freezing tolerance when compared to field data (Pellet et al. 1986). Electrolyte leakage is usually calculated as the ratio of ion-leakage from freeze-injured to the total ions in the tissue and expressed as a percent leakage (Flint et al. 1967).

Researchers often rely on empirical mathematical models to predict plant response to environmental stress over time. When using a computerized simulation for estimating any plant response, the accuracy of predictions will depend on the appropriateness of the mathematical function (Hopper et al. 1996). Plant response to temperature stress is characterized by an asymmetric sigmoid function (von-Fircks and Verwijst 1993). Simple straight line or interpolation techniques (Holt and Pellet 1981) however, have also been used. Each plant tissue has its own unique sigmoidal response curve that may or may not differ during the initial and final rate of injury. Therefore, one limitation with using the logistic function (Zhu and Liu 1987; Andrews and Morrison 1992; Oldum and Blake 1996) is that it considers the rate of initial and

final injury to be identical (symmetric sigmoid function). A more appropriate choice for a function to be used in data fitting of plant response to temperature stress would be an asymmetric sigmoid one that would take into account differing rates of injury.

Conventionally, the temperature giving an index of 50\% ion-leakage (or injury) is termed $\mathrm{LT}_{50}$ (Burr et al. 1990). Most reports use $\mathrm{LT}_{50}$ as a measure of relative freezing tolerance (Palta et al. 1978; Sakai et al. 1986; Arora et al. 1992; Sutinen et al. 1992). When working with woody 
plants however, even the lowest treatment temperature employed in the experimental protocol, often fails to reach the $\mathrm{LT}_{50}$ level (Zatylny et al. 1996). Alternatively, others have used the rate of freezing injury and the point of inflection $\left(\mathrm{T}_{\max }\right)$ as a measure of maximum rate of injury due to freeze-thaw stress (von-Fircks and Verwijst 1993; Anisko and Lindstrom 1995). Frequently, the quantitative values for freezing tolerance are based on single point estimates (Sakai et al. 1986; Hummer et al. 1995) and no variances or standard errors are provided due to complex experiment protocols and limitations on the availability of ample plant sample. Therefore, there is a need to reevaluate methods of data analysis for the estimation of the relative freezing tolerance using the electrolyte leakage method that would provide more consistent and reliable results.

The amount of winter injury to Rhododendron cultivars may vary from year to year depending on the severity of the winter season and the level of bud and leaf cold hardiness (Holt and Pellet 1981). Information is available on midwinter cold hardiness of various Rhododendron species and cultivars (Holt and Pellet 1981; Sakai et al. 1986; Wagner 1994), however, it is mostly based on sampling from a single source or period at a particular location (Pellet et al. 1986). Apart from visual estimations of freezing tolerance, limited data are available on seasonal changes in freezing tolerance of Rhododendron (Holt and Pellet 1981; Sakai et al. 1986; Anisko and Lindstrom 1996a). Rhododendron breeders are particularly interested in cold hardiness but the irregular occurrence and unpredictability of severe or test winters has limited the breeding selection. Hence, there is a need to develop laboratory protocols under controlled conditions that produce reliable relative injury estimates and enable comparison among cultivars (Wagner 1994). Therefore, a study was undertaken to evaluate two asymmetric sigmoid functions, Richards (von-Fircks and Verwijst 1993) and Gompertz (Messori 1997), in order to estimate the seasonal patterns for two quantitative measures $\left(\mathrm{LT}_{50}\right.$ and $\left.\mathrm{T}_{\max }\right)$ of the leaf freezing-tolerance of Rhododendron cultivars (that vary in freezing tolerance) using electrolyte leakage method. Additionally, data on $\mathrm{LT}_{50}$ and $\mathrm{T}_{\max }$ (obtained by fitted curve) were compared with visual estimates of $\mathrm{LT}_{50}$. 


\section{MATERIAL AND METHODS}

Plant material. Rhododendron cultivars ('Autumn Gold', 'Chionoides', 'Grumpy Yellow', 'Roseum Elegans' and 'Vulcan's Flame') were obtained as 2 year-old rooted cuttings and potted in 7-inch pots with artificial mix (70\% pine bark, 15\% sand and 15\% sphagnum peat). The plants were fertilized with Azalea Special 21-7-7 (W.R. Grace, Fogelsville, PA, USA) at 1.5 g. $\mathrm{L}^{-1}$ plus Fe chelate (Sequestrene $330 \mathrm{Fe}, 10 \% \mathrm{Fe}$, Ciba-Geigy, Greensboro, NC, USA) at 0.25 $\mathrm{g} \cdot \mathrm{L}^{-1}$ to maintain $\mathrm{pH}$ at $4.5-5.5$ and electrical conductivity (EC) at $0.5-0.9 \mathrm{dS} \cdot \mathrm{m}^{-2}$ of the potting medium. The plants were irrigated as needed and maintained under natural photoperiod and temperature conditions. These cultivars are adapted to hardiness zones 4-7 and are expected to have a varying degree of nonacclimated freezing tolerance and cold acclimation ability [Van Veen Nursery, Portland, OR, and Appalachian Nurseries, Waynesboro, PA, (from where cuttings were obtained) provided a ranking of bud midwinter hardiness]. Current-year leaves from five Rhododendron cultivars were collected monthly from September 1995 until June 1996. Fifteen twenty two leaves were randomly collected from 10-15 plants of each cultivar, kept on ice and brought to the laboratory for freezing tolerance estimation.

\section{Relative freezing tolerance estimation and data transformation.}

Leaves were cut into $1 \mathrm{~cm}^{2}$ discs and placed into test tubes $(25 \times 200 \mathrm{~mm})$ containing $50-75 \mu \mathrm{L}$ water. Leaf margins and midribs were excluded from the discs. Six replicates (one disc per tube) per temperature per cultivar were placed in a glycol-freezing bath (model $2325 \mathrm{CH} / \mathrm{P}$; Forma Scientific, Marietta $\mathrm{OH}$ ) and frozen to various treatment temperatures as described by Arora et al. (1996). Tubes were removed at various treatment temperatures, first placed in ice (2 h minimum) and then transferred to $4^{\circ} \mathrm{C}$ (overnight) to allow slow thawing. A set of 3 discs per cultivar was removed from the freezing bath (after reaching at least $-10^{\circ} \mathrm{C}$ ) and placed in $-80^{\circ} \mathrm{C}$ freezer for $4-5 \mathrm{~h}$ and was thawed similar to other samples. Following thaw, discs from three replicates were placed on a wet filter paper in a petri dish at $100 \%$ relative humidity and $20^{\circ} \mathrm{C}$. After 5-6 days, visual injury (browning and water soaking) was estimated in these discs and given a ranking of $0 \%, 25 \%, 50 \%, 75 \%$ or $100 \%$ injured. Discs from the other 3 replicates were 
placed in $20 \mathrm{~mL}$ of distilled deionized water immediately after thaw, vacuum infiltrated for 3-5 minutes and shaken at $250 \mathrm{rpm}$ on gyratory shaker (model G10; New Brunswick Scientific, Edison, NJ) for $3 \mathrm{~h}$ for ion-leakage measurements as described by Arora et al. (1996). A preliminary time-course study revealed no significant change in the percent ion-leakage from leaf discs when shaken for three or up to six hours (data not shown). Percent-injury (as described by Arora et al. 1992) was then calculated using the percent ion-leakage data.

The percent-injury data transformations take into account the ion-leakage from unfrozen control samples but do not adjust for ion-leakage from "100\% freeze-injured" leaf discs. Therefore, percent-injury data were transformed to percent-adjusted injury using the following method. Ion-leakage and percent-injury measurements were also made on discs frozen to $-80^{\circ} \mathrm{C}$ (representing "100\% freeze-injured" samples by extreme freezing). The "percent-adjusted injury" was then calculated by the equation:

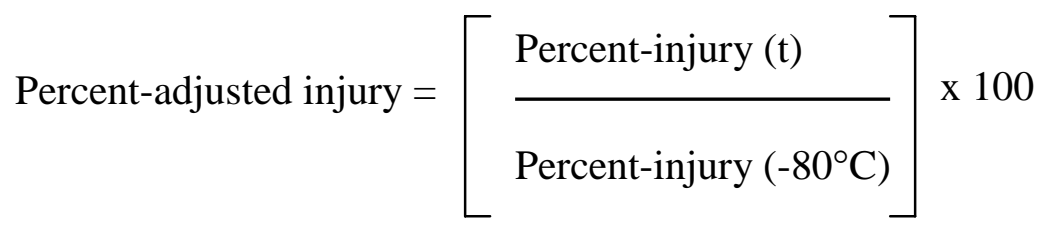

where, percent-injury (t) is the measurement of injury at respective freeze-treatment temperature. An example of data calculations and transformations is provided in Table 1. A full statistical correlation analysis between different data transformations cannot be conducted because the plants' response to freeze-thaw stress is not linear. Therefore, a partial correlation analysis (holding treatment temperatures and months constant) was conducted to find the closest correlation between the different data transformations and the visual estimates.

Comparison of Richards to Gompertz. The Gompertz and Richards functions were fitted to the percent-adjusted injury data by the Marquardt method using the NLIN procedure of SAS (SAS Institute 1996). The obstacle in using Richards or Gompertz function for fitting data lies with estimating the initial starting parameters. These parameters are crucial for the function to converge, and for a good fit to the data. A SAS program was written for finding the best starting parameters of the Gompertz function, an example of which is 
provided in Figure 1.

An assumption, that leaf tissues are completely killed (100\% injured) at $-80^{\circ} \mathrm{C}$ was made which eliminated the need to estimate parameter A. Parameter A represents the maximum injury level, where it is always $100 \%$ when percent-adjusted injury data were used. The modified Richards and Gompertz equations (without parameter A) are listed in Table 2. Using the monthly data for all cultivars, both Gompertz and Richards functions were compared to the GLM (General Linear Model) for lack of fit using an F-test.

\section{Comparisons of freezing tolerance quantitative expressions. The}

$\mathrm{LT}_{50}$ and $\mathrm{T}_{\max }$ (the point of inflection of a fitted curve of freezing tolerance) were estimated based on the computer simulated sigmoid curves of Richards and Gompertz functions fitted to adjusted injury data. The $\mathrm{LT}_{50}$ in adjusted injury data will always be at the $50 \%$ injury level and $\mathrm{T}_{\max }$ is located at the highest point of the first derivative of the equation (equate the $2^{\text {nd }}$ derivative to zero). The $\mathrm{LT}_{50}$ and $\mathrm{T}_{\max }$ equations are listed in Table 2. A partial correlation analysis (holding month constant) was conducted to evaluate the closeness of all freezing tolerance quantitative expressions in comparison with the visual $\mathrm{LT}_{50}$.

Leaf freezing-tolerance. A single estimate of $\mathrm{LT}_{50}$ and $\mathrm{T}_{\max }$ was assessed for each month. These estimates cannot be distinguished from each other without some information provided by its variance. Repeating the entire experiment to obtain the $\mathrm{LT}_{50}$ and $\mathrm{T}_{\max }$ variances is impractical and inefficient. Therefore, the Jackknife method (Efron 1982) was used to estimate the standard error of $\mathrm{LT}_{50}$ and $\mathrm{T}_{\max }$. The Jackknife method involved taking out one data point at a time and estimating the $\mathrm{LT}_{50}$ and $\mathrm{T}_{\max }$. The removed data point was replaced by another data point and $\mathrm{LT}_{50}$ and $\mathrm{T}_{\max }$ were reestimated. This process was repeated until all data points were removed and reincorporated. By the end of this process, there were at least 30 estimates of $\mathrm{LT}_{50}$ and $\mathrm{T}_{\max }$ per cultivar per month; thus, giving a mean and standard error. Multiple t-tests at 5\% level were used to compare all the estimates. An example of a SAS program using Jackknife method and Gompertz function to find $\mathrm{LT}_{50}$ and $\mathrm{T}_{\max }$ means and standard errors is provided in Figure 2. 


\section{RESULTS}

Data transformation analysis. Partial correlation analysis (for a linear model comparing each treatment temperature for all cultivars and every month in the entire sampling season) revealed the highest correlation (0.753) between the percent-adjusted injury data and the visual estimate data (Table 3). The percent leakage (0.693) and percent-injury data (0.699) were not much different from each other when compared with the visual estimate data. Therefore, the asymmetric functions were fitted using percent-adjusted injury data.

Comparison of Richards to Gompertz. When compared with the General Linear Model (GLM), the adjusted injury data fit better using the Gompertz function (Fig. 3) than the Richards; $82.2 \%$ vs. $75.5 \%$, respectively (Table 4 ). Of the forty-five functions (5 cultivars x 9 months) fitted to percent-adjusted injury data, thirty-four of Gompertz functions fitted as adequately as General Linear Model (GLM). In addition, utilization of Richards function produced a higher overall mean error sum of squares (117.21) than Gompertz function. Although, both functions produced similar but not identical estimates of $\mathrm{LT}_{50}$ and $\mathrm{T}_{\max }$ (data not shown), Gompertz function was less complicated (one less parameter to be estimated) and easier to produce freezing tolerance estimates than Richards.

\section{Comparisons of quantitative expressions for freezing tolerance.}

Partial correlation analysis of all freezing tolerance quantitative estimates made by Gompertz and Richards in comparison with visual $\mathrm{LT}_{50}$ (per month) revealed similar closeness (Table 5). The $\mathrm{LT}_{50}$ estimations made by Richards function and $\mathrm{T}_{\max }$ estimations made by Gompertz function were the two best correlated to visual $\mathrm{LT}_{50}$ estimate (0.793). Although statistical analysis could not distinguish a significant difference between freezing tolerance estimators, the Gompertz function's estimations of $\mathrm{T}_{\max }$ were selected as the criteria for comparison of freezing tolerance among cultivars. We believe that $\mathrm{T}_{\max }$ may be more descriptive than $\mathrm{LT}_{50}$ in representing plant stress-response (injury) from a physiological standpoint because it is an estimated point where the rate of injury is maximum. 
Leaf freezing-tolerance. The seasonal fluctuations of $\mathrm{T}_{\max }$ for all cultivars revealed maximum acclimation by December 1995 followed by slow deacclimation (Fig. 4). The cultivars were divided into two groups based on freezing tolerance of non-acclimated leaf tissues and into three groups at the maximum cold acclimation (Table 6). In September (when the leaves are non-acclimated), $R$. 'Autumn Gold', $R$. 'Grumpy Yellow' and $R$. 'Vulcan's Flame' were assessed as the tender group and $R$. 'Chionoides' and $R$. 'Roseum Elegans' as the hardy group. At fully cold acclimated state by December, $R$. 'Autumn Gold', $R$. 'Grumpy Yellow', $R$. 'Chionoides' and $R$. 'Roseum Elegans' were still grouped in their respective groups but $R$. 'Vulcan's Flame' was significantly different from the other cultivars and was placed in the intermediate group by itself. When the leaves were deacclimated in June, $R$. 'Autumn Gold', $R$. 'Chionoides' and $R$. 'Roseum Elegans' remained in their grouping as of when non-acclimated; however, $R$. 'Grumpy Yellow' and $R$. 'Vulcan's Flame' were in a transitional group overlapping the other groups. Data indicated that $R$. 'Grumpy Yellow' and $R$. 'Vulcan's Flame' had yet to fully deacclimate (to the levels in September 1995) to the non-acclimated state by June.

\section{DISCUSSION}

Data transformation analysis. Estimation of stress response using ion-leakage is favored because of its nondestructiveness (i.e., requires only a portion of and not the entire plant) and rapidity. Stuart (1939) first described the transformation of percent ion-leakage data to percent-injury and further refined by Flint et al. (1967). Percent-injury calculations have since been widely used in many electrolyte leakage studies to assess plant injury. Although the method of Flint et al. takes into account and adjusts for ion-leakage from unfrozen (control) tissues, it assumes that tissues exhibit $100 \%$ ion-leakage (similar to heat-killed) when maximally freeze-injured. Whereas this may be a safe assumption for herbaceous plants, all too often, cold acclimated tissues of woody plants exhibit a relatively low percent ion-leakage even when frozen to temperatures that cause lethal injury (assessed visually). This is indicated in a study by Sutinen et al. (1992) where the ion-leakage from cold acclimated (December 7) Pinus rensinosa needles was only $20 \%$ when slowly frozen to $-196^{\circ} \mathrm{C}\left(\mathrm{LN}_{2}\right)$. In comparison, visual browning 
caused by identical freeze-thaw stress was assessed at $64.2 \%$. Therefore, we believe that using percent-injury data in Flint's equation may result in biased estimation of $\mathrm{LT}_{50}$ for freeze-injured tissues of woody plants.

In the present study, not all ions were "leaked" during freeze-thaw treatments as evidenced by percent ion-leakage and percent-injury data of leaf tissues exposed to $-80^{\circ} \mathrm{C}$ that caused $100 \%$ visual browning (Table 1). Thus, we implemented the percent-adjusted injury data transformations. The percent-adjusted injury data also allow for the ease of sigmoidal fitting with a fixed initial point of zero and final point of 100 . Thus, the $\mathrm{LT}_{50}$ will always be at $50 \%$-adjusted injury. Furthermore, the percent-adjusted injury showed a higher correlation to the injury data based on visual observations (Table 3). This makes percent-adjusted injury data transformation more appropriate and not just arbitrary.

Comparison of Richards to Gompertz. Many reports that use ion-leakage to assess relative injury to plant tissues do not include the analysis of data fitting to an asymmetric sigmoidal curve partly because it involves complex and numerous calculations. Some have chosen to fit the data in a straight line while others have interpolated the mean of three or more replications. Hence, the typical quantitative measure of freezing tolerance is somewhat biased with a single estimate obtained from one sampling period, and provides no ranges of the estimate. In conducting freeze-thaw experiments, the supply of tissue samples and the coldest temperature to which tissue can be cooled (limited by the freezing bath) are often a limitation. Therefore, in some reported experiments, the coldest treatment temperatures have failed to reach $\mathrm{LT}_{50}$ and prompted researchers to use $\mathrm{LT}_{40}$ estimates (Zatylny et al. 1996). Fitting the data with an asymmetrical curve would eliminate this problem as the curve would begin with zero and ends with $100 \%$ injury. There have been a few reports that used Richards function (von-Fircks and Verwijst 1993; Anisko and Lindstrom 1996b) in fitting the freezing tolerance data; however, no reports were found on the use of Gompertz function in determining a plant's response to freezing stress.

The most difficult part in getting Richards or Gompertz function to fit data is estimating the initial starting parameters. These parameters are crucial for the function to converge, and for a good fit to the data. A SAS program was written in this study for the grid search of the best 
starting parameters. Alternatively, the availability of a commercial program, (PCNONLIN) may be used for the complex matrix search of the parameters (Messori 1997). Based on the assumption we made on leaf tissue being $100 \%$ injured at $-80^{\circ} \mathrm{C}$, we eliminated the need to estimate parameter A. However, this assumption may not hold up when plant material other than leaves is used as experimental units. The elimination of parameter A simplified both asymmetric functions in that the modified functions have one less parameter each to be estimated which reduced the size of the matrix grid search of parameters. Our report estimated 45 different sets of parameters for each function. No significant difference was found between the two functions used, however, the Gompertz function was chosen to estimate the quantitative expressions $\left(\mathrm{LT}_{50}\right.$ and $\mathrm{T}_{\max }$ ) of freezing tolerance because it has only two parameters to be estimated (compared to three in Richards) and fitted better (than Richards) when compared with the GLM (Table 4). It is noteworthy that Richards function is expected to be more flexible than Gompertz with an additional parameter to fit the data; however, the extra parameter may also introduce more error, and use an extra degree of freedom (Table 4).

\section{Comparisons of quantitative expressions for freezing tolerance.}

$\mathrm{T}_{\max }$ was selected (instead of $\mathrm{LT}_{50}$ ) as the quantitative measure of freezing tolerance because we believe that physiologically, $\mathrm{T}_{\max }$ is more descriptive. Conventionally, in the literature, $\mathrm{LT}_{50}$ is regarded as the temperature that causes 50\%-injury and the critical temperature of cold hardiness of the particular tissue evaluated (Sakai et al. 1986; Zhang and Willison 1987; Arora et al. 1992). However, it may be argued, whether $\mathrm{LT}_{50}$ represents a temperature that causes injury to only $50 \%$ of the total tissue area or causes all cells to be half-injured. On the other hand, $\mathrm{T}_{\max }$ is the temperature that causes maximum rate of injury where any lowering of temperature beyond $\mathrm{T}_{\max }$ results in diminishing rates (Fig. 3). Evidence is accumulating in the literature supporting the use of $\mathrm{T}_{\max }$ as a quantitative cold hardiness index (Zhu and Liu 1987; von-Fircks and Verwijst 1993; Anisko and Lindstrom 1995; Repo et al. 1996;).

Leaf freezing-tolerance. A rather unique portion of this study relies on the Jackknife method (Efron 1982) for predictions of $\mathrm{T}_{\max }$ 's standard errors. von-Fircks and Verwijst (1993) used 100 simple random samplings with replacement for each data set to predict 
the standard errors. Instead of using random samplings, the Jackknife involves manipulation of the actual data set. For example, a 9-point data set could potentially produce nine different data sets, each having one less data point if the Jackknife method is employed. This would allow for the estimation of mean $\mathrm{T}_{\max }$ with standard errors that were derived from the nine different data sets. Therefore, the standard errors of $\mathrm{T}_{\max }$ should be proportional to the fluctuations of each experiment data point. Also, the standard errors are generated from the number of sigmoidal curves fitted by the computer (which are equal to experimental data points). Hence, each $\mathrm{T}_{\max }$ value in this report represents at least 30 estimates per cultivar per month, providing a statistically sound estimate of freezing tolerance and saving experimental cost and time.

Data indicated that the Rhododendron cultivars exhibit an increase in freezing tolerance during the fall, reached a maximum in December and gradually decreased thereafter (Fig. 4). All cultivars exhibited four to five-fold increase (with exception of about eight-fold increase for $R$. 'Vulcan' flame') in freezing tolerance during cold acclimation. Based on $\mathrm{T}_{\max }$ values, we ranked $R$. 'Autumn Gold' and $R$. 'Grumpy Yellow' in tender group, $R$. 'Vulcan's Flame' in intermediate group and $R$. 'Chionoides' and $R$. 'Roseum Elegans' in the hardy group at maximum cold acclimation. Sakai et al. (1986) consistently reported Rhododendron leaf tissues to be significantly more freeze tolerant than bud tissues. In this study, however, the relative leaf freezing-tolerance (cold-acclimated) estimates were somewhat similar to midwinter bud hardiness of the respective cultivars (Table 6). We were unable to evaluate bud hardiness due to the lack of flower buds in relatively younger plants (2-3 year old). The closeness between the leaf freezing-tolerance (assessed in this study) and the presumed bud hardiness (reported by nurseries for mature plants) of these cultivars may be due to the use of relatively younger plants that have yet to express their maximum cold acclimation ability. Many reports have attempted to associate laboratory freezing tolerance estimates to the field data and found that electrolyte leakage method tends to overestimate cold hardiness of plant tissues (Zhang and Willison 1987; Sutinen et al. 1992; Anisko and Lindstrom 1995; Oldum and Blake 1996; Repo et al. 1996). Others have abandoned the electrolyte leakage method entirely and used more complex techniques, such as ionic conductance as a measure of membrane competence, to determine plant cold hardiness (Whitlow et al. 1992). Manley and Hummel (1996) however, concluded that electrolyte leakage method was simpler and did not require additional extensive measurements such as tissue ionic conductance as suggested by Whitlow et al. (1992). 
This study provides baseline information on the relative freezing tolerance of five Rhododendron cultivars at non-acclimated and cold acclimated state as well as cold acclimation ability. We have shown that the percent-adjusted injury data fitted to Gompertz function coupled with Jackknife method (in estimating standard errors) allows for "reliable" and statistically sound estimations of freezing tolerance $\left(\mathrm{T}_{\max }\right)$ of Rhododendron leaf tissues.

\section{ACKNOWLEDGEMENTS}

We sincerely thank Dr. Bradford C. Bearce for his technical advice on growing rhododendrons and, Susan G. Myers and Gail Sikorsky for their help in maintenance of the Rhododendron plants. This research is supported, in part, by the grants from Horticulture Research Institute and West Virginia Nurserymen's Association. Published as West Virginia Agricultural and Forestry Experiment Station Scientific article No. 2619. 


\section{LITERATURE CITED}

Andrews CJ, Morrison MJ (1992) Freezing and ice tolerance tests for winter brassica. Agron J 84:960-962

Anisko T, Lindstrom OM (1995) Applying the Richards function in freezing tolerance determination with electrolyte and phenolic leakage techniques. Physiol Plant 95:281-287

Anisko T, Lindstrom OM (1996a) Seasonal-changes in cold-hardiness of Rhododendron L catawbiense 'Boursault' grown under continuous and periodic water-stress. J Amer Soc Hort Sci 121: 301-306.

Anisko T, Lindstrom OM (1996b) Survival of water-stressed Rhododendron subjected to freezing of fast or slow cooling rates. HortSci 31:357-360

Arora R, Wisniewski ME, Scorza R (1992) Cold acclimation in genetically related (sibling) deciduous and evergreen peach (Prunus persica [L.] Batsch) I. Seasonal changes in cold hardiness and polypeptides of bark and xylem tissues. Plant Physiol 99:1562-1568

Arora R, Wisniewski ME, Rowland LJ (1996) Cold acclimation and alterations in dehydrin-like and bark storage proteins in the leaves of sibling deciduous and evergreen peach $\mathrm{J}$ Amer Soc Hort Sci 121:915-919

Burr KE, Tinus RW, Wallner SJ, King RM (1990) Comparison of three cold hardiness tests for conifer seedlings. Tree Physiol 6:351-369

Efron B (1982) The Jackknife, the Bootstrap and other resampling plans. CBMS-NSF regional conference series in applied mathematics 38. Society for Industrial and Applied Mathematics, Philadelphia, PA

Flint HL, Boyce BR, Beattie DJ (1967) Index of injury: a useful expression of freezing injury to plant tissues as determined by the electrolytic method. Can J Plant Sci 47: 229-230

Holt MA, Pellett NM (1981) Cold hardiness of leaf and stem organs of Rhododendron cultivars. J Amer Soc Hort Sci 106:608-612

Hopper DA, Hammer PA, Wilson JR (1996) Comparison of two simulation-based methods for modeling plant growth. HortSci 31:25-28

Hummer K, Fuchigami LH, Peters V, Bell A (1995) Cold hardiness in Rubus. Fruit Var J 49:5258

Manley RC, Hummel RL (1996) Index of injury compared to tissue ionic conductance for calculating freeze damage of cabbage tissues. J Amer Soc Hort Sci 121:1141-1146 
Messori A (1997) Survival curve fitting using the Gompertz function: a methodology for conducting cost-effectiveness analyses on mortality data. Comp Meth Prog Biomed 52:157164

Oldum KD, Blake TJ (1996) A comparison of analytical approaches for assessing freezing damage in black spruce using electrolyte leakage methods. Can J Bot 74:952-958

Palta JP, Levitt J, Stadelmann EJ (1978) Plant viability assay. Cryobiology 15:249-255

Pellett H, Moe S, Mezitt W (1986) Flower bud hardiness of Rhododendron Taxa. ARS Journal Oct. 1986:203-205

Repo T, Hanninen H, Kellomaki S (1996) The effects of long-term elevation of air temperature and $\mathrm{CO}_{2}$ on the frost hardiness of Scots pine. Plant Cell Environ 19:209-216

Sakai A, Fuchigami L, Weiser CJ (1986) Cold hardiness in the genus Rhododendron. J Amer Soc Hort Sci 111:273-280

SAS Institute (1996) SAS user's guide. SAS Institute, Cary, NC

Stuart NW (1939) Comparative cold hardiness of scion roots from fifty apple varieties. Proc Amer Soc Hort Sci. 37:330-334

Sutinen ML, Palta JP, Reich PB (1992) Seasonal differences in freezing stress resistance of needles of Pinus nigra and Pinus rensinosa: evaluation of the electrolyte leakage method. Tree Physiol 11:241-254

von-Fircks HA, Verwijst T (1993) Plant viability as a function of temperature stress. Plant Physiol 103:125-130

Wagner I (1994) Measurement of frost resistance in Rhododendron-hybrids. Acta Horticulturae 364:169-174

Whitlow TH, Bassuk NL, Ranney TG, Reichert DL (1992) An improved method for using electrolyte leakage to assess membrane competence in plant tissues. Plant Physiol 98:198205

Zatylny AM, Proctor JTA, Sullivan JA (1996) Assessing cold hardiness of red raspberry genotypes in the laboratory and field. J Amer Soc Hort Sci 121: 495-500

Zhang MIN, Willison JHM (1987) An improved conductivity method for the measurement of frost hardiness. Can J Bot 65:710-715

Zhu GH, Liu ZQ (1987) Determination of median lethal temperature using logistic function, $p$ 291-298. In Li PH (ed) Plant cold hardiness. Alan R. Liss Inc., New York, NY 
Table 1. Example of ion-leakage data calculations and transformation for $R$. 'Vulcan's flame' leaf tissues in December $1995^{z}$

\begin{tabular}{ccccccr}
\hline $\begin{array}{l}\text { Treatment } \\
\text { Temp. }\left({ }^{\circ} \mathrm{C}\right)\end{array}$ & $\begin{array}{l}\text { Initial } \\
\text { Leakage }^{\mathrm{y}}\end{array}$ & $\begin{array}{l}\text { Final } \\
\text { Leakage }\end{array}$ & $\begin{array}{l}\text { Percent } \\
\text { Leakage }^{\mathrm{x}}\end{array}$ & $\begin{array}{l}\text { Percent } \\
\text { Injury }\end{array}$ & $\begin{array}{l}\text { Percent } \\
\text { Ad. Injury }\end{array}$ & $\begin{array}{l}\text { Visual }^{\mathrm{v}} \\
\text { Est. }^{\mathrm{u}}\end{array}$ \\
\hline 0 & 1.9 & 26.9 & 7.1 & 0.0 & 0.0 & 0.0 \\
-13 & 3.9 & 22.6 & 17.2 & 10.9 & 14.1 & 0.0 \\
-15 & 4.2 & 19.5 & 22.3 & 16.4 & 21.3 & 16.7 \\
-17 & 5.9 & 24.3 & 24.3 & 18.5 & 24.0 & 16.7 \\
-19 & 7.1 & 21.3 & 33.5 & 28.3 & 36.9 & 25.0 \\
-21 & 7.7 & 21.4 & 36.0 & 31.1 & 40.5 & 41.7 \\
-23 & 11.3 & 26.3 & 43.7 & 39.4 & 51.2 & 75.0 \\
-25 & 12.0 & 25.1 & 47.9 & 43.8 & 57.1 & 83.3 \\
-27 & 15.9 & 23.1 & 68.6 & 66.2 & 86.1 & 91.7 \\
-80 & 20.4 & 26.0 & 78.5 & 76.8 & 100.0 & 100.0 \\
\hline
\end{tabular}

$\mathbf{z}=$ Values are mean of three separate measurements at each treatment temperature

$\mathbf{y}=\mu$ mhos, raw data

${ }^{x}=($ Initial leakage $/$ Final leakage $) * 100$

${ }^{\mathbf{w}}=\left[\left(\%\right.\right.$ Leakage $_{(\mathrm{T})}-\%$ Leakage $\left._{(\mathrm{C})}\right) /\left(100-\%\right.$ Leakage $\left.\left._{(\mathrm{C})}\right)\right] * 100$

$\mathbf{v}=\left(\%\right.$ Injury $_{(\mathrm{T})} / \%$ Injury $\left._{(-80)}\right)$

$\mathbf{u}=\%$ Browning and water-soaked 
Table 2. Empirical calculations used in the determination of freezing tolerance ${ }^{\mathrm{z}}$

\begin{tabular}{llccc}
\hline Function & Equation & Slope & $\mathrm{LT}_{50}$ & $\mathrm{~T}_{\max }$ \\
\hline Richards & $100\left(1-\boldsymbol{e}^{(\mathrm{b}-\mathrm{k} \mathbf{T})}\right)^{-1 / \mathrm{d}}$ & $\frac{\left.\left.100 \mathrm{k} \boldsymbol{e}^{(\mathrm{b}-\mathrm{k} \mathbf{T})}\right)\right]^{*}\left[1-\boldsymbol{e}^{(\mathrm{b}-\mathrm{k} \mathbf{T})}\right]^{(-1 / \mathrm{d}+1)}}{\mathrm{d}}$ & $\frac{\left(\mathrm{b}-\log \left(1-(1 / 2)^{\mathrm{d}}\right)\right)}{\mathrm{k}}$ & $\frac{(\mathrm{b}-\log (-\mathrm{d}))}{\mathrm{k}}$ \\
Gompertz & $100 \boldsymbol{e}^{-\mathrm{b} \boldsymbol{e}-\mathrm{k} \mathbf{T}}$ & $100 \mathrm{bk} \boldsymbol{e}^{-\mathrm{k} \mathbf{T} * \boldsymbol{e}^{-\mathrm{b} \boldsymbol{k}-\mathrm{k} \mathbf{T}}}$ & $\frac{-\log ((\log (100)-\log (50)) / \mathrm{b})}{\mathrm{k}}$ & $\frac{-\log (1 / \mathrm{b})}{\mathrm{k}}$ \\
\hline
\end{tabular}

${ }^{\mathrm{z}}$ Where $\mathrm{b}, \mathrm{d}, \mathrm{k}$ are function parameters, $\mathrm{A}=100, \mathrm{~T}=$ temperature and $\boldsymbol{e}=$ exponential

Table 3. Partial correlation coefficients derived from the Error Sum of Squares for the comparison of three different freeze-thaw injury estimates with visual estimates ${ }^{\mathrm{yz}}$

\% Leakage \%-Injury \%-Adjusted Injury Visual Estimates

$\begin{array}{llll}\text { Visual Estimates } & 0.693 & 0.699 & 0.753\end{array}$

${ }^{\mathrm{y}}$ GLM-multivariate ANOVA, holding treatment temperatures and sampling dates constant ${ }^{\mathrm{z}} \mathrm{df}=1467$, correlation probability $=0.0001$

Table 4. Comparison of two asymmetric functions to GLM using F-test for lack of fit

\begin{tabular}{lcccc}
\hline Function & $\mathrm{N}$ & No. Adequate fit as GLM & Percentage (\%) & Overall mean ESS $^{\mathrm{z}}$ \\
\hline Gompertz & 45 & 37 & $82.2 \%$ & 112.97 \\
Richards & 45 & 34 & $75.5 \%$ & 117.21 \\
\hline
\end{tabular}

${ }^{\mathrm{z}}$ Overall mean error sum of squares for GLM=105.47 
Table 5. Partial correlation coefficients derived from the Error Sum of Squares for comparison of four freezing tolerance quantitative expression with visual $\mathrm{LT}_{50}{ }^{\mathrm{yz}}$

\begin{tabular}{|c|c|c|c|c|c|}
\hline & \multicolumn{2}{|c|}{ Richards } & \multicolumn{2}{|c|}{ Gompertz } & \multirow{2}{*}{$\begin{array}{l}\text { Visua } \\
\mathrm{LT}_{50}\end{array}$} \\
\hline & $\mathrm{LT}_{50}$ & $\mathrm{~T}_{\max }$ & $\mathrm{LT}_{50}$ & $\mathrm{~T}_{\max }$ & \\
\hline Visual $\mathrm{LT}_{50}$ & 0.793 & 0.769 & 0.790 & 0.793 & 1.000 \\
\hline
\end{tabular}

${ }^{\mathrm{y}} \mathrm{GLM}$-multivariate analysis of variance, holding month constant

${ }^{\mathrm{z}} \mathrm{df}=36$, correlation probability $=0.0001$

Table 6. Leaf freezing tolerance $\left(\mathrm{T}_{\max } ;{ }^{\circ} \mathrm{C}\right)$ of five Rhododendron cultivars ${ }^{\mathrm{z}}$

\begin{tabular}{llcc}
\hline & $\begin{array}{l}\text { Non acclimated } \\
\text { Sept. 1995 }\end{array}$ & $\begin{array}{c}\text { Cold acclimated } \\
\text { Dec. 1995 }\end{array}$ & $\begin{array}{c}\text { Deacclimated } \\
\text { June 1996 }\end{array}$ \\
\cline { 2 - 4 } Cultivars & Mean $\pm \mathrm{SE}^{\mathrm{y}}$ & Mean \pm SE & Mean $\pm \mathrm{SE}$ \\
\hline Grumpy Yellow (GY) & $-2.9 \pm .43^{\mathrm{a}}$ & $-16.8 \pm .42^{\mathrm{e}}$ & $-4.1 \pm .28^{\mathrm{bc}}$ \\
Autumn Gold (AG) & $-3.8 \pm .51^{\mathrm{ac}}$ & $-17.2 \pm .40^{\mathrm{e}}$ & $-2.7 \pm .12^{\mathrm{a}}$ \\
Vulcan's Flame (VF) & $-2.2 \pm .86^{\mathrm{ab}}$ & $-19.1 \pm .38^{\mathrm{f}}$ & $-5.3 \pm .58^{\mathrm{cd}}$ \\
Chionoides (CH) & $-5.8 \pm .41^{\mathrm{d}}$ & $-30.3 \pm 1.1^{\mathrm{g}}$ & $-5.8 \pm .37^{\mathrm{d}}$ \\
Roseum Elegans (RE) & $-6.0 \pm .34^{\mathrm{d}}$ & $-28.5 \pm 1.3^{\mathrm{g}}$ & $-6.3 \pm .41^{\mathrm{d}}$ \\
\hline
\end{tabular}

${ }^{\mathrm{z}}$ Using Gompertz function fitted to adjusted injury data, std. error estimated by Jackknife method ${ }^{\mathrm{y}}$ Mean separation in matrix by multiple t-test, $5 \%$ level. Midwinter bud hardiness of these cultivars (provided by nurseries) is as follows: $-17.8^{\circ} \mathrm{C}(\mathrm{GY}),-20.6{ }^{\circ} \mathrm{C}(\mathrm{AG}),-26.1{ }^{\circ} \mathrm{C}(\mathrm{VF})$, $-28.9^{\circ} \mathrm{C}(\mathrm{CH}) \&-31.7^{\circ} \mathrm{C}(\mathrm{RE})$. 
Fig. 1. A SAS program for finding the best starting parameters of the Gompertz function

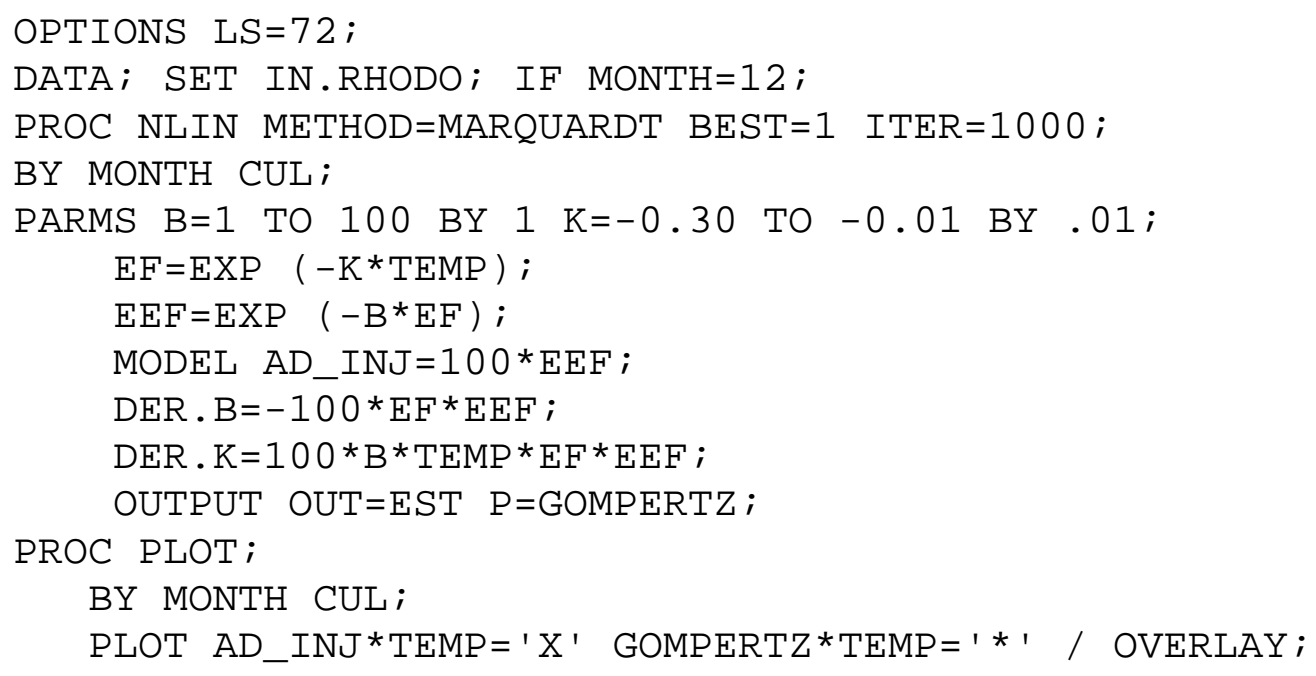


Fig. 2. A SAS program using the Jackknife method and the Gompertz function to find $\mathrm{LT}_{50}$ and

$\mathrm{T}_{\max }$ means and standard errors

OPTIONS LS=72; DATA LIM; SET IN.RHODO;

BY MONTH CUL TEMP; IF MONTH $=12$;

IF FIRST.CUL THEN NUM=0; NUM=NUM+1; RETAIN NUM;

PROC MEANS NOPRINT; BY MONTH CUL; VAR TEMP; OUTPUT OUT=MN N=N;

DATA ; MERGE LIM MN; BY MONTH CUL;

DATA BIG; SET ; DO JACK=1 TO N;

IF NUM NE JACK THEN OUTPUT; END;

PROC SORT; BY MONTH CUL JACK; PROC PRINTTO UNIT=2O NEW;

PROC NLIN METHOD=MARQUARDT BEST=1 ITER=1000 OUTEST=EST;

BY MONTH CUL JACK;

PARMS $B=15.18,6.53,9.04,17.88,13.48$

$$
\mathrm{K}=-.158,-.062,-.131,-.101,-0.136 ;
$$

$\mathrm{EF}=\mathrm{EXP} \quad(-\mathrm{K} * \mathrm{TEMP}) ; \mathrm{EEF}=\mathrm{EXP} \quad(-\mathrm{B} * \mathrm{EF})$;

MODEL AD_INJ $=100 * E E F$;

$\mathrm{DER} . \mathrm{B}=-100 * \mathrm{EF} \star \mathrm{EEF} ; \mathrm{DER} . \mathrm{K}=100 * \mathrm{~B}$ * TEMP $* \mathrm{EF} \star \mathrm{EEF}$;

DATA; SET EST; IF_TYPE_='FINAL'; IF _TYPE_='FINAL' THEN CONVERGD $=1$;

GOMPLT50=-LOG ((LOG $(100)-$ LOG $(50)) / B) / K$;

GOMP TMAX $=-\mathrm{LOG}(1 / \mathrm{B}) / \mathrm{K}$;

PROC PRINTTO; /*PROC PRINT;

VAR MONTH CUL JACK _SSE_--GOMPLT50; */

PROC MEANS NOPRINT; BY MONTH CUL;

VAR GOMPLT50 GOMPTMAX CONVERGD;

OUTPUT OUT $=$ FORJACK $\mathrm{N}=\mathrm{N}$

MEAN=GOMPLT50 GOMP TMAX CSS=LT50CSS TMAXCSS SUM=S1 S2 CONVERGD;

DATA ; SET ;

GOMP $50 \mathrm{ER}=\mathrm{SQRT}((\mathrm{N}-1)$ *LT50CSS $/ \mathrm{N})$;

GOMPTMER=SQRT $((\mathrm{N}-1)$ *TMAXCSS $/ \mathrm{N})$;

PROC PRINT; ID MONTH CUL;

VAR N CONVERGD GOMPLT50 GOMP50ER GOMPTMAX GOMPTMER 
Fig. 3. Determinations of $\mathrm{LT}_{50}$ and $\mathrm{T}_{\max }$ (quantitative expressions of freezing tolerance) by employing the Gompertz function fitted to \%-adjusted injury data and by interpolating the mean of three data points per treatment temperature $\left(\mathrm{LT}_{50}\right.$ only). $\mathrm{LT}_{50}$ is always at $50 \%$ injury for \%-adjusted injury whereas the inflection point of the slope of Gompertz curve corresponds to $\mathrm{T}_{\max }$. The slope of the curve ( $\mathrm{d}$ Ad Injury/ $\mathrm{d}$ Temp) bears no units and does not correspond to \%-adjusted units on the y-axis.

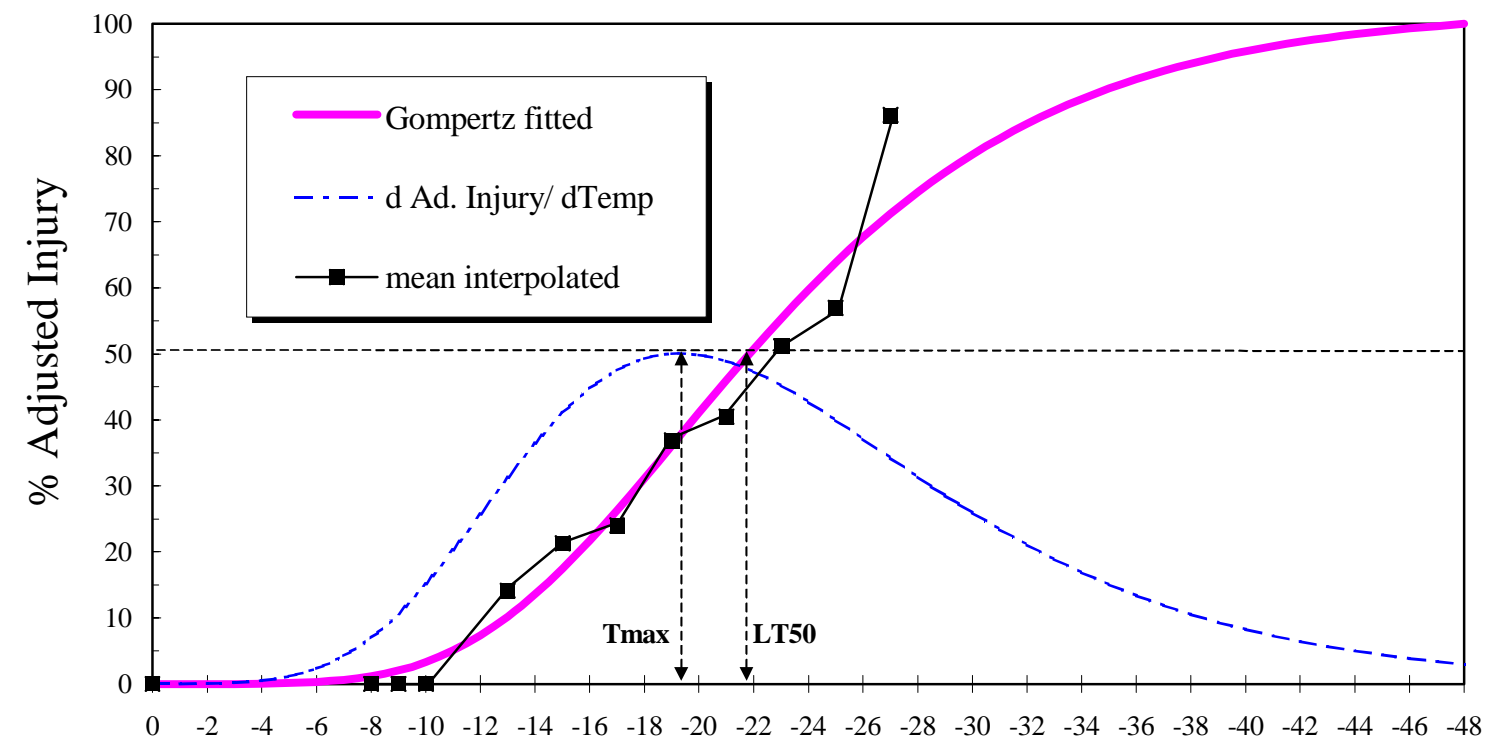

Temperatures $\left({ }^{\circ} \mathrm{C}\right)$ 
Fig. 4. Seasonal fluctuations of leaf freezing tolerance $\left(\mathrm{T}_{\max } ;{ }^{\circ} \mathrm{C}\right)$ of five Rhododendron cultivars

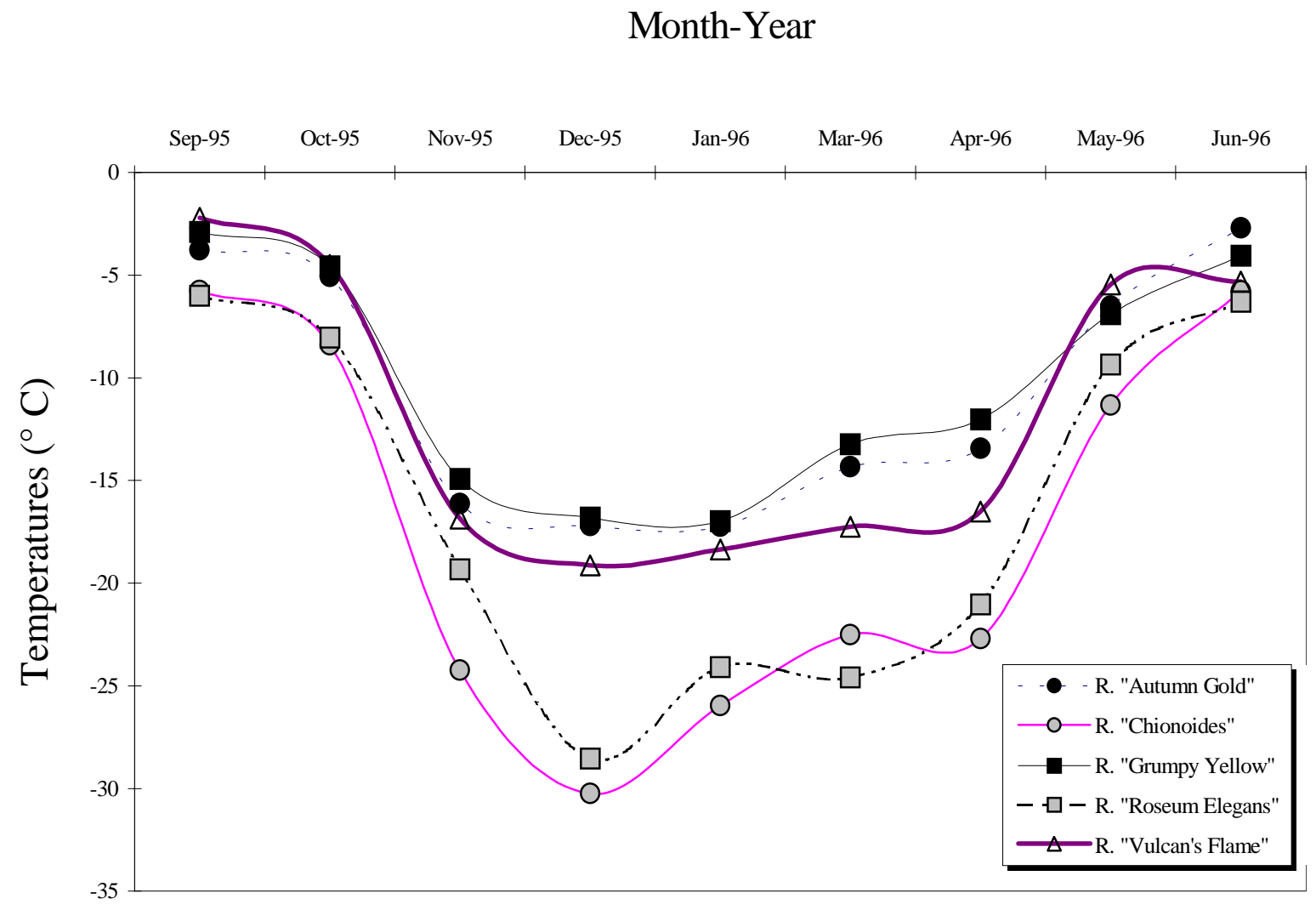




\title{
CHAPTER THREE \\ FREEZING-TOLERANCES IN RHODODENDRON \\ POPULATIONS: GENETICS
}

published as:

Genetic Study of Freezing Tolerance in Rhododendron

Populations: Implications for Cold Hardiness Breeding.

J Amer Rhodo Soc (1998) 52:143-148

\author{
Chon C. Lim ${ }^{1}$, Stephen L. Krebs ${ }^{2}$ and Rajeev Arora ${ }^{1}$ \\ ${ }^{1}$ Division of Plant and Soil Sciences \\ West Virginia University, Morgantown, WV 26506 \\ ${ }^{2}$ The David G. Leach Research Station of \\ the Holden Arboretum, Madison, $\mathrm{OH} 44057$
}

\begin{abstract}
Few genetic studies have been conducted on the inheritance of cold hardiness $(\mathrm{CH})$ in woody plants. We initiated the research presented here to develop a reliable and non-destructive method of determining $\mathrm{CH}$ in rhododendrons by using controlled laboratory freeze-thaw tests, and to apply this methodology to progeny populations segregating for this trait. The distributions of leaf-freezing tolerances (a measure of $\mathrm{CH}$ ) -in $\mathrm{F}_{2}$ and backcross populations derived from a $R$. catawbiense x $R$. fortunei cross- suggested that as few as three genes with strong additive effects were controlling variation in hardiness. Differences in midwinter freezing tolerance were primarily due to differences in acclimating ability among the segregants. Laboratory-based cold hardiness screens of Rhododendron seedlings can help predict mature plant performance in the field, thus providing a powerful tool for breeders and researchers investigating plant response to freezing stress.
\end{abstract}




\section{INTRODUCTION}

A unique feature of many temperate-zone rhododendrons is their ability to withstand severe low temperatures as broad-leaved evergreens. Within the genus, this ability varies widely. Sakai et al. (1986) found that many species in the Ponticum subsection (R. brachycarpum and $R$. maximum) are leaf-hardy to $-60^{\circ} \mathrm{C}$ and bud-hardy to $-30^{\circ} \mathrm{C}$, whereas coldtender species, such as $R$. barbatum and $R$. griersonianum, show both leaf and bud damage at temperatures approaching $-18^{\circ} \mathrm{C}$. These researchers found that hardiness correlates with provenance (altitude and latitude), suggesting that the trait has evolved through natural selection acting on existing genetic variability.

The primary goal of most Rhododendron breeders working in cold climates has been to combine the ornamental diversity found in less hardy Asian taxa with the superior cold hardiness $(\mathrm{CH})$ characteristic of several North American and Asian species. This goal has been achieved in many instances but the process has often been slow and inefficient. Part of the reason for this has been methodological. The conventional approach of pedigree breeding and single-site evaluation is likely not optimal for breeding a multigenic and physiologically complex trait. Breeding efficiency has been improved in programs in which mass selection and multiple site testing are used to increase $\mathrm{CH}$ (Uosukainen and Tigerstedt 1988).

A limited understanding of the genetic control of freezing tolerance has also hampered efforts in cold hardiness breeding. It would be very useful, for example, to be able to predict the outcome of cold-hardy $\mathrm{x}$ cold-tender crosses and have a sense of how much variability in hardiness occurs among progeny. Prediction is important because it influences population size, number of generations, and breeding strategy needed to arrive at a desired trait. We know, anecdotally, that segregation for $\mathrm{CH}$ exists among advanced-generation progeny (e.g., families in which siblings differ in their bud hardiness by as much as a hardiness zone), but the full variation in discarded populations is generally not described or quantified.

The efficiency of breeding programs is further restricted by the difficulty in obtaining early and reliable estimates of a plant's cold hardiness. Currently, breeders generally grow seedlings to maturity in order to assess winter damage to floral buds. This is a slow (5+ years) and sometimes unreliable process - bud damage on a single plant can often range from 0 to 
$100 \%$ in one season (Gilkey 1996; Krebs, unpublished data). Annual variation in field estimates of $\mathrm{CH}$ can also occur due to uncontrollable factors such as snow cover, wind, fluctuating temperatures, and desiccation (Fowler and Gusta 1979).

The research presented here was undertaken to improve methods of measuring $\mathrm{CH}$ in rhododendrons and increase our understanding of the genes controlling this trait. Much of this paper describes a laboratory assay developed to simulate natural freeze-thaw stresses on Rhododendron tissues. Although field trials provide the ultimate test of winter survival, controlled laboratory measurements of freezing tolerance offer significant advantages. Estimates of $\mathrm{CH}$ by this method appear to be more reliable and consistent because severe cold conditions can be generated in the laboratory under controlled conditions without complicating variables such as snow cover, wind desiccation, etc. Furthermore, this test is non-destructive because detached tissues (e.g., leaves or buds) are used instead of the whole plant.

Our laboratory assay was used to characterize segregation for $\mathrm{CH}$ among progeny of controlled crosses. We chose to evaluate juvenile plant material (seedlings) with the thought that estimates of freezing tolerance at this stage might predict mature plant performance and thus provide greater efficiency in breeding programs. Measurements were made on seedlings in both cold-acclimated and non-acclimated conditions, because variation in $\mathrm{CH}$ among woody plants usually reflects differences in cold acclimation ability -ability of a frost hardy plant to increase its freezing tolerance during fall and winter, full realization of which depends upon a myriad of factors, such as plant species, its provenance, seasonal timing and speed of acclimation, etc. (Raulston and Tripp 1995). Based on the distribution of hardiness phenotypes in these segregating populations, we could draw conclusions about the number of genes that control freezing tolerance and the type of gene action involved. The implications of our methodology and gene model for $\mathrm{CH}$ are discussed in the context of Rhododendron breeding and cold hardiness research in general. 


\section{MATERIAL AND METHODS}

Determination of leaf-freezing tolerance. Leaf-freezing tolerance (LFT) in rhododendrons was determined according to a method developed by Lim et al. (1998). Basically, the method involves relatively slow freezing followed by gradual thawing of plant tissues to simulate what plants generally experience under natural conditions (Steffen et al. 1989), and then conducting a physiological assay to evaluate the induced injury.

Leaves were cut into $1 \mathrm{~cm}^{2}$ discs and placed into test tubes containing 25-50 $\mu 1$ water. Following ice nucleation at $-1{ }^{\circ} \mathrm{C}$ (by dropping small ice crystals in the test tubes), the nonacclimated leaf discs were slowly cooled at approximately $0.5^{\circ} \mathrm{C} / 30 \mathrm{~min}$. to $-4^{\circ} \mathrm{C}$ and $1{ }^{\circ} \mathrm{C} / 30$ min. to $-10^{\circ} \mathrm{C}$ thereafter to obtain treatment temperatures ranging from -2 to $-10^{\circ} \mathrm{C}$ (at $2^{\circ} \mathrm{C}$ increments). Cold-acclimated leaf discs were ice nucleated and cooled similarly to $-10^{\circ} \mathrm{C}$ but continued at $3.5^{\circ} \mathrm{C} / 30 \mathrm{~min}$. (to $-24^{\circ} \mathrm{C}$ ) thereafter to obtain treatment temperatures ranging from -10 to $-52^{\circ} \mathrm{C}$ (at $7^{\circ} \mathrm{C}$ increments). The sample tubes were initially cooled in a glycol bath (to $-24^{\circ} \mathrm{C}$ ) then transferred to a $-80^{\circ} \mathrm{C}$ freezer to subject them to temperatures as low as $-52^{\circ} \mathrm{C}$. Tubes were removed at various temperature intervals, placed in ice for overnight thawing, and then allowed to reach room temperature gradually. A separate set of leaf discs from each plant was ice nucleated and placed directly in $-80^{\circ} \mathrm{C}$ freezer for $4-5 \mathrm{~h}$ to obtain $100 \%$ freeze-killed samples.

Thawed leaf discs were placed in $6 \mathrm{~mL}$ of $\mathrm{ddH}_{2} \mathrm{O}$, vacuum infiltrated for 5-8 min (at about $-0.15 \mathrm{MPa}$ ) and placed on a gyratory shaker for $3 \mathrm{~h}$ at $275 \mathrm{rpm}$. Cell membranes injured by freeze-thaw leak their contents (cell sap) into the water. Because cell sap contains ions (electrolytes), an increase in conductivity of the solution is a quantitative measure of increased freezing injury in the leaf tissue (Dexter 1930). After measuring freeze-induced electrolyte leakage $\left(\mathrm{C}_{1}\right)$ with a conductivity probe, samples were autoclaved to disrupt all remaining intact cells and determine the total electrolyte leakage $\left(\mathrm{C}_{2}\right)$. Percent ion leakage due to freezing was calculated as $\left[\left(\mathrm{C}_{1} / \mathrm{C}_{2}\right) \times 100\right]$. 
Percent freeze-injury was calculated by the equation:

$$
\% \operatorname{Injury}(\mathrm{t})=\left[\frac{\{\% \text { leakage }(\mathrm{t})-\% \text { leakage }(\mathrm{c})\}}{\{100-\% \text { leakage }(\mathrm{c})\}}\right] \times 100
$$

(Flint et al. 1967)

where \% leakage(t) and \% leakage(c) are the measurements of \% ion leakage for a respective freeze-treatment temperature and an unfrozen control (some slight leakage is caused by cutting the leaf disc). Percent-adjusted injury was calculated by the equation:

$$
\% \text {-Adjusted injury }=\left[\frac{\% \text { injury }(\mathrm{t})}{\% \text { injury }\left(-80^{\circ} \mathrm{C}\right)}\right] \times 100
$$

Ion leakage over a range of freezing temperatures typically displays a sigmoidal response in Rhododendron leaves, i.e., a slow increase in leakage during the initial cooling phase, followed by a sharp increase in freezing injury and leakage at some critical temperature, which eventually levels off. A number of statistical procedures have been used to fit this response curve to known arithmetic functions to help determine the rates of freezing injury (Lim et al. 1998). For this study, we fitted percent-injury data to a Gompertz function and used the parameter $\mathrm{T}_{\max }$, defined as the temperature causing the maximum rate of injury, as an estimator of $\mathrm{CH}$ (Fig. 1).

Plant populations. When a primary $\left(\mathrm{F}_{1}\right)$ cross is made between a cold-hardy and a cold-tender species, the expectation is for uniform, intermediate hardiness among the progeny. Subsequent generations, such as the $F_{2}$ (derived from sib mating or selfing the $F_{1}$ ) and the backcross (BC, created by crossing the $\mathrm{F}_{1}$ back to either parent) are expected to display more variability and segregation for $\mathrm{CH}$. We selfed a single $\mathrm{F}_{1}$ plant, 'Ceylon' ( $R$. catawbiense x $R$. fortunei), to create an $\mathrm{F}_{2}$ population. We also made reciprocal backcrosses: $R$. fortunei $\mathrm{x}$ 'Ceylon' and 'Ceylon' x R. fortunei; unfortunately, backcrosses involving R. catawbiense as the 
recurrent parent were not available for this study. The reciprocal cross was used to estimate any maternal component to $\mathrm{CH}$. Our preliminary data showed significant differences in parental LFTs: $R$. catawbiense had a $\mathrm{T}_{\max }$ of $-52^{\circ} \mathrm{C}$ and $R$. fortunei $-31^{\circ} \mathrm{C}$. The hybrid 'Ceylon' was intermediate, leaf hardy to about $-43^{\circ} \mathrm{C}$. The uniformity in $\mathrm{CH}$ within $\mathrm{F}_{1}$ population could not be tested due to unavailability of $\mathrm{F}_{1}$ 'Ceylon' siblings. However, a related study in our laboratory revealed little variation in cold hardiness values among $15 \mathrm{~F}_{1}$ plants derived from $R$. catawbiense $\mathrm{x} R$. dichroanthum cross (Arora and Lim, unpublished results). In the present study, measurements of the parents were taken from clones 30-40 years old. The $\mathrm{F}_{2}$ and $\mathrm{BC}$ populations were evaluated as 3-year-old seedlings maintained in outdoor ground frames at the Leach Research Station in Madison, Ohio.

Non-acclimated and acclimated LFTs. Leaves from naturally coldacclimated $(\mathrm{CA})$ parents, $\mathrm{F}_{1}, \mathrm{BC}$ and $\mathrm{F}_{2}$ populations were collected on the premises of the Leach Research Station in December 1996, moistened, and shipped in a cold box overnight to West Virginia University for analysis of $\mathrm{CH}$. Our data from earlier studies suggest that rhododendrons are maximally acclimated to midwinter temperatures by December (Lim et al. 1998). Estimates of LFT for the non-acclimated (NA) condition were obtained from leaves collected from the same plants in July and August 1997, moistened, and shipped overnight at ambient temperatures. The difference in $\mathrm{T}_{\max }$ between NA and CA states is termed cold-acclimation ability, and is a measure of how strongly plants respond to environmental cues, such as decreasing photoperiod and temperature, during the acclimation period.

\section{RESULTS AND DISCUSSION}

The leaf-freezing tolerance assay. Ion leakage assays have been widely used by researchers to evaluate $\mathrm{CH}$ in both herbaceous and woody plants (Lim et al. 1998; Steffen et al. 1989; Stone et al. 1993). Our adaptation of this method to rhododendrons - the 
determination of a diagnostic range of treatment temperatures and the statistical curve fitting of percent-injury data in order to estimate $\mathrm{T}_{\max }-$ is evidently reliable, correlating well $(r=0.79)$ with visual estimates of freezing injury based on water soaking and browning (Lim et al. 1998).

Although our treatment samples (leaf discs) were comprised of pooled leaves from single plants, this protocol produced consistent $\mathrm{T}_{\max }$ estimates and small standard errors. Moreover, utilization of leaf discs instead of whole leaves or flower buds minimized the degree of plant damage. Much of the experimental variability commonly associated with field trials is significantly reduced by our protocols and the somewhat subjective method of estimating $\mathrm{CH}$ by visual assessment of leaf injury is replaced by a more quantitative measure (ion leakage). By using simple statistics (multiple $t$ tests comparison), we are able to compare and rank individual genotypes by their $\mathrm{T}_{\max }$ values and standard errors (Lim et al. 1998).

\section{Cold hardiness distributions within segregating populations}

Most genetic studies on freezing tolerance in herbaceous and woody plants have involved genotypes that differ in acclimating ability, i.e. crosses between hardy (able to cold acclimate) and sensitive (unable to acclimate) parents. However, studies involving progenies derived from two acclimating species are scarce. One such study used populations derived from latitudinal ecotypes of Cornus sericea L. to examine the genetic control of seasonal timing of cold acclimation in woody perennials (Hummel et al. 1982). Our study, however, characterizes segregation for LFT in crosses derived from two acclimating species (Table 1), one with moderate freezing tolerance $\left(R\right.$. fortunei, $\left.\mathrm{T}_{\max }=-32.4^{\circ} \mathrm{C}\right)$ and the other with extreme freezing tolerance $\left(R\right.$. catawbiense, $\left.\mathrm{T}_{\max }=-51.2^{\circ} \mathrm{C}\right)$.

The $\mathrm{F}_{2}$ and $\mathrm{BC}$ populations of rhododendrons exhibited continuous and normal (bellshaped) distributions of progeny $\mathrm{CH}$ values (Fig. 2). A continuous pattern, as opposed to discrete groupings of hardiness types, suggests that genetic control at this level of freezing tolerance is multigenic, an interpretation consistent with reports from other genera (Arora et al. 1998; Stone et al. 1993; Teutonico et al. 1995).

In order to make inferences about the type of gene action involved (dominant, recessive,

or additive), geneticists often measure parent-offspring resemblance. If the average progeny resembles one parent more strongly than the other, then dominant or recessive gene action is 
implied, depending on which parent has the greater effect on offspring. If most offspring are intermediate in character to both parents, then the type of gene action is termed 'additive', referring to genes with incremental positive or negative effects on a metric trait such as $\mathrm{CH}$.

A major difficulty in our work results from the determination that parent-offspring comparisons are confounded by age-dependent freezing tolerances. For example, the freezetolerance values for the $\mathrm{BC}$ and $\mathrm{F}_{2}$ three-year-old seedling populations were substantially lower than those of their 30 to 40-year-old parents (Table 1), indicating that the majority of the progeny from a cold-hardy by cold-tender cross were more sensitive (or less hardy) than the cold-tender parent. This is an unexpected result, and we sought to explain it by looking at the effect of physiological age on $\mathrm{CH}$. To this end, we conducted a two-year study of different-aged seedlings from a wild $R$. maximum population and found that rhododendrons can gain about $10^{\circ} \mathrm{C}$ or more in freezing tolerance as they age physiologically from the preflowering juvenile stage (1 to $\sim 4$ years) to maturity (Lim, unpublished data).

Therefore, inferences on gene action in our study are best made on comparisons of averages of $\mathrm{CH}$ values from $\mathrm{BC}$ and $\mathrm{F}_{2}$ populations consisting of similar-aged juvenile plants. The average freeze-tolerance of reciprocal backcrosses ('Ceylon' crossed with $R$. fortunei) were 26 and $45 \%$ lower than the $F_{2}$ values (Table 1). The nuclear genetic background of the $F_{2}$ is 50:50 (fortunei:catawbiense) whereas in both BCs it is approximately 75:25 (fortunei:catawbiense). A significant additive component to $\mathrm{CH}$ genes in these populations is inferred from the reasonably close correspondence between the $25-45 \%$ reduction in BC mean freezing tolerance and the $50 \%$ reduction in genetic contribution from the hardier $R$. catawbiense parent.

Other types of gene action may be involved in Rhododendron $\mathrm{CH}$. From reports in other plant genera, it appears that additive gene effects on $\mathrm{CH}$ are modified by partially recessive (Arora et al. 1998; Stone et al. 1993) or dominant gene action (Teutonico et al. 1995). Maternal effects may also determine plant phenotype. A difference between the reciprocal BC populations in our study (Table 1) indicated a partial maternal effect in which the $R$. fortunei cytoplasm conferred greater freezing tolerance than did the $R$. catawbiense cytoplasm. This unexpected result may be due to complex nuclear-cytoplasmic interactions in the interspecific hybrids, or it may represent an experimental artifact (we are planning to reassess these populations for $\mathrm{CH}$ at least one more time while still in the juvenile condition). 
Conflicting reports exist in literature regarding maternal effect on $\mathrm{CH}$. For example, Dorsey and Bushnell (1925) first reported a positive maternal effect on cold hardiness in Prunus, in that using $P$. americana (a hardier species than $P$. salicina) as a pistillate parent resulted in $80 \%$ of interspecific seedlings as hardy compared to only $45 \%$ when $P$. salicina was the female parent. On the other hand, Quamme (1978) detected no reciprocal differences in $\mathrm{CH}$ of progenies of apple cultivars with different $\mathrm{CH}$ levels. Similar results were obtained by Hummel et al. (1982) in the study of inheritance of photoperiodically induced cold acclimation in Cornus sericea.

Another method of comparing parent-offspring performance in these populations is to predict the 'mature' $\mathrm{F}_{2}$ or $\mathrm{BC}$ hardiness distributions by adding a 'correction factor' of $\sim 10^{\circ} \mathrm{C}$ (the gain in freezing tolerance from juvenility to maturity in different-aged $R$. maximum populations). For example, the predicted mature $\mathrm{F}_{2} \mathrm{CH}$ distribution would range from $-25^{\circ} \mathrm{C}$ to $52^{\circ} \mathrm{C}$, well within the temperature interval defined by the parent species. By this method, there could be at least one segregant in this population of 47 plants that recovers the hardiness level of the $R$. catawbiense parent (Fig 2C). Given the probability that $\left({ }^{1} / 4\right)^{\mathrm{n}} \mathrm{F}_{2}$ segregants will resemble either parent value (where $n=$ number of gene pairs) and assuming additive gene effects, it is possible that as few as 3 genes are responsible for the phenotypic variation observed in these populations $\left[\left({ }^{1} / 47\right) \approx(1 / 4)^{3}\right]$. Research in other genera has suggested a similar oligogenic (few gene) control of freezing tolerance (Arora et al. 1998; Stone et al. 1993; Teutonico et al. 1995).

Cold-acclimation ability. Midwinter cold hardiness is really the outcome of two conditions in an individual plant - its freezing tolerance in the non-acclimated state and its ability to increase that tolerance (cold-acclimation ability). The cold-acclimation process is triggered by environmental cues, such as shorter photoperiods and cooler temperatures beginning in late summer and extending into late fall (Fuchigami et al. 1971), and acclimating plants undergo physiological and structural changes that condition them to survive low temperatures during winter.

The acclimating ability of a plant in our research was defined as the leaf-freezing tolerance (LFT) in the cold-acclimated (CA) condition minus the LFT in the non-acclimated (NA) condition. As expected, non-acclimated leaf-freezing tolerance (NA-LFTs) from summer- 
collected progenies in $\mathrm{BC}$ (data not shown) and $\mathrm{F}_{2}$ populations were much lower than coldacclimated leaf-freezing tolerance (CA-LFTs) determined for the same individuals during the previous winter (compared Fig. 2C with Fig. 3). There was, however, significant variation in NA-LFTs ( -2 to $-7^{\circ} \mathrm{C}$ in the $\mathrm{F}_{2}$; Fig. 3), and we were interested to determine whether these freezing tolerance differences observed in the NA state had an impact on a plant's midwinter hardiness level.

Scatterplots of these $\mathrm{CH}$ components indicate that NA-LFT is not correlated with cold acclimation ability (Fig 4A), whereas CA-LFT was highly correlated with acclimation ability (Fig. 4B). These results suggest that the physiological processes involved in NA hardiness and acclimation ability in Rhododendron are independent of each other, a conclusion also drawn from research on potatoes (Stone et al. 1993). The relationships also indicate that, of the two components, it is the variation in acclimating ability $\left(-13.6\right.$ to $-37.3{ }^{\circ} \mathrm{C}$ in the $\mathrm{F}_{2}$ generation) rather than NA hardiness that accounts for the bulk of observed differences in $T_{\max }$ in rhododendrons. This is a meaningful variation from a $\mathrm{CH}$ breeding perspective, and more broadly, it suggests that the genetic model based on observed $\mathrm{T}_{\max }$ variation involves only a few genes with major effects on cold-acclimation ability in Rhododendron.

\section{Seedlings LFTs as predictors of field performance. Although floral} bud survival is conventionally used to describe $\mathrm{CH}$ in rhododendrons and certain other ornamental plants, the use of leaves for the same purpose is more desirable in research and breeding programs, because one can assess juvenile populations for $\mathrm{CH}$ without waiting 5+ years for flowering to occur. The applicability of this method to 'real life' conditions involves two factors - 1) how well leaf $\mathrm{CH}$ assay predict floral bud hardiness and 2) the degree to which freezing tolerance of juvenile seedlings predicts mature plant performance.

Vegetative buds and leaves of Rhododendron are generally able to withstand colder temperatures than can floral buds (Sakai et al. 1986). However, evidence suggests that estimates of $\mathrm{CH}$ based on leaf performance can be used as a general measure of flower bud hardiness in rhododendrons. A statistical analysis of data presented by Sakai et al. (1986), indicated that leaf and floral bud hardiness in Rhododendron species were significantly correlated $\left(r^{2}=0.64\right)$ (Fig 5). In addition, we recently reported that LFT rankings of five Rhododendron cultivars corresponded 
to their USDA hardiness zone rankings based on flower bud hardiness (Lim et al. 1998).

Data from other research supports the notion that the measurement of ion leakage on freeze-injured leaf discs in the laboratory is a valid method to estimate field performance of whole plants. For example, Teutonico et al. (1993) reported a strong correlation $(r=0.82-0.85)$ between laboratory- and field- generated estimates of $\mathrm{CH}$ among nine rapeseed cultivars. Similarly, controlled freeze-thaw stress of leaf discs from 35 broadleaf evergreen species (Lagerstroemia, Malus, Pyracantha, Syringa, Viburnum, Prunus, etc.) resulted in cold hardiness estimates that corresponded well with field measurements (Johnson and Hirsh 1995).

Surveys at the juvenile seedling stage will probably underestimate $\mathrm{CH}$ levels determined at physiological maturity (flowering). As we indicated above, juvenile plants in our experiments have displayed significantly lower $\mathrm{T}_{\max } \mathrm{s}$ than did mature plants. However, it is unknown at the present time whether relative $\mathrm{CH}$ rankings per se among genotypes will change with physiological and/ or chronological age. In order to test whether seedling $\mathrm{CH}$ accurately predicts mature plant $\mathrm{CH}$, we are planning to grow our populations to maturity by establishing them in field rows, and observing how well their leaves and floral buds tolerate midwinter freezes. If cold hardiness rankings are consistent over time, then seedling hardiness screenings would be useful for breeding and selection purposes as well as for more basic investigations in which early determination of cold-hardy phenotypes is important.

\section{CONCLUSIONS}

We developed a reliable in vitro laboratory protocol for assessing $\mathrm{CH}$ in rhododendrons based on leaf-freezing tolerance (LFT). This method is relatively nondestructive, repeatable and statistically sound. Patterns of variation for $\mathrm{CH}$ in $\mathrm{F}_{2}$ and $\mathrm{BC}$ populations suggested that a few genes with strong additive effects are controlling this trait. A major breeding application of this work was demonstrated by the recovery of super hardy phenotypes in a relatively small $\mathrm{F}_{2}$ population $(<50)$. The identification of those desired types is greatly facilitated by laboratory freeze tests at the seedling stage, allowing most of the breeding population to be culled early on. It is quite possible that seedling LFTs can be used to predict field performance of mature 
(flowering) plants.

From the perspective of basic research, the prospect of a few major genes controlling $\mathrm{CH}$ makes genetic mapping and 'tagging' of cold hardiness genes a feasible objective. Placing cold hardiness genes on a linkage map of rhododendrons could allow for 'marker-assisted' selection (e.g., initially identifying hardy types by DNA profile rather than by actual freeze tests) and would facilitate the search for genes and gene products associated with tolerance to maximal low-temperature stress in this genus.

\section{ACKNOWLEDGEMENTS}

This research was supported, in part, by a grant from the Research Foundation of the American Rhododendron Society, West Virginia Nurserymen's Association and "in house" funds from West Virginia Agricultural \& Forestry Experiment Station and Holden Arboretum. Published as West Virginia Agricultural and Forestry Experiment Station Scientific article No. 2675. 


\section{LITERATURE CITED}

Arora R, Rowland LJ, Panta GR, Lim CC, Lehman JS, Vorsa N (1998) Genetic control of cold hardiness in blueberry. In: Li PH, Chen THH (eds) Plant cold hardiness: molecular biology, biochemistry, and physiology. Plenum Press, New York, pp. 99-106

Dexter ST, Tottingham WE, Graber LF (1930) Preliminary results in measuring the hardiness of plants. Plant Physiol 5:215-223

Dorsey JM, Bushnell J (1925) Plum investigation. II. The inheritance of hardiness. Univ of Minn Agric Expt Stn Techn Bull 32:1-24

Flint HL, Boyce BR, Beattie DJ (1967) Index of injury: a useful expression of freezing injury to plant tissues as determined by the electrolytic method. Can J Plant Sci 47:229-230

Fowler DB, Gusta LV (1979) Selection for winter survival in wheat: I. Identification of genotype variability. Crop Sci 19:769-772

Fuchigami LH, Weiser CJ, Evert DR (1971) Induction of cold acclimation in Cornus stolonifera Michx. Plant Physiol 47:98-103

Gilkey R (1996) Cold hardiness rankings of rhododendrons by means of flower bud damage. J Amer Rhodo Soc 50:100-102

Hummel RL, Ascher PD, Pellett HM (1982) Inheritance of photoperiodically induced cold acclimation response in Cornus sericea L., Red Osier Dogwood. Theor Appl Genet 62:385394

Johnson GR, Hirsh AG (1995) Validity of screening for foliage cold hardiness in the laboratory. J Environ Hort 13:26-30

Lim CC, Arora R, Townsend ED (1998) Comparing Gompertz and Richards functions to estimate freezing injury in Rhododendron using electrolyte leakage. J Amer Soc Hort Sci 123:246-252

Quamme HA (1978) Breeding and selecting temperate fruit crops for cold hardiness. In Li PH, Sakai A (eds) Plant cold hardiness and freezing stress: mechanisms and crop implications. Academic Press, New York pp. 313-332

Raulston JC, Tripp KE (1995) Exploring the complexities of plant hardiness. J Amer Rhodo Soc 49:227-230

Sakai A, Fuchigami L, Weiser CJ (1986) Cold hardiness in the genus Rhododendron. J Amer Soc Hort Sci 111:273-280 
Steffen KL, Arora R, Palta JP (1989) Relative sensitivity of photosynthesis and respiration to freeze-thaw stress in herbaceous species. Importance of realistic freeze-thaw protocols. Plant Physiol 89:1372-1379

Stone JM, Palta JP, Bamberg JB, Weiss LW, Harbage JF (1993) Inheritance of freezing resistance in tuber-bearing Solanum species: evidence for independent genetic control of nonacclimated freezing tolerance and cold acclimation capacity. Proc Natl Acad Sci USA 90:7869-7873

Teutonico RA, Palta, JP Osborn TC (1993) In vitro freezing tolerance in relation to winter survival of rapeseed cultivars. Crop Sci 33:103-107

Teutonico RA, Yandell B, Satagopan JM, Ferreira ME, Palta JP, Osborn TC (1995) Genetic analysis and mapping of genes controlling freezing tolerance in oilseed Brassica. Mol Breeding 1:329-339

Uosukainen M, Tigerstedt PMA (1988) Breeding of frosthardy rhododendrons. J Agr Sci Finland, 60:235-254 
Table 1. Leaf-freezing tolerance $\left(\mathrm{T}_{\max }\right)$ of three Rhododendron populations

\begin{tabular}{lcc}
\hline Parents & $\mathrm{N}^{\mathrm{z}}$ & $\mathrm{T}_{\max }\left({ }^{\circ} \mathrm{C}\right) \pm \mathrm{SE}^{\mathrm{y}}$ \\
\hline$R$. catawbiense & 1 & $-51.2 \pm 0.2^{\mathrm{a}}$ \\
$R$. fortunei & 1 & $-32.4 \pm 0.9^{\mathrm{c}}$ \\
$R$. 'Ceylon', $\mathrm{F}_{1}$ & 1 & $-43.2 \pm 1.3^{\mathrm{b}}$ \\
& & \\
Populations & 62 & $-20.3 \pm 0.6^{\mathrm{e}}$ \\
BC $_{\mathrm{F}}$ progeny, $R$. fortunei x $R$. 'Ceylon' & 62 & $-15.1 \pm 0.4^{\mathrm{f}}$ \\
$\mathrm{BC}_{\mathrm{C}}$ progeny, $R$. 'Ceylon' x $R$. fortunei & 47 & $-27.6 \pm 0.7^{\mathrm{d}}$ \\
$\mathrm{F}_{2}$ progeny, $R$. 'Ceylon' selfed & & \\
\hline
\end{tabular}

${ }^{\mathrm{z}} \mathrm{N}=$ number of plants evaluated. Three replicate discs were measured at each treatment temperature. Parents and $F_{1}$ were included as standards in all population screenings. ${ }^{\mathrm{y}}$ Mean separation in column by multiple $t$ test, $P=0.05$. 
Fig. 1. Percent-injury as a function of freezing temperatures in $R$. 'Ceylon' leaf tissues. Data are fitted to a Gompertz function where the slope of the curve is the rate of injury. $T_{\max }$, inflection point of the slope, is the temperature causing maximum injury rate.

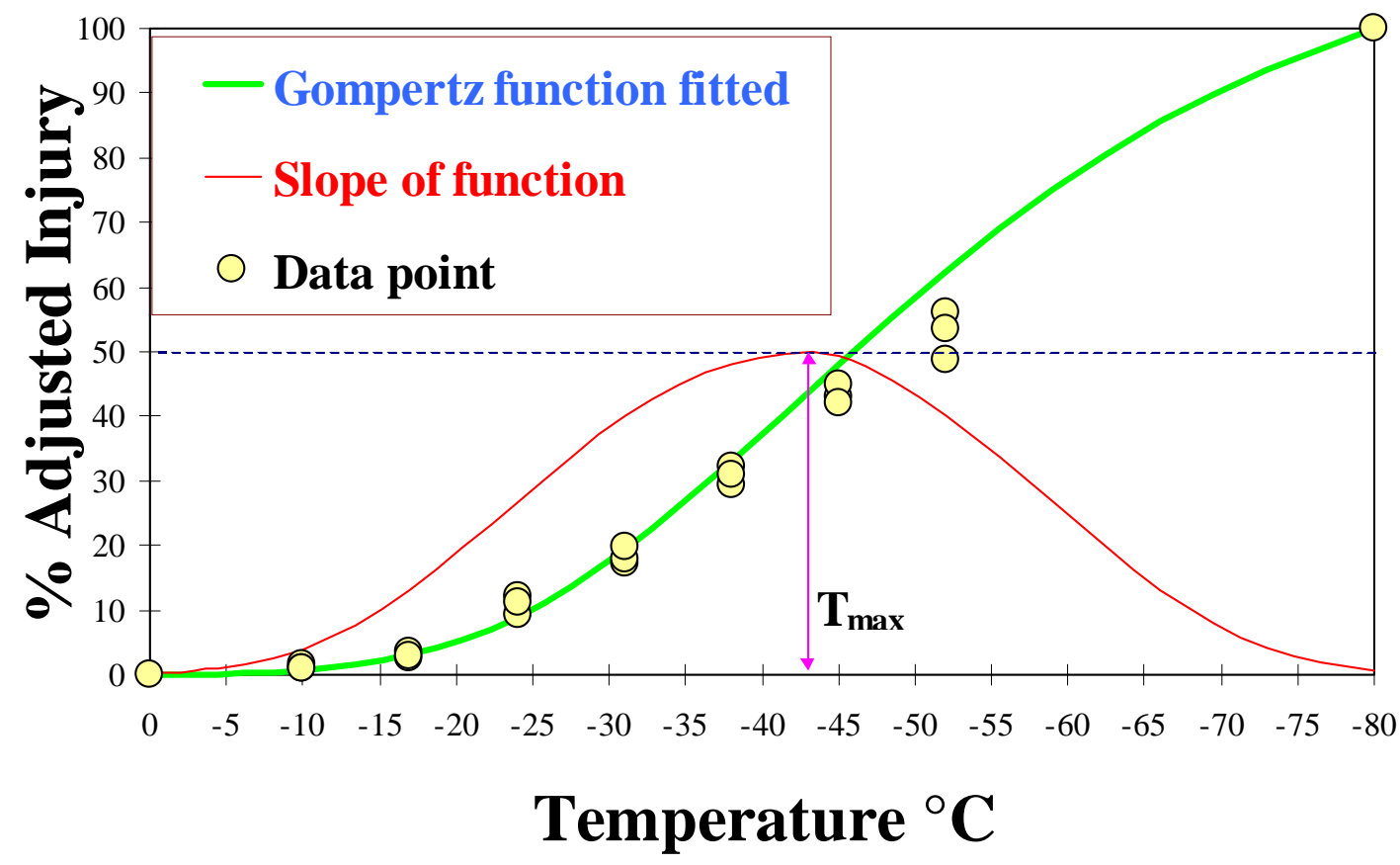


Fig. 2. Leaf-freezing tolerance $\left(\mathrm{T}_{\max }\right)$ distributions at cold-acclimated state of three Rhododendron populations. $\mathrm{n}=$ number of plants screened.

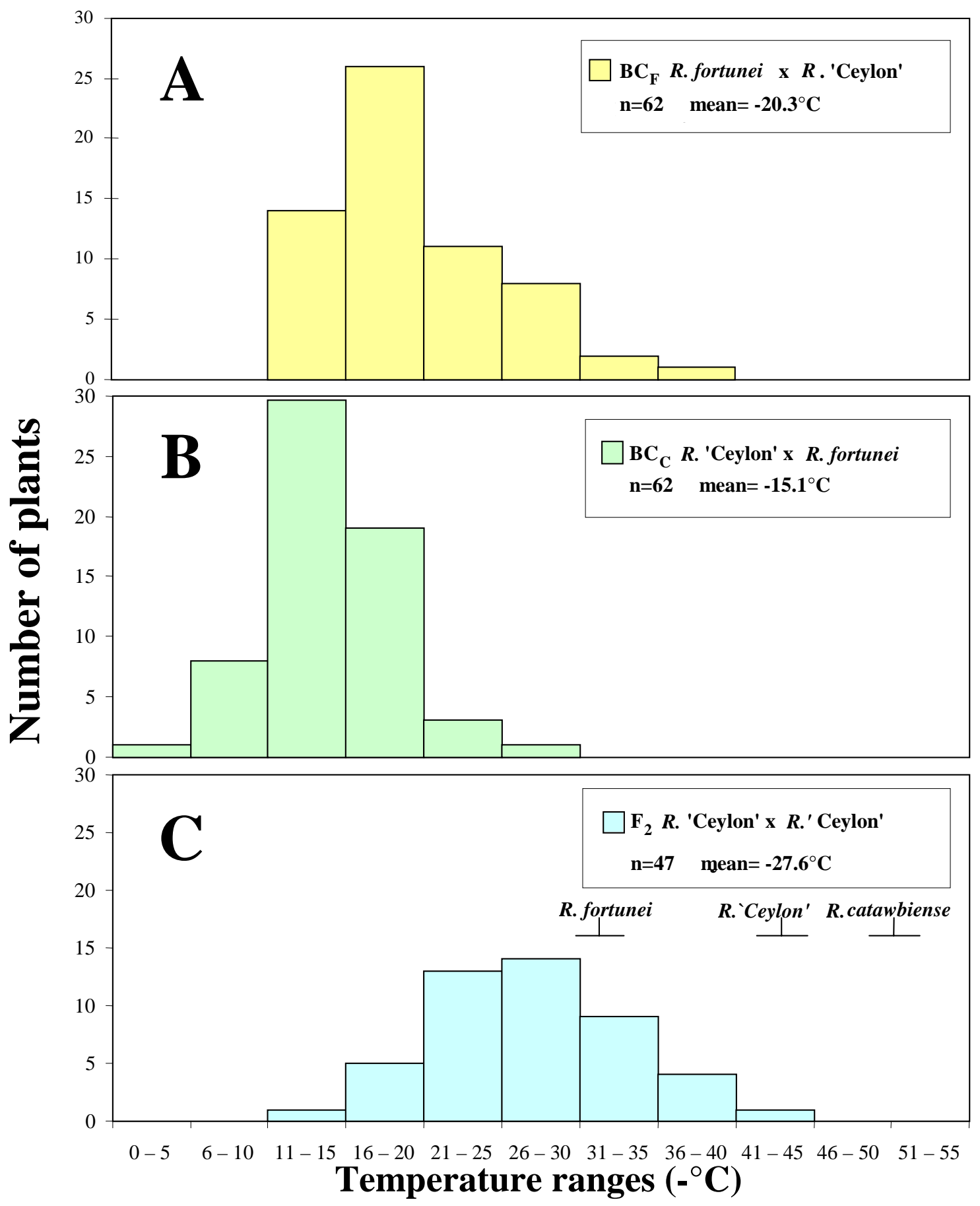


Fig. 3. Leaf-freezing tolerance $\left(\mathrm{T}_{\max }\right)$ distributions at non-acclimated state of a $\mathrm{F}_{2}$ Rhododendron population. $n=$ number of plants screened.

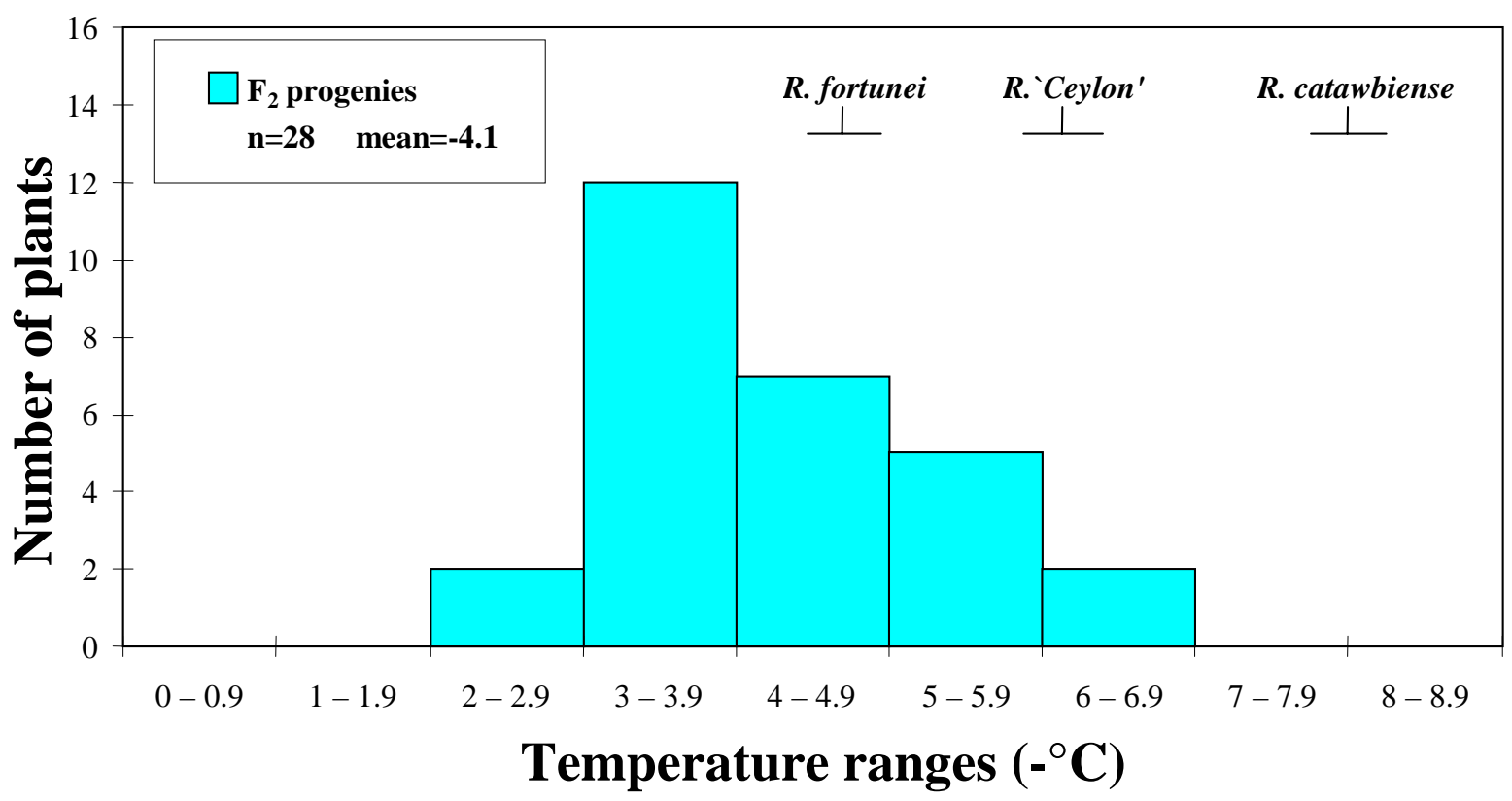


Fig. 4. Relationships between the components of cold hardiness in $F_{2}$ progenies. (A) Nonacclimated LFT vs. Cold acclimation ability. (B) Cold-acclimated LFT vs. Cold acclimation ability.

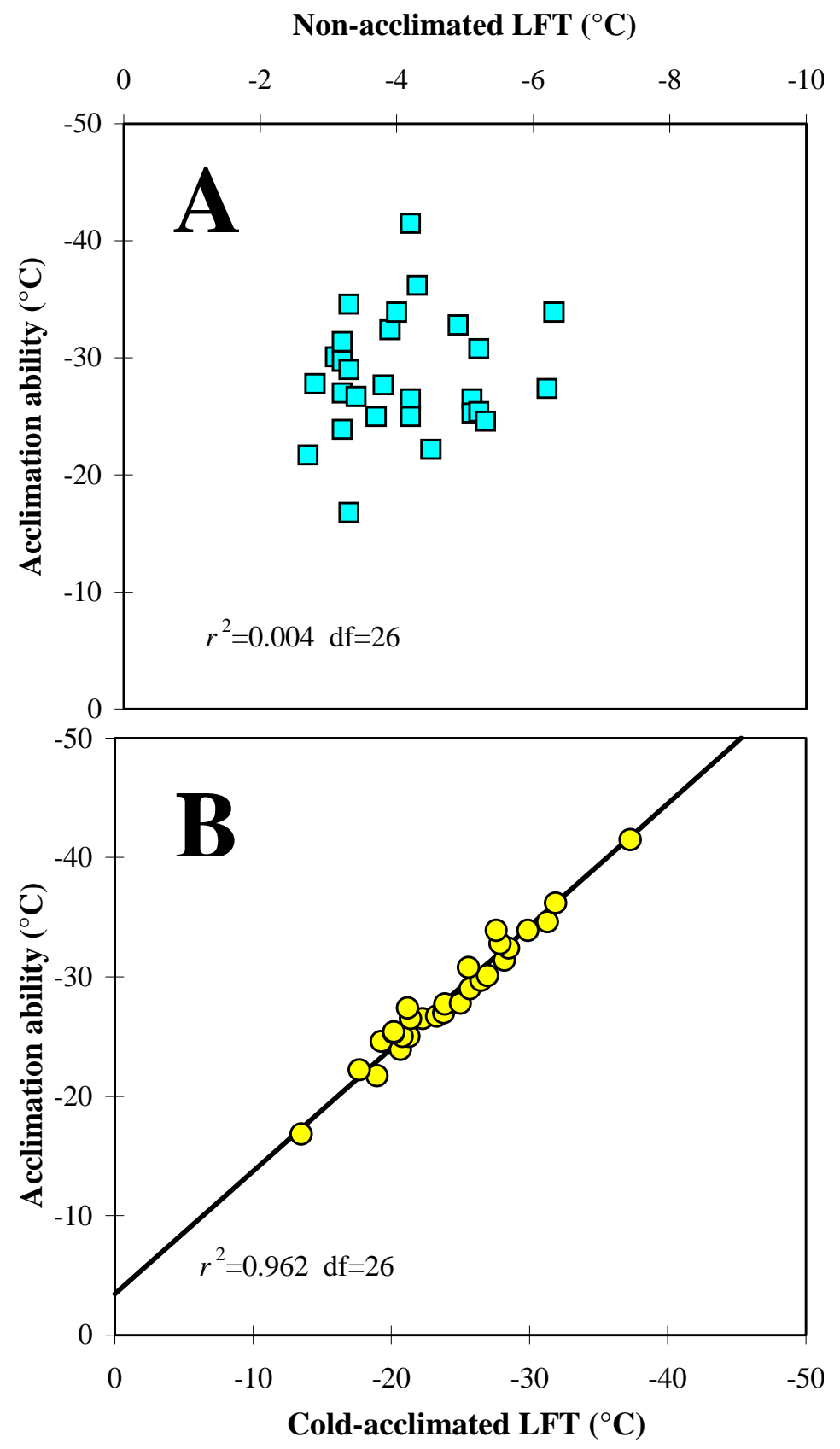


Fig. 5. Regressions of floral bud freeze-tolerance on leaf freeze-tolerance (LFT) in Rhododendron species accessions (large and small; 37 plants total), analysis of data presented by Sakai et al. 1986.

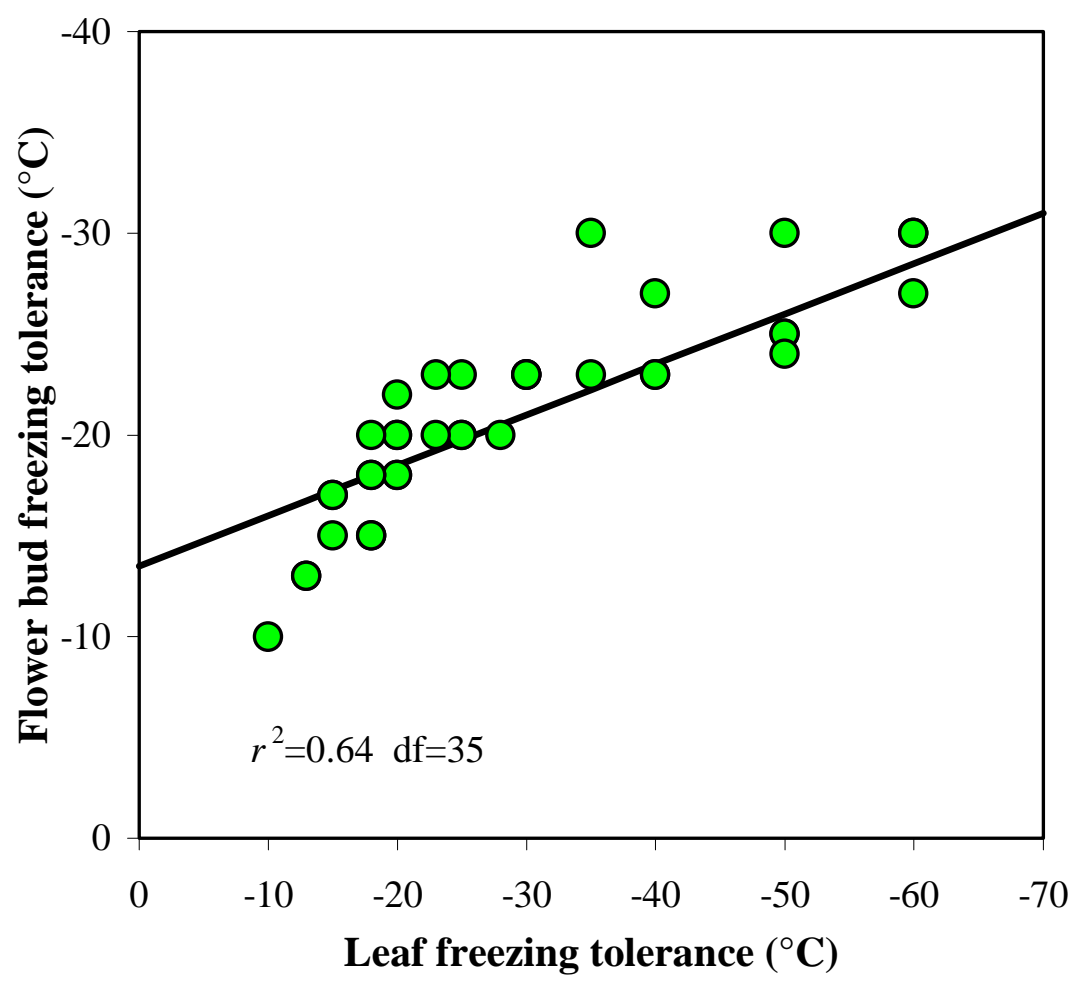




\title{
CHAPTER FOUR \\ DEHYDRIN AND ITS ASSOCIATION WITH RHODODENDRON COLD HARDINESS
}

published as:

\author{
A 25-kDa dehydrin associated with genotype-and \\ age-dependent leaf freezing-tolerance in Rhododendron: \\ a genetic marker for cold hardiness?
}

Theor Appl Genet (1999) 99(5):910-918

\author{
Chon C. Lim ${ }^{1}$, Stephen L. Krebs ${ }^{2}$ and Rajeev Arora ${ }^{1}$ \\ ${ }^{1}$ Division of Plant and Soil Sciences \\ West Virginia University, Morgantown, WV 26506 \\ ${ }^{2}$ The David G. Leach Research Station of \\ the Holden Arboretum, Madison, OH 44057
}

\begin{abstract}
Dehydrins are plant proteins that may play a critical role in stabilizing cell functions during freezing and other dehydrative stresses. This study examines whether dehydrin expression in leaves is associated with varying levels of freezing-tolerance among F2 segregants, species, and cultivars of evergreen Rhododendron. Experiments were also conducted to determine whether physiological and chronological aging affects freezing-tolerance and dehydrin accumulation in Rhododendron leaf tissues. Our results indicate that in cold-acclimated F2 populations, levels of a $25-\mathrm{kDa}$ dehydrin were closely associated with differences in leaf freezing-tolerance (LFT) among segregants. Studies of wild and cultivated plants indicated that LFT increased with both chronological age and developmental phase-change (juvenile to mature plants) and that this trend was accompanied by increased accumulation of the 25-kDa dehydrin.
\end{abstract}


It is suggested that the presence or absence of the $25-\mathrm{kDa}$ dehydrin could serve as a genetic marker to distinguish between super cold-hardy and less cold-hardy rhododendron genotypes. Similarly, the relative level of this protein within a genotype can serve as a physiological indicator of freezing-tolerance status under a range of phenological (acclimation) or developmental (age) conditions.

\section{INTRODUCTION}

Dehydrins (also known as group 2 LEA family of proteins) are hydrophilic, heat-stable proteins that are induced in response to plant stresses possessing a dehydration component, such as salt, water, or freezing stress (Close 1996). Dehydrins vary in molecular weight and $\mathrm{p} I$ but share one or more copies of a consensus sequence - a 15 residue, amphipathic $\alpha$-helix-forming domain (K-segment) — that is highly conserved in higher and lower plants (Close et al. 1993; Close 1997). During the cold acclimation (CA) process, dehydrins and dehydrin-like proteins and/or their transcripts accumulate in a wide array of plant tissues (Lång et al. 1989; Neven et al. 1993; Welin et al. 1994; Wisniewski et al. 1996) and have been cellularly localized in the cytosol and nucleus (Neven et al. 1993; Egerton-Warburton et al. 1997; Danyluk et al. 1998; Wisniewski et al. 1999).

A functional role for dehydrins in freezing-tolerance (FT) is suggested, in part, by their in vitro cryoprotectant properties (Lin and Thomashow 1992; Wisniewski et al. 1999). Recently, a direct relationship between dehydrins and FT was demonstrated by the ability of constitutively regulated cor proteins (some of which are dehydrins) in Arabidopsis to confer FT without prior acclimation (Jaglo-Ottosen et al. 1998). It has also been postulated that dehydrins may act as ionsequesters (Palva and Heino 1998) or as molecular chaperones (Campbell and Close 1997; Close 1997) under stressful conditions, thereby stabilizing proteins and membranes via hydrophobic interactions.

Accumulation of dehydrin protein and transcripts during CA has been amply documented in a number of herbaceous species (Close 1997), where the FT of cold-acclimated tissues typically does not exceed $-15^{\circ} \mathrm{C}$. Investigations of dehydrin expression and its association with 
CA in woody perennials, which exhibit significantly higher CA ability and FT than herbaceous plants, are comparatively scarce. Thus far, studies of woody perennials have been conducted with deciduous species to document $\mathrm{CA}$ and dehydrin profiles in overwintering tissues such as xylem, bark, and floral buds (Arora and Wisniewski 1994; Muthalif and Rowland 1994; Salzman et al. 1996; Artlip et al. 1997; Welling et al. 1997). The results of these studies are in general agreement with findings from herbaceous plants, indicating that dehydrins accumulate during the acclimation period.

Woody plants have several physiological traits that confound cold hardiness $(\mathrm{CH})$ research. A juvenile period in woody perennials raises the possibility of differences in FT between the juvenile versus mature (flowering) phases of development. In addition, tissues within an overwintering plant can exhibit different FT mechanisms, for example, supercooling in xylem parenchyma and bud tissues in contrast to equilibrium freezing in leaf and bark tissues (Wisniewski and Arora 1993). Furthermore, some woody plant tissues (e.g., buds) undergo dormancy and CA transitions simultaneously, making it difficult to associate physiological changes with one or the other phenological event (Arora et al. 1992; Arora et al. 1997).

We are using species of Rhododendron to study the genetics and physiology of CA and FT in a woody plant. This genus has a number of attributes that make it amenable to $\mathrm{CH}$ research. There are over 800 species of Rhododendron distributed throughout the Northern Hemisphere, ranging from tropical to polar climates and varying widely in FT (Leach 1961; Sakai et al. 1986). Some species, notably those in section Ponticum, are evergreens with leaves that can withstand freezing temperatures as low as $-40^{\circ}$ to $-60^{\circ} \mathrm{C}$ (Sakai et al. 1986 ; Uosukainen and Tigerstedt 1988). By using leaves to estimate $\mathrm{CH}$, the problem of dormancy transitions in buds is avoided. In addition, FT is conferred without supercooling in Rhododendron leaves (Sakai et al. 1986), enabling the use of freeze-thaw experiments and ion-leakage assays for the determination of leaf freeze-tolerance (LFT). This method of estimating CH provided LFT rankings in an array of evergreen Rhododendron cultivars that were consistent with USDA hardiness zone rankings (Lim et al. 1998a).

Our present research was initiated to determine whether dehydrin profiles differ qualitatively and quantitatively among progeny from a population segregating for $\mathrm{CH}$. This line of inquiry was derived from earlier work, which documented that $\mathrm{F}_{2}$ segregants from a cross 
between moderately cold-hardy and super cold-hardy Rhododendron species varied from $-18^{\circ}$ to $-48^{\circ} \mathrm{C}$ in LFT (Lim et al. 1998b). Remnant leaf tissue from progeny already evaluated for LFT was used for dehydrin analysis in order to determine the relationship between biochemical phenotypes (dehydrin accumulation) and $\mathrm{CH}$ phenotypes in the $\mathrm{F}_{2}$ population. A second research objective was to study the effect of plant age on $\mathrm{CH}$. The study of $\mathrm{F}_{2}$ segregants (Lim et al. 1998b) revealed that 2-3-year-old progeny displayed a mean LFT that was $12^{\circ} \mathrm{C}$ less hardy than the approximately 30 years-old $\mathrm{F}_{1}$ parent. This parent-offspring discrepancy in $\mathrm{CH}$ is difficult to account for genetically, and an alternative explanation was sought in the dependency of FT on physiological age (juvenile progeny vs. mature parents). Age-dependent $\mathrm{CH}$ in rhododendrons and parallel changes in dehydrin profiles were studied by comparing juvenile and mature (flowering) plants in natural populations (physiological-age effects) and by comparing mature cultivars differing widely in age (chronological-age effects).

\section{MATERIAL AND METHODS}

Plant material. Current-year leaves were collected from three groups of naturally cold-acclimated plants.

Group 1. Comparisons of LFT and dehydrin profiles among $F_{2}$ segregants included a super cold-hardy parent (R. catawbiense, approx. 40 years-old), a moderately-hardy parent $(R$. fortunei, approx. 40 years-old), the $\mathrm{F}_{1}$ hybrid cultivar 'Ceylon' (approx. 30 years-old) derived from the cross $R$. catawbiense x $R$. fortunei, and $\mathrm{F}_{2}$ seedlings resulting from the self-pollination of 'Ceylon'. This group of field-grown plants is maintained at the Holden Arboretum's Leach Research Station in Madison, Ohio. A collection of acclimated leaves from $51 \mathrm{~F}_{2}$ progeny (3year-old seedlings) and the parental plants was made in December 1997, and $\mathrm{T}_{\max }$ values (an estimate of LFT defined as the temperature causing the maximum rate of cell injury) were determined for each individual by the ion-leakage method described below. $\mathrm{T}_{\max }$ distributions for this population based on a similar collection of acclimated leaves in 1996 (2-year-old seedlings) were previously reported (Lim et al. 1998b). 
Remnant leaf tissue from selected progeny in the 1997 study was used for dehydrin analysis. Initially, the progeny were classified by hardiness phenotype into "low", "medium", and "high" LFT groups. Each group differed significantly from the adjacent group by a mean leaf $\mathrm{T}_{\max }$ of approximately $10^{\circ} \mathrm{C}$. Leaves from 5 random progeny in each group were pooled on an equal fresh weight basis, and the three phenotypic "bulks" were extracted and analyzed for differences in dehydrin profiles. Once bulk differences in dehydrin expression were evident, leaves from 3 individuals in each $\mathrm{F}_{2}$ bulk were extracted and evaluated separately.

Group 2. To examine the effect of physiological aging on LFT and dehydrin levels in rhododendrons, we compared juvenile seedlings and mature plants of $R$. maximum - growing in the wild near Cooper's Rock State Forest, West Virginia. Leaf collections from 7 seedlings without floral buds (approx. 2-3 years-old) and 3 large mature plants (approx. 30 years-old) were made in mid-January 1996, and individual LFTs were determined. A similar collection from the population was made in February 1997 using different juvenile and mature individuals. Leaves from the 1996 and 1997 collections were used to determine individual $\mathrm{T}_{\max }$ values for each year. For dehydrin comparisons, remnant leaf tissue from 1997 was pooled equally by fresh weight to form juvenile $(n=5)$ and mature plant $(n=3)$ leaf bulks.

Group 3. Comparisons of LFT and dehydrin profiles also were made among mature plants differing in chronological age. For this study, leaves were field-collected in January 1997 from the 'ortets' (seedling/ stock plants) of 'Hawaii', 'Swansdown', and 'Pink Parasol' maintained as 30-40 years-old cultivars at the Leach Research Station. At the same time, leaves were collected from 4-year-old 'ramets' (cuttings taken from ortets for vegetative propagation) of these cultivars grown as container plants at Losely Nursery in Perry, Ohio. These propagated plants had been maintained outdoors through mid-November, then placed in cold storage for the winter. For each of the three cultivars, LFTs were determined for a single ortet and three propagated ramets. For dehydrin analysis, leaves from the older ortets were compared to a leaf bulk from the three younger ramets. 


\section{Leaf freezing-tolerance (LFT) determination. Leaf discs $(1 \mathrm{~cm}$ in} diameter) were punched from individual plants (24 discs per plant) and frozen to various treatment temperatures ( 3 discs per treatment temperature) to obtain electrolyte leakage data as described in Lim et al. (1998a). Ion leakage data transformations, Gompertz functions fitting, and statistical analyses were also performed as described by Lim et al. (1998a) to obtain values for $\mathrm{T}_{\max }$ - the temperature at which the maximum rate of freezing injury occurs. In this study, $\mathrm{T}_{\max }$ is used synonymously with LFT as indicators of $\mathrm{CH}$.

Protein extractions. Extraction protocols described for other woody plants (Arora and Wisniewski 1994; Arora et al. 1997) were modified to optimize protein extraction from Rhododendron leaves. Leaf tissue ( $2 \mathrm{~g}$ ) was ground finely in $\mathrm{LN}_{2}$ and stored at $-80^{\circ} \mathrm{C}$ until used. Tissue was extracted with PVPP (35\% of tissue weight) in a borate buffer (50 mM sodium tetraborate, $50 \mathrm{mM}$ ascorbic acid, $1 \mathrm{mM}$ of PMSF, $\mathrm{pH} 9.0)$ using a 1: 4 (w:v, tissue+PVPP: buffer) extraction ratio. Crude extracts were shaken on a gyratory shaker at $4^{\circ} \mathrm{C}$ for $30 \mathrm{~min}$ followed by centrifugation at $26,000 \mathrm{~g}_{\mathrm{n}}$ for $15 \mathrm{~min}$ at $4^{\circ} \mathrm{C}$. To improve protein yields, the pellet was resuspended, shaken, and centrifuged as described above. The pellet was resuspended a third time, then placed on the shaker for $1 \mathrm{~h}$ at $4^{\circ} \mathrm{C}$ followed by a final centrifugation for $2 \mathrm{~h}$ as described above. Supernatant (soluble proteins) was collected and filtered twice through 0.45$\mu \mathrm{m}$ and $0.20-\mu \mathrm{m}$ filters.

Protein measurement. The method of Esen (1978) for determining total protein content in crude leaf extractions from rhododendrons proved more reliable than the Bradford assay (Arora and Wisniewski 1994) based on our observation of SDS-PAGE profiles. Equal aliquots ( $5 \mu \mathrm{l}$; triplicates) from various extractions and BSA standards $(0-4 \mathrm{mg} / \mathrm{ml}$; triplicates) were spotted on Whatman No. 1 chromatography paper and stained with $0.1 \%$ Coomassie brilliant blue dye R-250. After brief rinsing with water and drying, the stained spots were eluted with $1 \%$ SDS, and absorbance of the dye-protein complex was measured at $600 \mathrm{~nm}$. 
SDS-PAGE and immunoblotting. Concentrating the protein in the crude extracts was necessary in order to improve band intensity and resolution on SDS-PAGE gels. Proteins were precipitated from $1.3 \mathrm{ml}$ samples of extract by adding TCA (10\% of volume) and centrifuging at $16,000 \mathrm{~g}_{\mathrm{n}}$ for $30 \mathrm{~min}$ at $4^{\circ} \mathrm{C}$. Protein pellets were washed three times with cold acetone by centrifuging at $16,000 \mathrm{~g}_{\mathrm{n}}$ for $30 \mathrm{~min}$. During the second acetone wash a sterile sealed pipette tip was used to physically break the pellets. The pellets were broken once again before being air-dried. Dried protein pellets were rehydrated with $100 \mu \mathrm{l}$ of SDS-PAGE sample buffer and mixed quickly using a sterile sealed pipette tip. Concentrated protein samples were heated in boiling water for $3 \mathrm{~min}$ and then gently vortexed for $1 \mathrm{~h}$ followed by centrifugation at 16,000 $g_{\mathrm{n}}$ for $30 \mathrm{~s}$ to precipitate the pellet. The breaking of pellets significantly improved band intensities and resolution on SDS-PAGE (visual observation), as did the procedure of multiple resuspension and shaking of the crude extract described above.

Equal amounts of total protein $(30 \mu \mathrm{g})$ were separated by discontinuous SDS-PAGE and visualized by Coomassie stain as described by Arora et al. (1992). For immunoblots, separated protein $(15 \mu \mathrm{g})$ from gel loadings were transferred to $0.45-\mu \mathrm{m}$ nitrocellulose membranes as described by Arora and Wisniewski (1994) and probed with 1:500 dilution of the antibody directed against a synthetic peptide of the 15 amino acid consensus sequence (EKKGIMDKIKEKLPG) that is highly conserved at the C-terminus of dehydrin protein from several plant species (Close et al. 1993; antibody was kindly provided by Dr. Close). Immunoreactive bands were detected by alkaline phosphatase assay using ProtoBlot Western Blot AP Kit (Promega).

\section{Gel imaging and optical density measurements. Gels were recorded} digitally using the Optimas image analysis system (Optimas Inc., Edmonds, Wash.). The immunoreactive bands were assigned with gray values by the Optimas system, and the optical densities (O.D.) were calculated by taking the inverse log of the integrated gray values. Mean and standard errors of optical densities were based on three separate assignments of gray threshold values. 


\section{RESULTS}

Group 1 plants. LFT estimates among parents and $F_{2}$ segregants in 1997 were similar to those obtained in a 1996 survey (Lim et al. 1998b). $\mathrm{T}_{\max }$ values for the super coldhardy parent ( $R$. catawbiense), the moderately cold-hardy parent ( $R$. fortunei), and the $\mathrm{F}_{1}$ hybrid 'Ceylon' with intermediate hardiness were $-52.0^{\circ} \mathrm{C},-31.4^{\circ} \mathrm{C}$, and $-43.4^{\circ} \mathrm{C}$, respectively (Table 1). The 1997 screen of $51 \mathrm{~F}_{2}$ progeny resulted in a $-18^{\circ} \mathrm{C}$ to $-48^{\circ} \mathrm{C}$ range in $\mathrm{T}_{\max }$ values which were normally distributed around a mean $\mathrm{T}_{\max }$ of $-32.1^{\circ} \mathrm{C}$ (data not shown). Subsets of progeny used to make tissue bulks of "low", "medium", and "high" $\mathrm{CH}$ phenotypes differed significantly in mean $\mathrm{T}_{\max }$ by at least $10^{\circ} \mathrm{C}$ (Table 1$)$.

Coomassie-stained SDS-PAGE profiles of total proteins and their anti-dehydrin immunoblots for the two parents, $F_{1}$ and $F_{2}$ "bulks" are presented in Fig. 1A, B. Anti-dehydrin immunoblots of parents and $F_{1}$ plants revealed a group of dehydrins differing in molecular weight and level of accumulation in the cold-acclimated state. The highest O.D. value derived from a $25-\mathrm{kDa}$ dehydrin that was present in the super-hardy $R$. catawbiense parent, absent in an equal loading of protein from the moderately-hardy $R$. fortunei parent, and present at intermediate levels in the $\mathrm{F}_{1}$ hybrid 'Ceylon', which also displayed an intermediate LFT (Fig. 1B, Table 1). Levels of the 25-kDa dehydrin in cold-acclimated leaves from $R$. catawbiense were about five fold higher than in non-acclimated leaves from the same source. Both parents and the $\mathrm{F}_{1}$ exhibited low level accumulation of an approximately 45-kDa dehydrin. Three higher molecular weight dehydrins (approx. 55-, 68-, and 83-kDa) appeared in total proteins from $R$. fortunei but not $R$. catawbiense. These three dehydrins also accumulated in the $\mathrm{F}_{1}$ hybrid at levels too low for O.D. determination but intermediate in appearance to the parental levels. None of these dehydrins were detected when parallel samples were probed with pre-immune serum (data not shown).

None of the bands detected by anti-dehydrin immunoblotting corresponded to major bands on Coomassie-stained SDS-PAGE protein gels from cold-acclimated parents and the $\mathrm{F}_{1}$ plant (Fig. 1A). The relatively abundant $25-\mathrm{kDa}$ dehydrin on Western blots appeared as a faint band on the corresponding protein gel. The reason for the apparent lower dehydrin intensities on 
SDS-PAGE (observed for leaf tissues) is not clear. However, other papers have reported similar low intensities of leaf dehydrins as compared to bark or xylem dehydrins from woody plants (Arora et al. 1996; Artlip and Wisniewski 1997). In contrast, a 30-kDa protein with no dehydrin homology was very abundant in acclimated leaves from $R$. catawbiense compared to $R$. fortunei; this protein was also abundant in the "high" LFT bulk from $F_{2}$ progenies (Fig. 1A) and in the 3 individuals constituting this bulk (data not shown).

Among $\mathrm{F}_{2}$ seedlings, the $25-\mathrm{kDa}$ dehydrin was the only protein clearly associated with differences in $\mathrm{CH}$. Comparisons of the $\mathrm{F}_{2}$ tissue bulks grouped by phenotypic class — "low", "medium", and "high" LFT — indicated a 50-100\% increase in the 25-kDa dehydrin level as the $\mathrm{CH}$ status increased (Table 1, Fig. 1B). When individual progeny from these $\mathrm{F}_{2}$ bulks were evaluated, most, but not all, of the offspring displayed increased dehydrin accumulation at higher levels of LFT (Table 1, Fig. 2A). Regression of $\mathrm{T}_{\max }$ on dehydrin O.D. values for this population (Fig. 2B) resulted in a significant positive relationship $\left(r^{2}=0.78, d f=10, P<0.05\right)$, an indication that $25-\mathrm{kDa}$ dehydrin levels were reasonably predictive of acclimated LFT status in this population.

The high-molecular-weight dehydrins unique to the $R$. fortune $i$ parent and present in the $F_{1}$ hybrid 'Ceylon' (Fig. 1B) were essentially absent among $F_{2}$. This result may be due to age factors described in more detail below. Since the physiologically mature $F_{1}$ plant displayed weak signals for these dehydrins in the cold-acclimated state, it is possible that juvenile $\mathrm{F}_{2}$ seedlings (2-3 years-old) contained undetectable levels at comparable protein loadings.

Group 2 plants. There was a significant difference in LFT and dehydrin levels between juvenile seedlings and mature plants of $R$. maximum collected from a wild population in the cold-acclimated condition. In two sampling years, mature plants (approx. 30 years-old) were more cold-hardy than the juvenile seedlings (approx. 3 years-old) by an average of $-9.5^{\circ} \mathrm{C} \mathrm{T}_{\max }$ (Table 2). Immunoblots of leaf bulks from the 1997 collection indicated an approximate 2.4-fold increase in levels of the $25-\mathrm{kDa}$ dehydrin in mature plant leaves relative to juvenile plants (Table 2, Fig. 3B).

Two other dehydrins (29-kDa and 55-kDa) were faintly detected by immunoblots of coldacclimated protein extracts of $R$. maximum. These dehydrins accumulated at very low levels 
during the cold-acclimated state in both juvenile seedlings and mature plants and did not appear to be associated with FT levels (complete immunoblots not shown). The homology of a $R$. maximum 55-kDa dehydrin to other similar-sized dehydrins in other Rhododendron groups has not yet been confirmed by running them on the same gel. Additionally, a 30-kDa non-dehydrin protein strongly accumulated at high levels in the mature and more cold-hardy tissues as compared to juvenile and less-hardy tissues (Fig. 3A).

Group 3 plants. Different aged ortets and ramets of the same cultivar also exhibited some correspondence between $\mathrm{T}_{\max }$ values and levels of the 25-kDa dehydrin (Table 2, Fig. 4A, B). In all three comparisons, young ramets from 'Hawaii', 'Swansdown' and 'Pink Parasol' had significantly lower LFTs than the ortets. Differences in the 25-kDa dehydrin levels paralleled LFT differences. The older ortets of 'Swansdown' and 'Hawaii' showed 1.4-to 2.3-fold higher dehydrin levels relative to younger ramets propagated from them (Table 2, Fig. 4B). However, LFT differences in the 'Pink Parasol' comparison (which were the smallest among all three cultivars) were associated with equal amounts of dehydrin. Taken as a whole, this group of cultivars showed a significant, positive relationship between $\mathrm{T}_{\max }$ and accumulation of the 25kDa dehydrin $\left(r^{2}=0.81, d f=4, P<0.05\right)$.

Five other dehydrins (ranging from $45-\mathrm{kDa}$ to $97-\mathrm{kDa}$ ) were detected by immunoblots of cold-acclimated protein extracts from these cultivars (complete immunoblots not shown). Two commonly expressed dehydrins (approx. $45-\mathrm{kDa}$ and approx. $83-\mathrm{kDa}$ ) may be homologous to similar-sized proteins noted above in $R$. fortunei. Other dehydrins were cultivar specific (approx. 55-kDa in 'Hawaii' and 'Pink Parasol', approx. 78-kDa in 'Swansdown' and 'Pink Parasol', and approx. 97-kDa in 'Hawaii' and 'Swansdown'). With the exception of the 25-kDa form, these dehydrins exhibited equally low accumulation in younger ramets and older ortets and appeared to lack any association with LFT levels. 


\section{DISCUSSION}

Genetic interpretation of dehydrin profiles. In a previous study, two Rhododendron species differing in $\mathrm{CH}$ were used as parents to generate $\mathrm{F}_{2}$ seedlings segregating for LFT (Lim et al. 1998b). In the present report we show that the parental genotypes express cold-acclimation-induced dehydrins and that the number and molecular weight of these proteins varies between the species. This result is consistent with reports on other plant taxa in which dehydrins are encoded by a variable gene family that is coordinately regulated by low temperatures (Houde et al. 1992a; Robertson et al. 1994; Rowland et al. 1996; Choi et al. 1999).

Several dehydrins were present in only one of the two species - a 25-kDa variant found in $R$. catawbiense and 55-, 68-, and 83-kDa forms observed in R. fortunei. Because the immunoblots are detecting temperature-induced proteins, the parental differences in dehydrin profiles (presence vs. absence of a specific molecular-weight protein) could be attributed to regulatory genes rather than dehydrin-encoding structural genes. For example, $R$. catawbiense and $R$. fortunei could share identical dehydrin genes under the control of regulatory genes, which respond differently to low temperatures. At present, we favor an interpretation of the data based on structural gene differences between the parents. Studies with cold-responsive regulatory elements (transcriptional factors) suggest that they promote coordinate expression of a suite of cold-regulated genes, some of which also encode dehydrin or dehydrin-like proteins (JagloOttosen et al. 1998). There is no evidence in the literature, to date, supporting the scenario described above - an identical dehydrin gene common to two cold-acclimating species but differentially induced by cold in only one of them. It is likely, then, that the dehydrin profiles observed in acclimated leaf tissue from each parent, in this study, represent the expression of the full set of cold-regulated dehydrins. It is important to note, however, that different dehydrin genes within the same genotype may be differentially regulated by altering the type of stimulus such as low temperature, water-stress, ABA, etc. (Choi et al. 1999).

The limited $F_{1}$ and $F_{2}$ data in this study also suggest that presence versus absence (+/-) of the $25-\mathrm{kDa}$ dehydrin, and possibly some of the other higher-MW dehydrins, is due to structural gene differences. The $F_{1}$ interspecific hybrid displayed all parental bands, indicating either a dominant or codominant inheritance of dehydrin presence. Accumulation of several dehydrins in 
the $F_{1}$ (based on O.D. or visual estimates) were intermediate to parental levels, suggesting a gene dosage effect, which could result from codominant expression of 'presence' and 'absence' alleles at the corresponding loci. The $F_{1}$ hybrid may be heterozygous for alleles that are homozygous for the presence trait $(+/+)$ in one parent and homozygous for dehydrin absence (-/-) in the other, resulting in high, intermediate, and null levels of protein accumulation respectively in each genotype. Given this model, the expectation for the $F_{2}$ is three dosage phenotypes segregating in a 1:2:1 ratio, or a 3:1 ratio for presence versus absence of a dehydrin. The 25-kDa dehydrin was absent in 3 of $9 \mathrm{~F}_{2}$ progeny, giving a 2:1 ratio for presence versus absence; this fits reasonably well to the $3: 1$ expectation $\left(\chi^{2}=0.15 ; 0.5<P<0.75\right)$. However, the total sample was too small to determine whether dehydrin accumulation formed a continuous distribution or fell within distinct low, intermediate, and high levels in the 1:2:1 ratio as predicted. Nevertheless, at least 1 progeny had high levels of accumulation $($ O.D. $\cong 0.75)$, which in addition to the null genotypes, suggests that both parental genotypes were recovered in the $F_{2}$ generation. No information could be gleaned from the higher MW dehydrins contributed by $R$. fortunei because they did not accumulate to detectable levels in individual $\mathrm{F}_{2}$ seedlings.

In maize, allelic variation at one of two dehydrin loci has a similar presence/ absence phenotype in some genotype comparisons. At both the $d h n 1$ and $d h n 2$ loci, different-sized alleles have been observed, but some individuals lacked a dehydrin band at the dhn2 locus (Campbell et al. 1998). In $F_{1}$ and $F_{2}$ progeny, the presence trait appears in a pattern consistent with dominant expression of structural genes, although some variation due to possible dosage and maternal influence was noted. The authors did not rule out the possibility that the absence trait at dhn2 could result from regulatory gene control.

\section{Association of freeze-tolerance and dehydrin levels. A number of} studies have established a positive correlation between dehydrin accumulation and $\mathrm{CH}$ phenotype among selected genotypes (Danyluk et al. 1994; Muthalif and Rowland 1994; Robertson et al. 1994; Cai et al. 1995; Arora et al. 1997; Artlip et al. 1997). In cowpea, the presence or absence of a $35-\mathrm{kDa}$ dehydrin in parents and $\mathrm{F}_{1}$ hybrids accounted for $19 \%$ of the variation in chilling tolerance at germination (Ismail et al. 1997). We postulated in an earlier report (Lim et al. 1998b) that as few as three genes with additive effects could produce the 
normally distributed $\mathrm{CH}$ phenotypes observed in an $\mathrm{F}_{2}$ population derived from the $R$. catawbiense x $R$. fortunei cross. This group of genes may include the 25-kDa dehydrin from $R$. catawbiense because variation in the accumulation of protein was closely associated with segregation for LFT. Linear regression analysis indicated that 25-kDa O.D. values accounted for $78 \%$ of the variation in LFT among parents, $F_{1}$, and $9 F_{2}$ progeny. The $25-\mathrm{kDa}$ dehydrin thus appears to be a key component of LFT in rhododendrons, although its function has not been ascertained.

$\mathrm{CH}$ is considered to be a physiologically complex trait under multigenic control (Hayes et al. 1993; Stone et al. 1993; Pellet 1998), and there are undoubtedly other gene products that play major roles in CA of rhododendrons. In this study, a 30-kDa non-dehydrin protein was visualized at lower levels under non-acclimated conditions than under cold-acclimated conditions, was observed at higher levels in $R$. catawbiense than in $R$. fortunei, and appeared to be one of the most abundant proteins in the "hardiest" $F_{2}$ bulk. This undetermined protein also displayed a close quantitative association with age-dependent LFT changes in $R$. maximum (a closely related species to $R$. catawbiense with comparable FT). We plan to look more closely at the association of this $30-\mathrm{kDa}$ protein with $\mathrm{CH}$ and possibly characterize it in the future.

\section{Age effects on cold hardiness and dehydrin accumulation. Woody}

perennials typically have lengthy juvenile phases that terminate upon flowering (maturation). Between these developmental phases, plants undergo morphological changes (Hartmann et al. 1997) as well as genetic, physiological, or biochemical changes (Hackett et al. 1990); a process known as "phase-change" or "maturation" (Brink 1962). However, to the best of our knowledge, very little is known about the effect of phase change on adaptive traits such as $\mathrm{CH}$.

In rhododendrons, there is a significant effect of physiological age on both $\mathrm{CH}$ and dehydrin accumulation. In the wild population of $R$. maximum, juvenile plants (approx. 2-3 years-old) were less hardy than mature plants by about $9^{\circ} \mathrm{C}$. Parallel differences were observed in the relative abundance of the $25-\mathrm{kDa}$ dehydrin in leaves from juvenile and mature plants. Phase-related, differential expression of proteins (qualitative and quantitative) has been reported for several woody species (Hand et al. 1996 and references within). The present study is the first to report the phase-dependent accumulation of a dehydrin and its correlation with $\mathrm{CH}$. The 
underlying mechanisms for this age-dependent effect are unknown but may involve regulatory elements (e.g., signal transduction linked with dehydrin expression) or phase changes in nutrient assimilation.

The data from the $R$. maximum population suggest that parent-offspring comparisons in genetic studies of $\mathrm{CH}$ can be confounded by age-dependent factors when the offspring are in a juvenile phase. In an earlier study (Lim et al. 1998b), we reported that the average $F_{2}$ progeny (2-3-year-old) was $12^{\circ} \mathrm{C}$ less freeze-tolerant than the $\mathrm{F}_{1}$ parent (approx. 30 years-old). This difference now appears to result from developmental rather than genetic factors. For future research and breeding efforts, further studies will be needed to determine how much LFT increases with juvenile-mature phase change, and how well seedling $\mathrm{CH}$ predicts mature plant performance.

Chronological age also appeared to have a positive effect on both $\mathrm{CH}$ and dehydrin accumulation. In the comparisons of younger ramets versus older stock plants, all of the three cultivars studied showed significantly higher LFT, and two of the three cultivars displayed higher dehydrin levels in the older ortets. In the case of 'Pink Parasol', age differences in LFT were the smallest among the three cultivar comparisons (only $5^{\circ} \mathrm{C}$ vs. $>20^{\circ} \mathrm{C}$ for the other two cultivars), but they corresponded to similar abundances of the $25-\mathrm{kDa}$ dehydrin in leaf tissues from ramets versus ortets. It is conceivable that the differences in dehydrin level (associated with relatively smaller differences in LFT) are marginal and could not be detected by the quantitative method used in this study.

Dehydrins as markers for freezing-tolerance. While the chronological age data are somewhat equivocal with respect to interpretation, it is interesting to note that a pooled analysis of the cultivar comparisons indicated a significant association between LFT and $25-\mathrm{kDa}$ dehydrin accumulations. As in the $\mathrm{F}_{2}$ population, 25-kDa dehydrin level alone is a reasonably good predictor of $\mathrm{CH}$ status among a diverse group of Rhododendron genotypes. Our data corroborate a suggestion by Houde et al. (1992b) that dehydrins could be used as both quantitative and qualitative markers for the FT phenotype in Gramineae and extend their applicability to woody plant systems. The $25-\mathrm{kDa}$ dehydrin present in the super-hardy R. catawbiense may have cryoprotectant/chaperone/ion-sequestration properties which exceed 
the higher MW dehydrins found only in the moderately-hardy $R$. fortunei (which lacks the 25$\mathrm{kDa}$ dehydrin). Differential transmission and accumulation of the $25-\mathrm{kDa}$ protein among Rhododendron genotypes in the $\mathrm{F}_{2}$ significantly affected $\mathrm{CH}$ status, suggesting that this dehydrin may be a genetic marker for $\mathrm{CH}$. The ability of the $25-\mathrm{kDa}$ dehydrin to serve as a physiological indicator of $\mathrm{CH}$ was demonstrated by the parallel changes in protein levels and LFT caused by phenological (acclimation) or developmental (age) factors.

\section{ACKNOWLEDGEMENTS}

We thank Losely Nursery, Ohio for the use of their cultivar materials and staff time. This research was supported, in part, by grants from American Rhododendron Society, Horticulture Research Institute, West Virginia Nurserymen's Association and funds appropriated through Hatch Act (RA), and financial support from Holden Arboretum (SLK). Published with the approval of the Director of the West Virginia Agriculture and Forestry Experimental Station as scientific article No. 2720. 


\section{LITERATURE CITED}

Arora R, Wisniewski ME (1994) Cold acclimation in genetically related (sibling) deciduous and evergreen peach (Prunus persica [L.] Batsch). II. A 60-kilodalton bark protein in coldacclimated tissues of peach is heat stable and related to the dehydrin family of proteins. Plant Physiol 105:95-101

Arora R, Wisniewski ME, Scorza R (1992) Cold acclimation in genetically related (sibling) deciduous and evergreen peach (Prunus persica [L.] Batsch). I. Seasonal changes in cold hardiness and polypeptides of bark and xylem tissues. Plant Physiol 99:1562-1568

Arora R, Wisniewski ME, Rowland LJ (1996) Cold acclimation and alterations in dehydrin-like and bark storage proteins in the leaves of sibling deciduous and evergreen peach (Prunus persica [L.] Batsch). J Amer Soc Hort Sci 121:915-919

Arora R, Rowland LJ, Panta GR (1997) Chill-responsive dehydrins in blueberry: Are they associated with cold hardiness or dormancy transitions? Physiol Plant 101:8-16

Artlip TS, Wisniewski ME (1997) Tissue-specific expression of a dehydrin gene in one-year-old 'Rio Oso Gem' peach trees. J Amer Soc Hort Sci 122:784-787

Artlip TS, Callahan AM, Bassett CL, Wisniewski ME (1997) Seasonal expression of a dehydrin gene in sibling deciduous and evergreen genotypes of peach (Prunus persica [L.] Batsch). Plant Mol Biol 33:61-70

Brink RA (1962) Phase change in higher plants and somatic cell heredity. Q Rev Biol 37:1-22

Campbell SA, Close TJ (1997) Dehydrins: Genes, proteins, and associations with phenotypic traits. New Phytol 137:61-74

Campbell SA, Crone DE, Ceccardi T, Close TJ (1998) An 40-kDaa maize (Zea mays L.) embryo dehydrin is encoded by the $d h n 2$ locus on chromosome 9. Plant Mol Biol 38:417-423

Cai QY, Moore GA, Guy CL, (1995) An unusual Group 2 LEA gene family in citrus responsive to low temperature. Plant Mol Biol 29:11-23

Choi DW, Zhu B, Close TJ (1999) The barley (Hordeum vulgare L.) dehydrin multigene family: sequences, allele types, chromosome assignments, and expression characteristics of $11 \mathrm{Dhn}$ genes of cv. Dicktoo. Theor Appl Genet 98:1234-1247

Close TJ (1996) Dehydrins: emergence of a biochemical role of a family of plant dehydration proteins. Physiol Plant 97:795-803

Close TJ (1997) Dehydrins: a commonality in the response of plants to dehydration and low temperature. Physiol Plant 100:291-296 
Close TJ, Fenton RD, Yang A, Asghar R, DeMason DA, Crone DE, Meyer NC, Moonan F (1993) Dehydrin: the protein. In: Close TJ, Bray EA (eds) Plant responses to cellular dehydration during environmental stress. American Society of Plant Physiologists, Rockville, MD., pp 104-114

Danyluk J, Houde M, Rassart EÂ, Sarhan F (1994) Differential expression of a gene encoding an acidic dehydrin in chilling sensitive and freezing tolerant Gramineae species. FEBS Lett $344: 20-24$

Danyluk J, Perron A, Houde M, Limin A, Fowler B, Benhamou N, Sarhan F (1998) Accumulation of an acidic dehydrin in the vicinity of the plasma-membrane during coldacclimation of wheat. Plant Cell 10:623-638

Egerton-Warburton LM, Balsamo RA, Close TJ (1997) Temporal accumulation and ultrastructural localization of dehydrins in Zea mays L. Physiol Plant 101:545-555

Esen A (1978) A simple method for quantitative, semiquantitative and qualitative assay of protein. Anal Biochem 89:264-273

Hackett WP, Murray JR, Woo HH, Stapfer RE, Geneve R (1990) Cellular, biochemical and molecular characteristics related to maturation and rejuvenation in woody species. NATO ASI Ser A: Life Sci 186:147-152

Hand P, Besford RT, Richardson CM, Peppitt SD (1996) Antibodies to phase related proteins in juvenile and mature Prunus avium. Plant Growth Regul 20:25-29

Hartmann HT, Kester DE, Davies FT Jr, Geneve RL (1997) Plant propagation: principles and practices, $6^{\text {th }}$ edn. Prentice Hall, Upper Saddle River, N.J., 242 p.

Hayes PM, Blake T, Chen THH, Tragoonrung S, Chen F, Pan A, Liu B (1993) Quantitative trait loci on barley (Hordeum vulgare L.) chromosome 7 associated with components of winter hardiness. Genome 36:66-71

Houde M, Danyluk J, Laliberte JF (1992a) Cloning, characterization, and expression of a cDNA encoding a 50-kilodalton protein specifically induced by cold acclimation in wheat. Plant Physiol 99:1381-1387

Houde M, Dhindsa RS, Sarhan F (1992b) A molecular marker to select for freezing tolerance in Gramineae. Mol Gen Genet 234:43-48

Ismail AM, Hall AE, Close TJ (1997) Chilling tolerance during emergence of cowpea associated with a dehydrin and slow electrolyte leakage. Crop Sci 37:1270-1277 
Jaglo-Ottosen KR, Gilmour SJ, Zarka DG, Schabenberger O, Thomashow MF (1998) Arabidopsis $\mathrm{CBF} 1$ overexpression induces cor genes and enhances freezing tolerance. Science 280:104-106

Lång V, Heino P, Palva ET (1989) Low temperature acclimation and treatment with exogenous abscisic acid induce common polypeptides in Arabidopsis thaliana (L.) Heynh. Theor Appl Genet 77:729-734

Leach DG (1961) Rhododendrons of the world and how to grow them. Charles Scribner's, New York

Lim CC, Arora R, Townsend ED (1998a) Comparing Gompertz and Richards functions to estimate freezing injury in Rhododendron using electrolyte leakage. J Amer Soc Hort Sci $123: 246-252$

Lim CC, Krebs SL, Arora R (1998b) Genetic study of freezing tolerance in Rhododendron populations: Implications for cold hardiness breeding. J Amer Rhododendron Soc 52:143148

Lin C, Thomashow MF (1992) A cold-regulated Arabidopsis gene encodes a polypeptide having potent cryoprotective activity. Biochem Biophy Res Commun 183:1103-1108

Muthalif MM, Rowland LJ (1994) Identification of dehydrin-like proteins responsive to chilling in floral buds of blueberry (Vaccinium, section Cyanococcus). Plant Physiol 104:1439-1447

Neven LG, Haskell DW, Hofig A, Li QB, Guy CL (1993) Characterization of a spinach gene responsive to low temperature and water stress. Plant Mol Biol 21:291-305

Palva ET, Heino P (1998) Molecular mechanisms of plant cold acclimation and freezing tolerance. In: Li PH, Chen THH (eds) Plant cold hardiness: molecular biology, biochemistry, and physiology. Plenum Press, New York, pp 1-14

Pellet H (1998) Breeding of cold hardy woody landscape plants. In: Li PH, Chen THH (eds) Plant cold hardiness: molecular biology, biochemistry, and physiology. Plenum Press, New York, pp 317-324

Robertson AJ, Weninger A, Wilen RW, Fu P, Gusta LV (1994) Comparison of dehydrin gene expression and freezing tolerance in Bromus inermis and Secale cereale grown in controlled environments, hydroponics, and the field. Plant Physiol 106:1213-1216

Rowland LJ, Muthalif MM, Levi A, Arora R (1996) Cloning and expression of dehydrin genes in blueberry. HortScience 31:585

Sakai A, Fuchigami L, Weiser CJ (1986) Cold hardiness in the genus Rhododendron. J Amer Soc Hort Sci 111:273-80 
Salzman RA, Bressan RA, Hasegawa PM, Ashworth EN, Bordelon BP (1996) Programmed accumulation of LEA-like proteins during desiccation and cold acclimation of overwintering grape buds. Plant Cell Environ 19:713-720

Stone JM, Palta JP, Bamberg JB, Weiss LS, Harbage JF (1993) Inheritance of freezing resistance in tuber-bearing Solanum species: evidence for independent genetic control of nonacclimated freezing tolerance and cold acclimation capacity. Proc Natl Acad Sci USA 90:7869-7873

Uosukainen M, Tigerstedt PMA (1988) Breeding of frosthardy rhododendrons. J Agric Sci Finland 60:235-254

Welin BV, Olson Å, Nylander M, Palva ET (1994) Characterization and differential expression of $d h n / l e a / r a b$-like genes during cold acclimation and drought stress in Arabidopsis thaliana. Plant Mol Biol 26:131-144

Welling A, Kaikuranta P, Päivi R (1997) Photoperiodic induction of dormancy and freezing tolerance in Betula pubescens. Involvement of ABA and dehydrins. Physiol Plant 100:119125

Wisniewski M, Arora R (1993) Adaptation and response of fruit trees to freezing temperatures. In: Biggs AR (ed) Cytology, histology and histochemistry of fruit tree diseases. CRC Press, Boca Raton, Fla., pp 299-320

Wisniewski M, Close TJ, Artlip T, Arora R (1996) Seasonal patterns of dehydrins and 70-kDa heat-shock proteins in bark tissues of eight species of woody plants. Physiol Plant 96:496505

Wisniewski M, Webb R, Balsamo R, Close TJ, Yu X-M, Griffith M (1999) Purification, immunolocalization, cryoprotective, and antifreeze activity of PCA60: a dehydrin from peach (Prunus persica). Physiol Plant 105:600-608 
Table 1. Leaf freezing-tolerance $\left(\mathrm{T}_{\max }\right)$ and corresponding levels of a $25 \mathrm{kD}$ dehydrin in a Rhododendron population segregating for FT

\begin{tabular}{|c|c|c|c|}
\hline Group 1 plants & $n^{\mathrm{a}}$ & $\begin{array}{l}\text { Mean } \mathrm{T}_{\max } \\
\left({ }^{\circ} \mathrm{C}\right) \pm \mathrm{SE}^{\mathrm{b}}\end{array}$ & $\begin{array}{l}\text { Mean O.D. of } 25-\mathrm{kDa} \\
\text { dehydrin } \pm \mathrm{SE}^{\mathrm{c}}\end{array}$ \\
\hline \multicolumn{4}{|l|}{ Parents } \\
\hline R. catawbiense, $\mathrm{P}_{1}$ & 1 & $-52.0 \pm 1.3^{\mathrm{a}}$ & $0.95 \pm 0.03^{\mathrm{a}}$ \\
\hline$R$. fortunei, $\mathrm{P}_{2}$ & 1 & $-31.4 \pm 1.5^{\mathrm{i}}$ & $0.00 \pm 0.00^{\mathrm{r}}$ \\
\hline$R$. 'Ceylon', $\mathrm{P}_{1} \times \mathrm{P}_{2}, \mathrm{~F}_{1}$ & 1 & $-43.4 \pm 3.4^{\text {cdefgh }}$ & $0.63 \pm 0.04^{\mathrm{bcd}}$ \\
\hline \multicolumn{4}{|c|}{ Bulked and individual $F_{2}$ progenies } \\
\hline $\mathrm{F}_{2}$-low group & 5 & $-20.5 \pm 1.0^{\mathrm{k}}$ & $0.40 \pm 0.05^{\text {eghikmnq }}$ \\
\hline $\mathrm{F}_{2}$-medium group & 5 & $-32.1 \pm 0.2^{\mathrm{i}}$ & $0.57 \pm 0.04^{\mathrm{cfg}}$ \\
\hline $\mathrm{F}_{2}$-high group & 5 & $-43.7 \pm 1.7^{\text {defg }}$ & $0.76 \pm 0.04^{\mathrm{b}}$ \\
\hline $\mathrm{L}_{1}$ & 1 & $-21.3 \pm 0.5^{\mathrm{k}}$ & $0.00 \pm 0.00^{\mathrm{r}}$ \\
\hline $\mathrm{L}_{2}$ & 1 & $-22.5 \pm 0.7^{\mathrm{jk}}$ & $0.26 \pm 0.07^{\text {hikmnpq }}$ \\
\hline $\mathrm{L}_{3}$ & 1 & $-22.5 \pm 0.8^{\mathrm{jk}}$ & $0.00 \pm 0.00^{\mathrm{r}}$ \\
\hline $\mathrm{M}_{1}$ & 1 & $-31.6 \pm 0.7^{\mathrm{i}}$ & $0.37 \pm 0.08^{\text {deghikmnpq }}$ \\
\hline $\mathrm{M}_{2}$ & 1 & $-31.8 \pm 1.2^{\mathrm{i}}$ & $0.00 \pm 0.00^{\mathrm{r}}$ \\
\hline $\mathrm{M}_{3}$ & 1 & $-32.6 \pm 1.9^{i}$ & $0.58 \pm 0.03^{\mathrm{ce}}$ \\
\hline $\mathrm{H}_{1}$ & 1 & $-39.3 \pm 1.2^{h}$ & $0.32 \pm 0.02^{1 \mathrm{~m}}$ \\
\hline $\mathrm{H}_{2}$ & 1 & $-40.9 \pm 1.3^{\mathrm{efgh}}$ & $0.75 \pm 0.03^{b}$ \\
\hline $\mathrm{H}_{3}$ & 1 & $-47.1 \pm 1.7^{b d}$ & $0.45 \pm 0.01^{\mathrm{fh}}$ \\
\hline
\end{tabular}

${ }^{\text {a }} n$ Number of plants. Three replicate discs were measured at each treatment temperature

${ }^{\mathrm{b}}$ Estimated by using the Gompertz function fitted to percentage adjusted injury data; mean and SE estimated by replicates (24 leaf discs) using the Jackknife method (Lim et al. 1998a). Mean separation in column was determined by multiple $t$-test. Values having different letters are significant at $P<0.05$

${ }^{c}$ Using Optimas System; mean and SE estimated from three separate gray values assigned. Mean separation in column was determined by multiple $t$-test. Values having different letters are significant at $P<0.05$ 
Table 2. Leaf freezing-tolerance $\left(\mathrm{T}_{\max }\right)$ and corresponding levels of a $25 \mathrm{kD}$ dehydrin in Rhododendron plants varying in physiological and chronological age

\begin{tabular}{|c|c|c|c|}
\hline Group 2 and 3 plants & $n^{\mathrm{a}}$ & $\begin{array}{l}\text { Mean } \mathrm{T}_{\max } \\
\left({ }^{\circ} \mathrm{C}\right) \pm \mathrm{SE}^{\mathrm{b}}\end{array}$ & $\begin{array}{c}\text { Mean O.D. of } 25-\mathrm{kDa} \\
\text { dehydrin } \pm \mathrm{SE}^{\mathrm{c}}\end{array}$ \\
\hline \multicolumn{4}{|l|}{ Physiological-aged $^{\mathrm{d}}$} \\
\hline R. maximum, juvenile seedlings- 1996 & 7 & $-38.5 \pm 2.0^{\mathrm{gh}}$ & ----------- \\
\hline R. maximum, mature plants- 1996 & 3 & $-50.2 \pm 0.2^{a b c}$ & ----------- \\
\hline R. maximum, juvenile seedlings-1997 & 5 & $-36.3 \pm 2.4^{h i}$ & $0.31 \pm 0.02^{\ln }$ \\
\hline R. maximum, mature plants- 1997 & 3 & $-43.5 \pm 0.9^{\mathrm{def}}$ & $0.76 \pm 0.03^{b}$ \\
\hline \multicolumn{4}{|l|}{ Chronological-aged } \\
\hline$R$. 'Hawaii', ramets & 3 & $-18.8 \pm 1.9^{\mathrm{k}}$ & $0.18 \pm 0.02^{\mathrm{op}}$ \\
\hline$R$. 'Hawaii', ortet & 1 & $-41.1 \pm 1.2^{\mathrm{efgh}}$ & $0.40 \pm 0.00^{\mathrm{jk}}$ \\
\hline$R$. 'Swansdown', ramets & 3 & $-24.7 \pm 1.1^{\mathrm{j}}$ & $0.45 \pm 0.00^{\mathrm{fi}}$ \\
\hline R. 'Swansdown', ortet & 1 & $-45.7 \pm 2.0^{\mathrm{de}}$ & $0.64 \pm 0.02^{b c}$ \\
\hline$R$. 'Pink Parasol', ramets & 3 & $-40.3 \pm 1.4^{\text {fgh }}$ & $0.73 \pm 0.03^{b c}$ \\
\hline$R$. 'Pink Parasol', ortet & 1 & $-45.4 \pm 1.4^{\mathrm{d}}$ & $0.73 \pm 0.03^{b}$ \\
\hline
\end{tabular}

${ }^{\mathrm{a}} n$ Number of plants. Three replicate discs were measured at each treatment temperature

${ }^{\mathrm{b}}$ Estimated by using the Gompertz function fitted to percentage adjusted injury data; mean and SE estimated by replicates (24 leaf discs) using the Jackknife method (Lim et al. 1998a). Mean separation in column was determined by multiple $t$-test. Values having different letters are significant at $P<0.05$

${ }^{c}$ Using Optimas System; mean and SE estimated from three separate gray values assigned. Mean separation in column was determined by multiple $t$-test. Values having different letters are significant at $P<0.05$

d 1997 plants were evaluated in late February 
Fig. 1A, B Group 1 plants: (A) SDS-PAGE profiles of total soluble proteins from coldacclimated leaves (30 $\mu \mathrm{g}$ per lane). $P_{1} R$. catawbiense, $P_{2} R$. fortunei, $F_{1} R$. catawbiense $x$ $R$. fortunei $=R$. 'Ceylon', $F_{2}=R$. 'Ceylon' selfed; $L, M$, and $H$ correspond to the low, medium, and high freeze-tolerant $\mathrm{F}_{2}$ bulks. (B) Anti-dehydrin immunoblots of parents, $\mathrm{F}_{1}$ and bulks of $F_{2}$ progenies. Protein $(15 \mu \mathrm{g})$ was loaded in each lane. $N A$ non-acclimated. O.D. optical densities, $T_{\max }$ quantitative measure of leaf freezing-tolerance

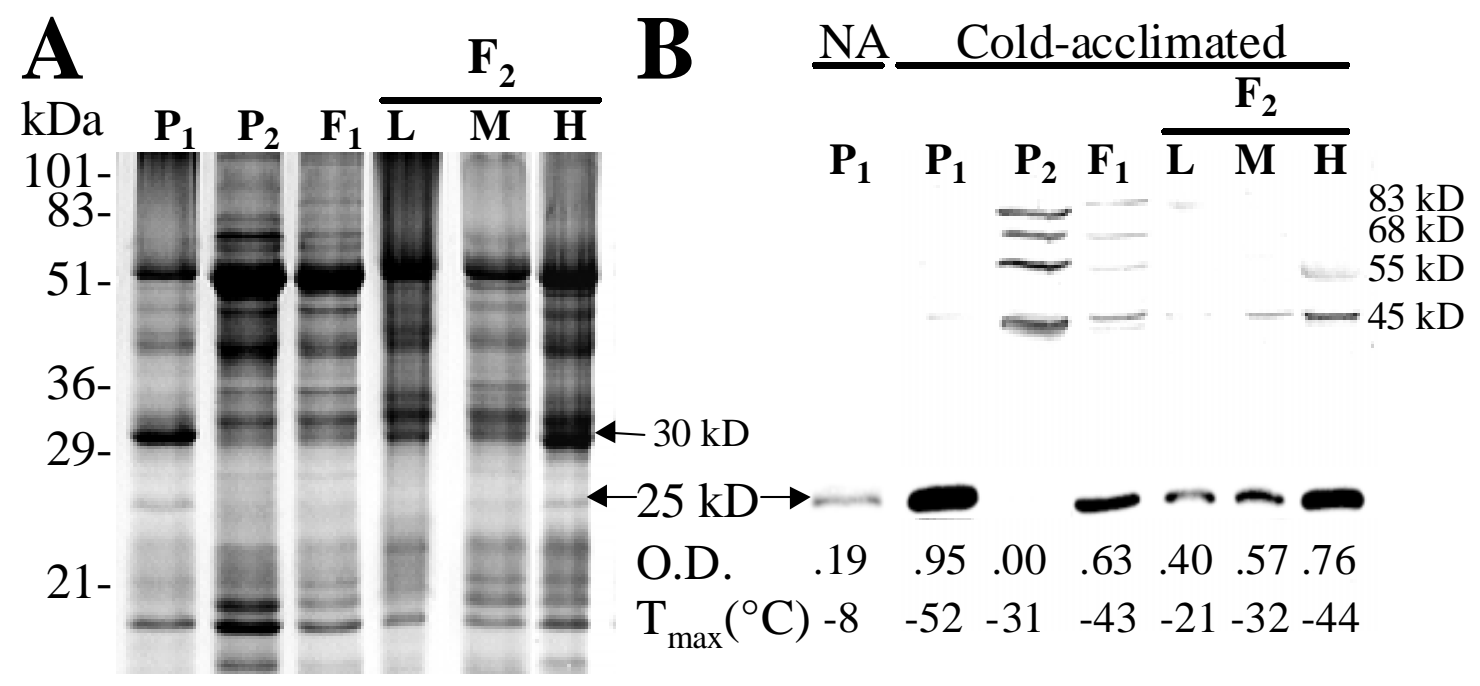


Fig. 2A, B Group 1 plants. (A) Anti-dehydrin immunoblots of nine individual $\mathrm{F}_{2}$ progenies. Protein $(15 \mu \mathrm{g})$ was loaded in each lane. (B) Regression analysis of LFT on dehydrin O.D. in the population comprised of parents, $\mathrm{F}_{1}$, and nine $\mathrm{F}_{2}$ progenies. O.D. optical densities, $T_{\max }$ quantitative measure of leaf freezing-tolerance

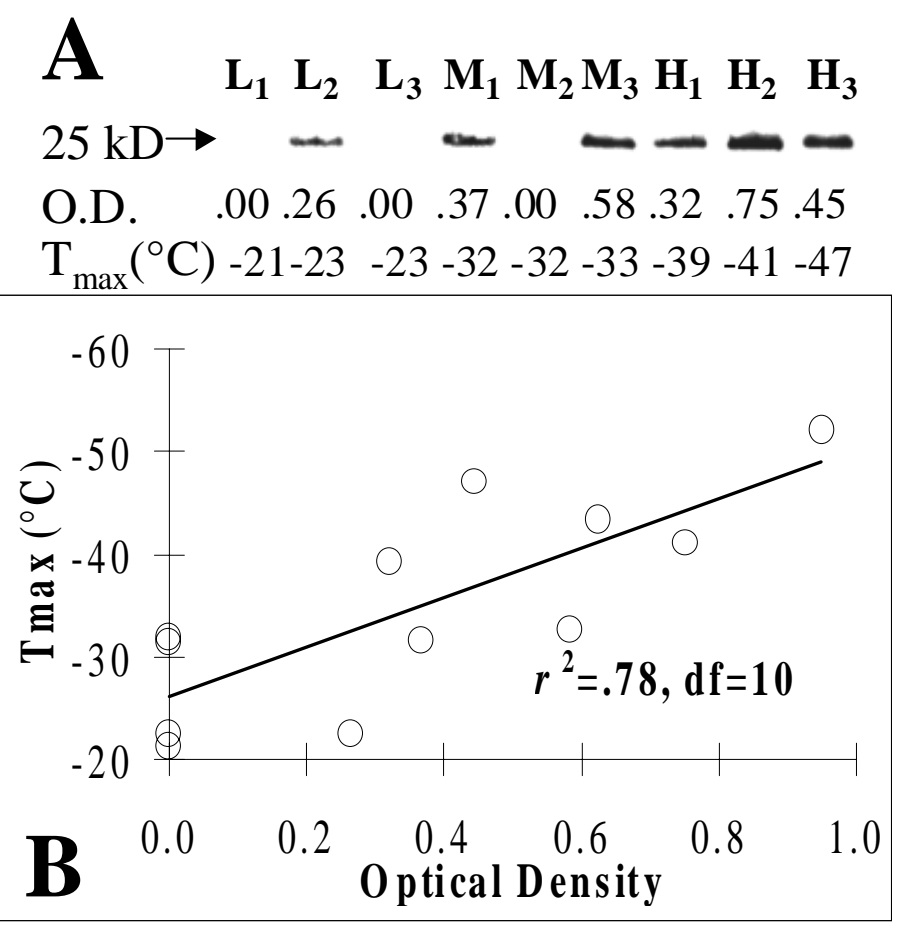


Fig. 3A, B Group 2 plants: Wild populations of $R$. maximum. (A) SDS-PAGE profiles of total soluble leaf proteins extracted from cold-acclimated state. Protein $(30 \mu \mathrm{g})$ was loaded in each lane. (B) Anti-dehydrin immunoblots of juvenile seedlings and mature plants. Protein $(15 \mu \mathrm{g})$ was loaded in each lane. $J$ juvenile seedlings (approx. 2-3 years-old), $M$ mature plants (approx. 30 years-old), O.D. optical densities, $T_{\max }$ quantitative measure of leaf freezingtolerance

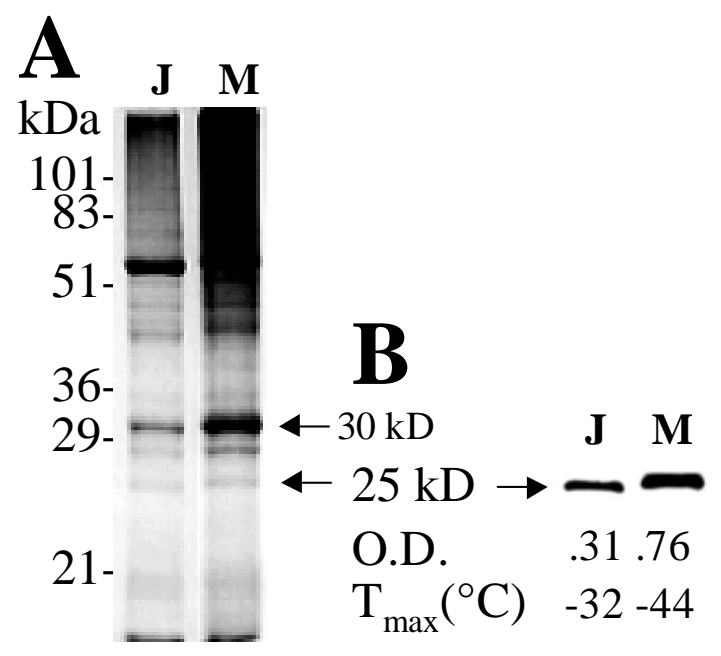


Fig. 4A, B Group 3 plants: $R$. 'Hawaii', R. 'Swansdown' and $R$. 'Pink Parasol' cultivars. (A) SDS-PAGE profiles of total soluble leaf proteins extracted from cold-acclimated state. Protein $(30 \mu \mathrm{g})$ was loaded in each lane. (B) Anti-dehydrin immunoblots of ramets (rootedcuttings) and ortets (stock plants). Protein $(15 \mu \mathrm{g})$ was loaded in each lane. $R$ ramet (approx. 4 years-old), $O$ ortet (approx. 30-40 years-old), O.D. optical densities, $T_{\max }$ quantitative measure of leaf freezing-tolerance

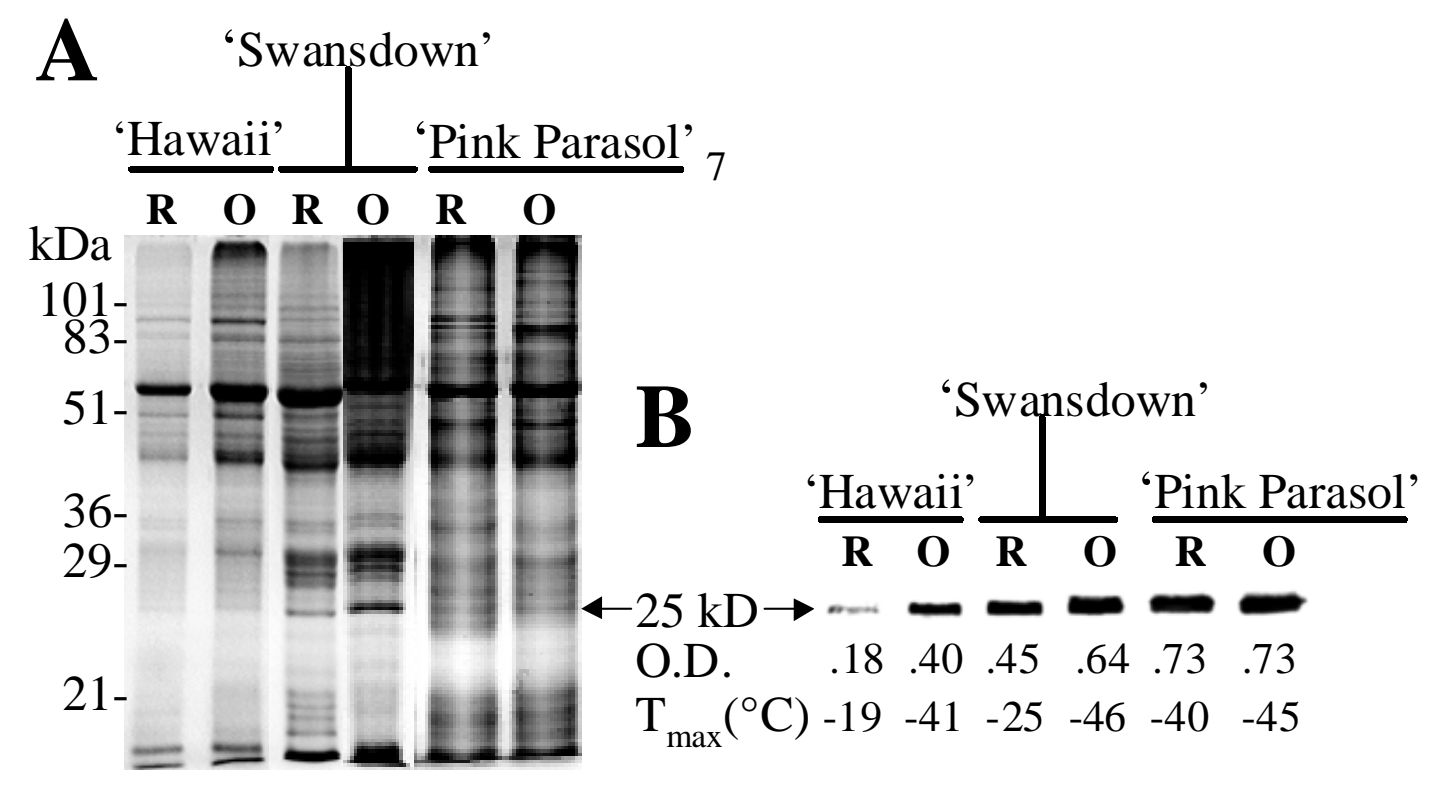




\title{
CHAPTER FIVE \\ PLANT AGE INFLUENCES LEAF FREEZING-TOLERANCE IN RHODODENDRON POPULATIONS
}

\begin{abstract}
Winter survival in woody plants is controlled by environmental and genetic factors that affect the plant's ability to cold acclimate. Because woody perennials are long-lived and often have a prolonged juvenile (pre-flowering) phase, it is quite possible that both chronological and physiological age factors influence adaptive traits such as stress tolerance. This study investigated the yearly cold hardiness $(\mathrm{CH})$ changes in several Rhododendron seedling populations and examined the relationship between leaf-freezing tolerance (LFT) and aging. Data from $\mathrm{F}_{2}(n=50)$ and backcross $(n=20)$ populations derived from $R$. catawbiense and $R$. fortunei parents indicated a significant increase in LFT of $\sim 5$ to $6{ }^{\circ} \mathrm{C} /$ year as the seedlings aged from 3-to 5-years old. A similar yearly increase was observed in comparisons of 1- and 2-yearold $\mathrm{F}_{1}$ progenies $(n=12)$ from a $R$. catawbiense $\mathrm{x} R$. dichroanthum cross. The feasibility of identifying hardy phenotypes at juvenile period and research implications of age-dependent changes in $\mathrm{CH}$ is discussed.
\end{abstract}

\section{INTRODUCTION}

Woody perennials typically go through a juvenile period of growth in which they remain vegetative and do not respond to flowering stimuli. This period of growth may last a few weeks in some plants and up to several years in certain shrub and tree species. Juvenility, and the associated phase-change to maturity, have strong influences on morphogenesis, tissue differentiation, and plant development (Hackett 1985, Zimmerman et al. 1985). 
Although phase change has been associated with a number of morphological, physiological, and biochemical alterations in plants (Hackett et al. 1990, Hand et al. 1996, Zimmerman et al. 1985), little is known about its effect on stress tolerance. Based on prior research, we postulated that age factors, possibly juvenility, were influencing cold hardiness (CH) in Rhododendron (Lim et al. 1998b and Lim et al. 1999). We observed that the leaf freezing-tolerance (LFT) distribution of a $\mathrm{F}_{2}$ seedling population (derived from a super-hardy $\mathrm{x}$ moderately-hardy cross) was skewed towards the moderate-hardy parent, and that the mean LFT of the $\mathrm{F}_{2}$ was lower than that of the moderate-hardy parent (Lim et al. 1998b). This unexpected result was explained by Lim et al. (1998b) as a possible effect of physiological and/ or chronological age on $\mathrm{CH}$, because the $\mathrm{F}_{2}$ was comprised of 3-year-old seedlings while the LFTs of parent plants were obtained from mature, 30-year-old individuals.

Although it is generally believed that juvenility influences woody plants' $\mathrm{CH}$, the notion is largely anecdotal. For example, Pellett (1998) observed that seedlings of Phellodendron sachalinense were easily killed by frosty weather in the Fall while mature plants suffered no visible damage. However, a systematic investigation of the relationship between juvenility, aging and $\mathrm{CH}$ has yet to be undertaken. The current study investigates these potential relationships in a variety of Rhododendron populations over consecutive years.

\section{MATERIAL AND METHODS}

Plant material. This study involved four different Rhododendron populations of naturally cold-acclimated plants. The current-year leaves of the same individual plants within a population (with the exception of wild population) were screened for two to three consecutive years between 1996 to 1998. All of the field-grown plants are maintained at the Holden Arboretum's Leach Research Station in Madison, OH. A natural, wild population of R. maximum plants were collected near Cooper's Rock State Forest, WV.

\section{Leaf freezing-tolerance (LFT) determination. Leaf discs $(1 \mathrm{~cm}$ diameter)} were punched from individual plants (24 discs per plant) and frozen to various treatment 
temperatures ( 3 discs per treatment temperature) to obtain electrolyte leakage data as described in Lim et al. (1998a). Ion leakage data transformations, Gompertz functions fitting and statistical analyses were also performed as described by Lim et al. (1998a) to obtain values for $\mathrm{T}_{\max }$ - the temperature at which the maximum rate of freezing injury occurs. In this study, $\mathrm{T}_{\max }$ is used synonymously with LFT as indicators of $\mathrm{CH}$.

$\mathbf{F}_{1}$ population. The $\mathrm{F}_{1}$ population was derived from a cross between a super coldhardy parent $\left(R\right.$. catawbiense, $\left.\mathrm{T}_{\max }=-52{ }^{\circ} \mathrm{C}\right)$ and a cold-tender parent $\left(R\right.$. dichroanthum, $\mathrm{T}_{\max }=-$ $16^{\circ} \mathrm{C}$ ). A collection of acclimated leaves from $12 \mathrm{~F}_{1}$ progeny was made in December 1997 (1year-old seedlings) and December 1998 (2-year-old seedlings).

$\mathbf{F}_{2}$ population. The $\mathrm{F}_{2}$ population was derived from the self-pollination of $R$. 'Ceylon' ( $\left.\mathrm{T}_{\max }=-43^{\circ} \mathrm{C}\right) . R$. 'Ceylon' is the $\mathrm{F}_{1}$ hybrid cultivar derived from the cross between a super cold-hardy parent $\left(R\right.$. catawbiense, $\mathrm{T}_{\max }=-52{ }^{\circ} \mathrm{C}$ ) and a moderately-hardy parent (R. fortunei, $\mathrm{T}_{\max }=-32{ }^{\circ} \mathrm{C}$ ). Cold acclimated leaves from $50 \mathrm{~F}_{2}$ progeny were collected and assayed in 1996 (3-year-old seedlings), and the $\mathrm{T}_{\max }$ distribution from that year was previously reported (Lim et al 1998b). A collection of acclimated leaves from the same progeny (4-year-old seedlings) was made in December 1997 and $\mathrm{T}_{\max }$ values were determined for each individual. Problems associated with low vigor of $F_{2}$ plants (most likely due to inbreeding depression) hindered LFT screening of the plants in 1998 and, thus, data for that year are not reported.

Backcross population. Leaf freezing-tolerances in reciprocal backcross (BC) populations - R. fortunei x 'Ceylon' and 'Ceylon' x R. fortunei - were determined for three consecutive years (1996 to 1998, 3-to 5-year-old seedlings). Collections of leaves from ten plants in each reciprocal cross were screened. Since the difference between the variances for mean $\mathrm{T}_{\max }$ in the reciprocal crosses was non-significant ( $F$-test not shown), the LFT data for the two backcrosses were pooled as a single (20 plants) BC population.

Natural population. Leaf collections from 12 wild $R$. maximum seedlings ( 1 to 3 yr-old) and 6 large mature plants ( 30-to 40-yr-old) were made (in 1996 \& 1997) and their 
individual LFTs were determined. Unlike other populations, identical plants could not be used in this population from year to year. This population was included in this study to compare LFTs for juvenile seedlings with that of mature plants. Data for the two years were pooled and presented as a unit.

\section{RESULTS}

With the exception of $R$. dichroanthum, the $\mathrm{T}_{\max }$ values of the parents used in these crosses have previously been reported (Lim et al. 1998b and Lim et al. 1999). Average $\mathrm{T}_{\max }$ of $R$. dichroanthum is about $-16^{\circ} \mathrm{C}$ (Table 1$)$.

$F_{1}$ population. The average $T_{\max }$ of the $12 F_{1}$ plants increased significantly from 1997 to 1998 (Table 1). Overall hardiness of individual $F_{1}$ progenies increased with at least eight of them having significant hardiness increments (Table 2), thus elevating the overall population hardiness by $\sim 7^{\circ} \mathrm{C}$.

$\mathbf{F}_{2}$ population. The $\mathrm{T}_{\max }$ data for $50 \mathrm{~F}_{2}$ progeny exhibited a continuous distribution (Fig. 1). Mean $\mathrm{T}_{\max }$ for the $\mathrm{F}_{2}$ population increased (by $\sim 6^{\circ} \mathrm{C}$ ) significantly from $-27.5^{\circ} \mathrm{C}$ in 1996 to $-33.9^{\circ} \mathrm{C}$ in 1997 (Table 1). The majority (46 out of 50) of progenies exhibited an increase in $\mathrm{T}_{\max }$ from 1996 to 1997 with 31 plants having a significant hardiness increment (Table 2). When the individual $F_{2}$ progenies were arranged from tender to hardy based on their average $T_{\max }$ and plotted against yearly $T_{\max }$ changes (from 1996 and 1997), a variable increment of hardiness by individual progenies was noted (Fig. 2), regardless of the progenies being "coldtender" or "cold-hardy".

Backcross population. The BC population was screened for LFT in three consecutive years. Mean $\mathrm{T}_{\max }$ of these progenies increased consistently over the three years from 1996 to 1998 by $\sim$ to $5{ }^{\circ} \mathrm{C}$ (Fig. 3, Table 1). Number of progenies with significant improvement in $\mathrm{CH}$ also increased from year to year (Table 2). Most individual progeny data indicated a 
yearly increase in hardiness regardless of progenies being "cold-tender" or "cold-hardy" (Fig. 4). However, the magnitudes of $\mathrm{CH}$ increments were uneven from year-to-year, as evidenced by rank correlations (Fig. 5). Hardiness rankings based on 1997 data deviated sharply from the 1996 rankings, while there was a fairly good correspondence between 1998 and 1997 rankings. In field observations we also noted that some progenies in the $\mathrm{BC}$ population had set flower buds in 1998, an indication of phase-change.

Natural population. The juvenile seedlings of the $R$. maximum population were observed to be significantly less-hardy (by $\sim 9^{\circ} \mathrm{C}$ ) than the mature plants (Table 3 ), even though all plants are growing within the same vicinity of each other.

\section{DISCUSSION}

Leaf freezing-tolerance increases with age. The data presented in this study indicate that there are yearly average increases in LFT of about $5-6^{\circ} \mathrm{C}$ during the juvenile period of Rhododendron seedling growth. This trend was observed in $\mathrm{F}_{1}, \mathrm{~F}_{2}$ and $\mathrm{BC}$ populations segregating for $\mathrm{T}_{\max }$. In Rhododendron, these shifts in average LFT most likely reflect an increased ability to cold acclimate.

Prior data have suggested that chronological age differences in non-juvenile Rhododendron can influence $\mathrm{CH}$, with older plants being more hardy (Lim et al. 1998b). It is possible that the age differences observed here in juvenile material were also due to chronological effects such as biomass accumulation and higher wood content. However, gradual loss of juvenility as these seedlings approached maturity ( $\sim 5$ years from seed in Rhododendron) may have also played a role in increased $\mathrm{CH}$. Age changes during the juvenile period are not usually associated with distinctive changes in any one characteristic (Hackett 1985).

Further studies of these populations, particularly at the post-flowering stage, will be required to determine whether maturity has any significant impact on average $\mathrm{CH}$ performance, and the duration of LFT increases. The incremental increase in $\mathrm{CH}$ at the seedling stage does not go on indefinitely, since our data show that in much older plants (20-to 40-year-old cultivated 
and naturally-occurring clones) $\mathrm{T}_{\max }$ is stabilized from year to year (Lim et al. 1998b). It is also interesting to note that Lim et al. (1999) recently found an association between dehydrin -heatstable proteins that are induced in response to plant stresses- and $\mathrm{CH}$ in Rhododendron and the relationship is also influenced by juvenility effects.

\section{Identifying cold-hardy phenotypes at juvenile stage. The ability to} predict mature plant performance by ranking $\mathrm{CH}$ in juvenile Rhododendron populations based on $\mathrm{T}_{\max }$ distributions would be of great value in breeding programs. However, our data indicate that, although mean $\mathrm{T}_{\max }$ of $\mathrm{F}_{1}, \mathrm{~F}_{2}, \mathrm{BC}$ and natural populations increase yearly, the annual increment of $\mathrm{CH}$ in juvenile progenies are not always uniform. In other words, there were varying degrees of $\mathrm{CH}$ increment in individual progenies from year to year; some exhibited high while others exhibited low yearly increase in $\mathrm{CH}$, irrespective of their relatively "tender" or "hardy" rankings. It is important to note that $\mathrm{T}_{\max }$ of mature/ parental plants ( $R$. catawbiense, $R$. fortunei, $R$. dichroanthum, $R$. 'Ceylon' and $R$. maximum) did not change significantly over 2 to 3 years of CH evaluation (Lim et al. 1998b, Lim et al. 1999).

We therefore conclude that the maximum (or 'true') cold acclimation potential of these populations could not be realized until they reached reproductive maturity. It is also probable that the relative $\mathrm{CH}$ rankings of progenies (within a population) determined at juvenile stage may not hold true when maturity is attained, and that yearly $\mathrm{CH}$ fluctuations will stabilize once the progenies mature. This notion is supported by a relatively less variable (and thus more uniform) yearly increment in $\mathrm{CH}$ observed for the BC population as they matured. Nevertheless the LFT method is still a valid predictor of $\mathrm{CH}$ within a year or particularly when the plants are fully matured as is evidenced by the populations' parental data.

\section{ACKNOWLEDGEMENTS}

We sincerely thank Mohd. Salleh Daim and Hatice S. Gulen for their technical assistant on evaluating the Rhododendron LFT. 


\section{LITERATURE CITED}

Hackett WP (1985) Juvenility, maturation, and rejuvenation in woody plants. Horticultural Rev 7:109-155

Hackett WP, Murray JR, Woo HH, Stapfer RE, Geneve R (1990) Cellular, biochemical and molecular characteristics related to maturation and rejuvenation in woody species. In Rodriguez R (ed) Plant Aging: Basic and Applied Approaches. Plenum Press, New York, pp. $147-152$

Hand P, Besford RT, Richardson CM, Peppitt SD (1996) Antibodies to phase related proteins in juvenile and mature Prunus avium. Plant Growth Regulat 20:25-29

Lim CC, Arora R, Townsend ED (1998 a) Comparing Gompertz and Richards functions to estimate freezing injury in Rhododendron using electrolyte leakage. J Amer Soc Hort Sci $123: 246-252$

Lim CC, Krebs SL, Arora R (1998 b) Genetic study of freezing tolerance in Rhododendron populations: Implications for cold hardiness breeding. J Amer Rhododendron Soc 52:143148

Lim CC, Krebs SL, Arora R (1999) A 25 kD Dehydrin Associated with Genotype-and AgeDependent Leaf Freezing-Tolerance in Rhododendron: A genetic marker for cold hardiness? Theor Appl Genet 99:910-918

Pellet H (1998) Breeding of cold hardy woody landscape plants. In: Li PH, Chen THH (eds) Plant Cold Hardiness: Molecular biology, Biochemistry, and Physiology. Plenum Press, New York, pp. 317-324

Zimmerman RH, Hackett WP, Pharis RP (1985) Hormonal aspects of phase change and precocious flowering. Encyclopedia of Plant Physiology. New series 11: 79-115 
Table 1. Average cold acclimated leaf freezing-tolerance $\left(\mathrm{T}_{\max }\right)$ in Rhododendron parents and populations segregating for freezing tolerance

\begin{tabular}{|c|c|c|c|c|}
\hline & \multirow[b]{2}{*}{$\mathrm{N}^{\mathrm{y}}$} & \multicolumn{3}{|c|}{ Average $T_{\max } \pm$ std. error ${ }^{z}$} \\
\hline & & 1996 & 1997 & 1998 \\
\hline \multicolumn{5}{|l|}{ Parental plant } \\
\hline R. dichroanthum & 1 & ------ & $-17.5 \pm 1.4^{\mathrm{a}}$ & $-15.7 \pm 2.6^{\mathrm{a}}$ \\
\hline \multicolumn{5}{|l|}{ Populations } \\
\hline \multicolumn{5}{|l|}{$\overline{\mathrm{F}_{1}-R . \text { catawbiense } \mathrm{x}}$} \\
\hline R. dichroanthum & 12 & ------ & $-16.1 \pm 0.6^{\mathrm{a}}$ & $-22.8 \pm 2.1^{b c}$ \\
\hline $\mathrm{F}_{2}-R$. 'Ceylon' x $R$. 'Ceylon' & 50 & $-27.5 \pm 0.8^{d}$ & $-33.9 \pm 0.9^{\mathrm{e}}$ & ------ \\
\hline $\begin{array}{c}\mathrm{BC}-R . \text { 'Ceylon' x } R . \text { fortunei or } \\
R . \text { fortunei } \mathrm{x} R \text {. 'Ceylon' }\end{array}$ & 20 & $-19.0 \pm 1.5^{a b}$ & $-22.7 \pm 0.6^{\mathrm{c}}$ & $-28.3 \pm 0.9^{d}$ \\
\hline
\end{tabular}

${ }^{\mathrm{z}}$ Estimated by using Gompertz function fitted to $\%$ adjusted injury data, mean \& std. errors estimated by replicates (24 leaf discs) using the Jackknife method (Lim et al., 1998a). Mean separation in row by multiple $t$-test, significant at $P<0.05$

${ }^{\mathrm{y}} \mathrm{N}=$ number of plants. Three replicate discs were measured at each treatment temperature 
Table 2. Significant increment in leaf freezing-tolerance $\left(\mathrm{T}_{\max }\right)$ in Rhododendron population from year-to-year

\begin{tabular}{|c|c|c|c|c|}
\hline \multirow[b]{2}{*}{ Cold-acclimated (December) populations } & \multirow[b]{2}{*}{$\mathrm{N}$} & \multicolumn{3}{|c|}{ \# plants having significant increase in $\mathrm{T}_{\max }$} \\
\hline & & 96 to 97 & 97 to 98 & 96 to 98 \\
\hline $\mathrm{F}_{1}-R$. catawbiensi $\mathrm{x} R$. dichroanthum & 12 & ---- & $8(66.7 \%)$ & ---- \\
\hline $\mathrm{F}_{2}-R$. 'Ceylon' $\mathrm{x} R$. 'Ceylon' & 50 & $31(62 \%)$ & --- & ---- \\
\hline $\begin{array}{c}\mathrm{BC}-R . \text { 'Ceylon' } \mathrm{x} R . \text { fortunei or } \\
R . \text { fortunei } \mathrm{x} R . \text { 'Ceylon' }\end{array}$ & 20 & $8(40 \%)$ & $10(50 \%)$ & $16(80 \%)$ \\
\hline
\end{tabular}

Table 3. Leaf freezing-tolerance $\left(\mathrm{T}_{\max }\right)$ differences between juvenile and mature plants of natural Rhododendron maximum populations

\begin{tabular}{lcc}
\hline$R$. maximum (natural population) & $\mathrm{N}^{\mathrm{z}}$ & Mean $_{\max }\left({ }^{\circ} \mathrm{C}\right) \pm$ std. error $^{\mathrm{y}}$ \\
\hline Juvenile seedlings & 12 & $-37.6 \pm 1.7^{\mathrm{b}}$ \\
Mature plants & 6 & $-46.8 \pm 1.6^{\mathrm{a}}$ \\
\hline
\end{tabular}

${ }^{\mathrm{z}} \mathrm{N}=$ number of plants. Three replicate discs were measured at each treatment temperature

${ }^{y}$ Estimated by using Gompertz function fitted to $\%$ adjusted injury data, mean \& std. errors estimated by replicates (24 leaf discs) using the Jackknife method (Lim et al., 1998a). Mean separation in column by multiple $t$-test, significant at $P<0.05$ 
Fig. 1 Cold hardiness $\left(\mathrm{T}_{\max }\right)$ distribution of a $\mathrm{F}_{2}$ population: (A) December 1996; (B) December 1997. $\mathrm{N}=$ number of plants

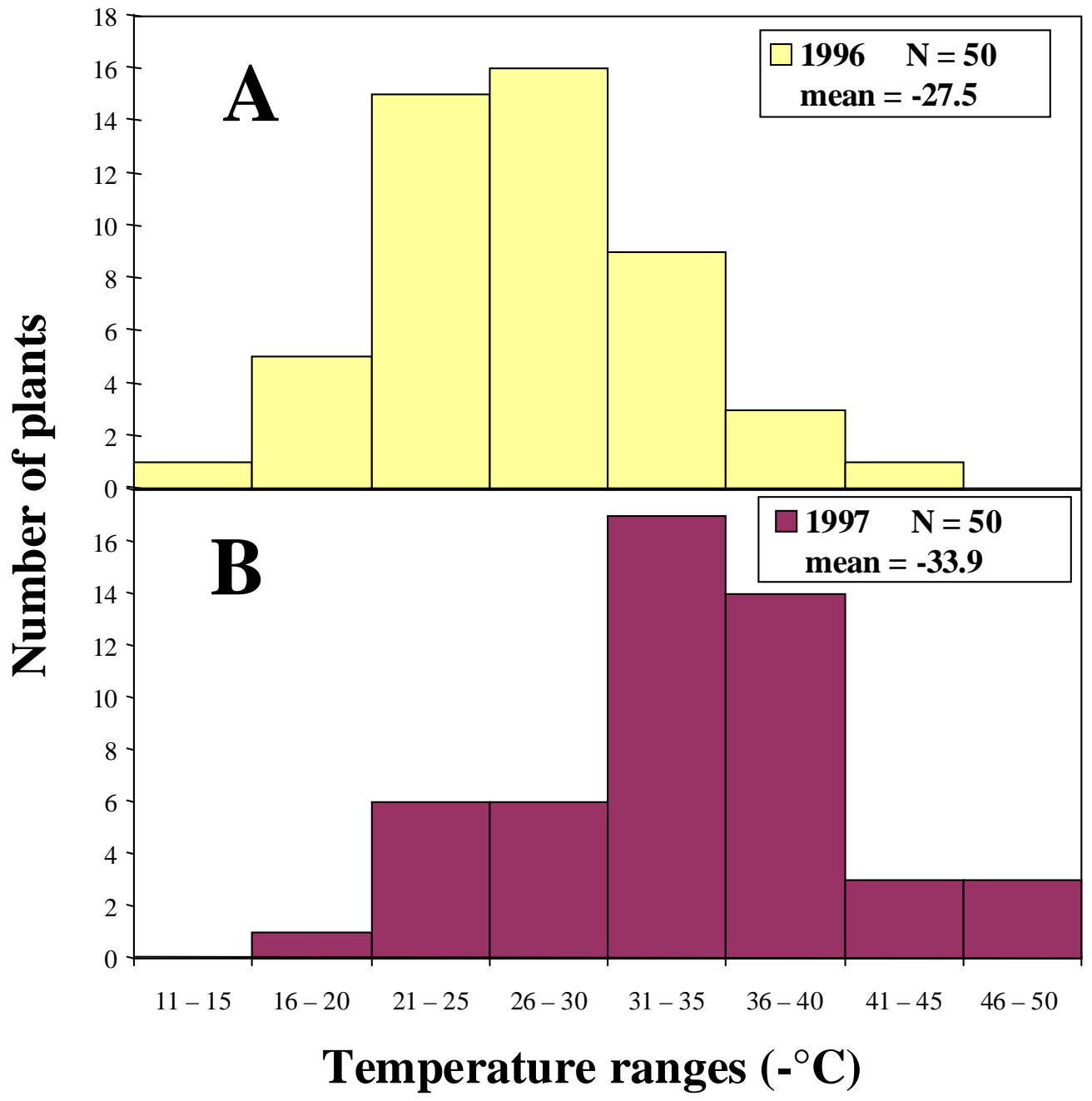


Fig. 2 Changes in cold hardiness $\left(\mathrm{T}_{\max }\right)$ of individual $\mathrm{F}_{2}$ progeny from December 1996 to 1997. Individual progeny are ranked from tender (left) to hardy (right) based on the mean $\mathrm{T}_{\max }$ (average of 1996 \& 1997)

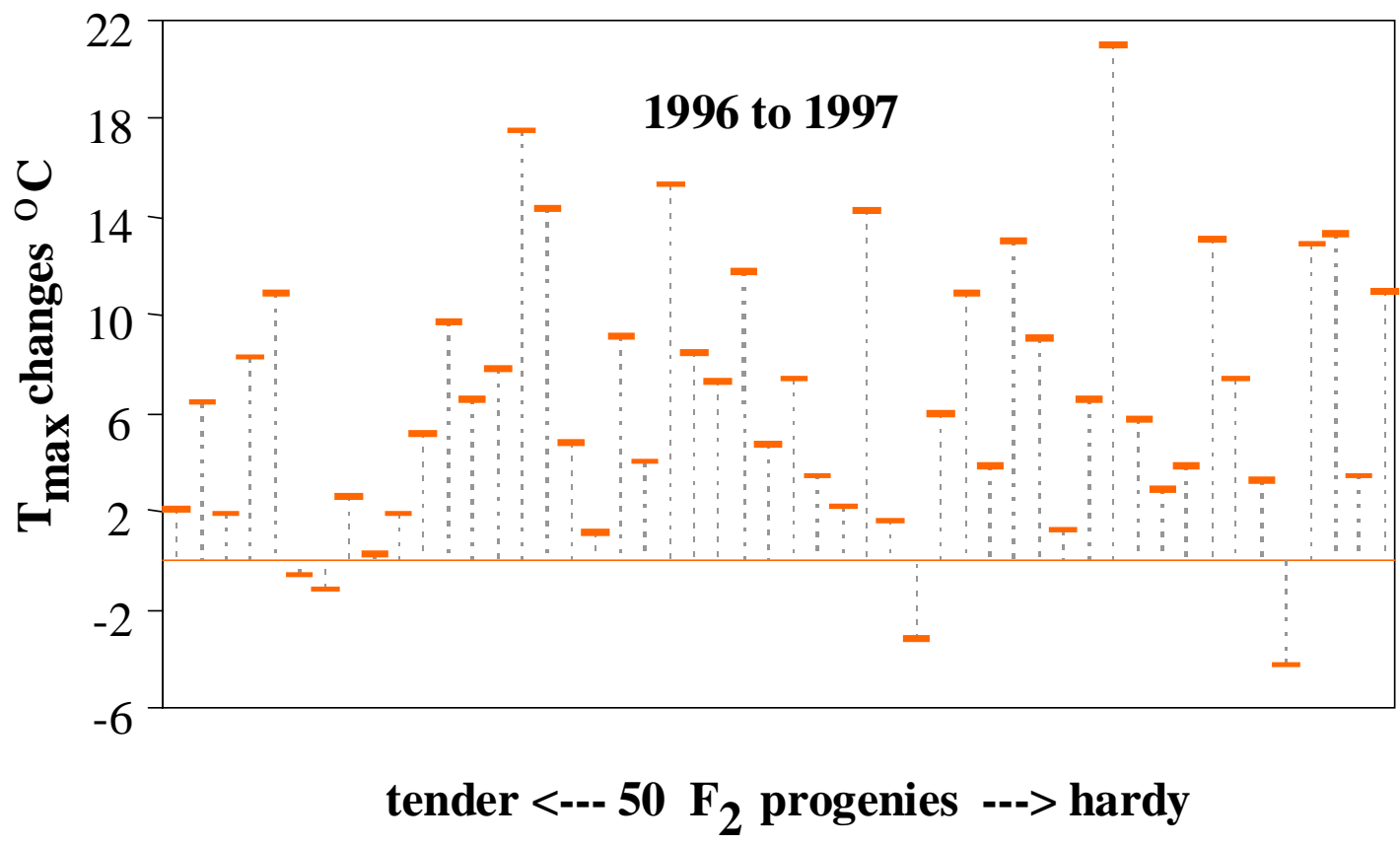


Fig. 3 Cold hardiness $\left(\mathrm{T}_{\max }\right)$ distribution of a BC population: (A) December 1996; (B) December 1997; (C) December 1998. N = number of plants

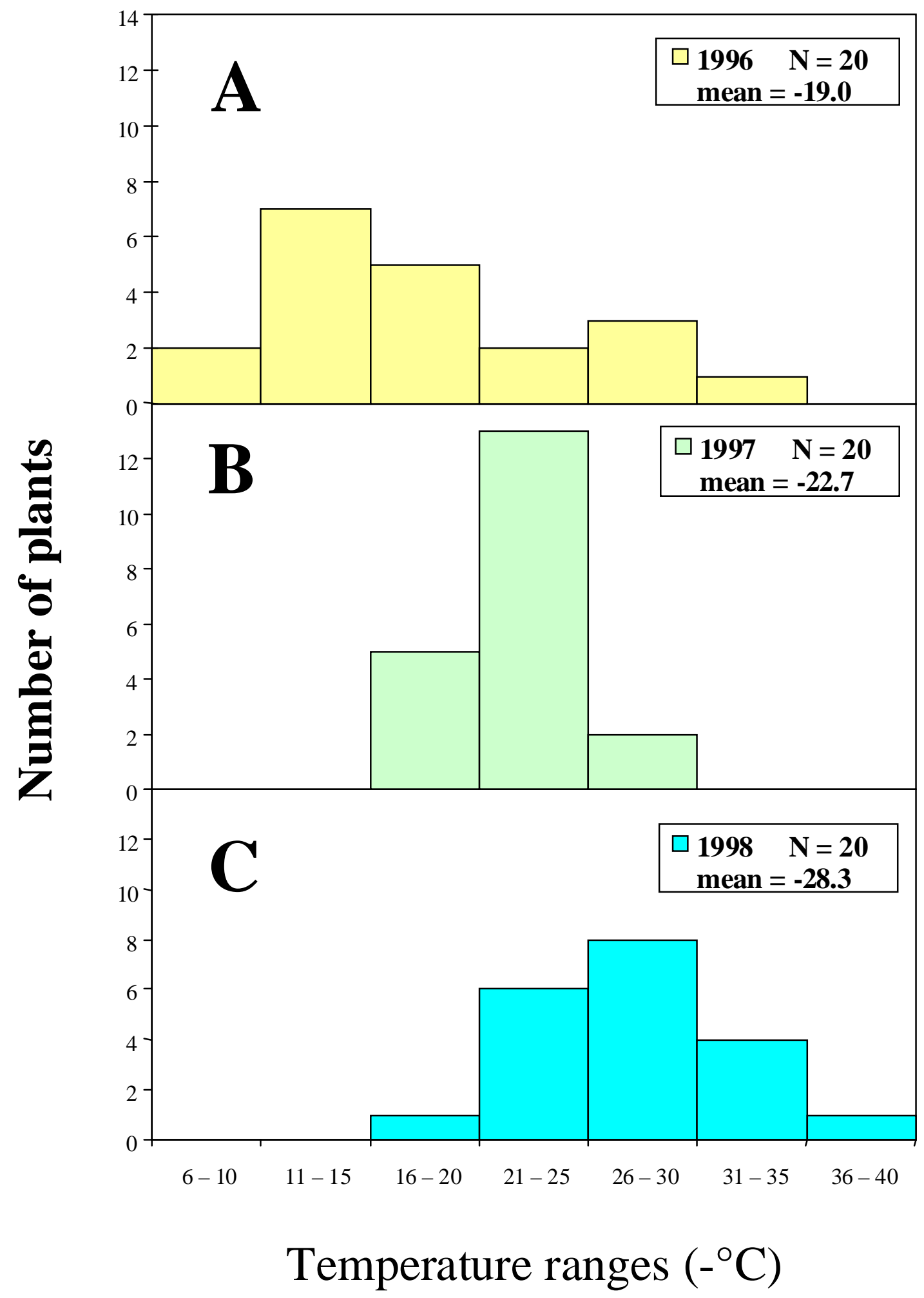


Fig. 4 Changes in cold hardiness $\left(\mathrm{T}_{\max }\right.$ ) of individual BC progeny from December 1996 to 1997 and 1996 to 1998. Individual progeny are ranked from tender (left) to hardy (right) based on the mean $\mathrm{T}_{\max }$ (average of 1996, $1997 \& 1998$ )

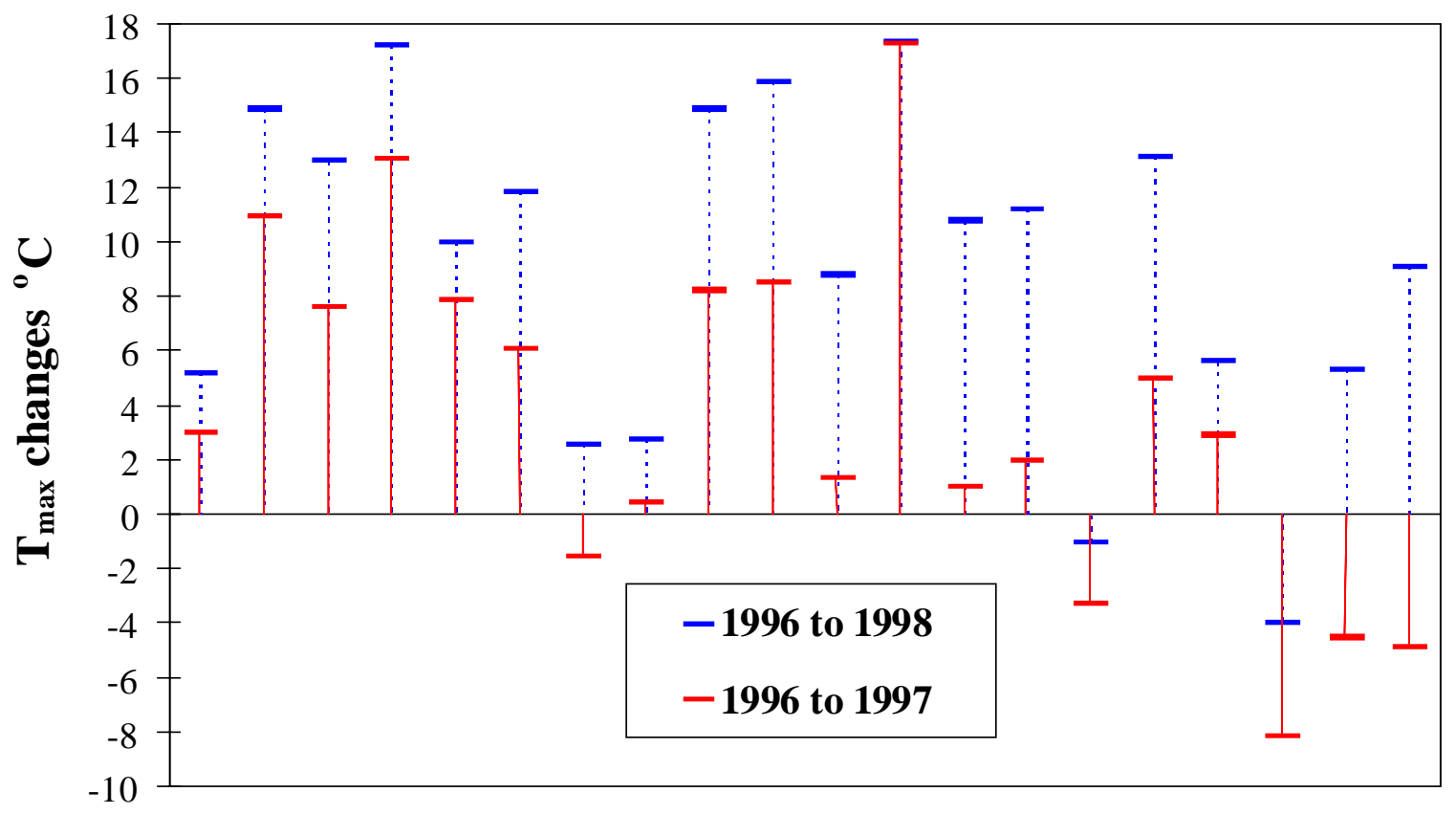

tender <--- 20 BC progenies ---> hardy 
Fig. 5 Relationship between the cold hardiness $\left(\mathrm{T}_{\max }\right)$ of individual $\mathrm{BC}$ progeny in successive years: (A) 1996 vs. 1997; (B) 1997 vs. 1998
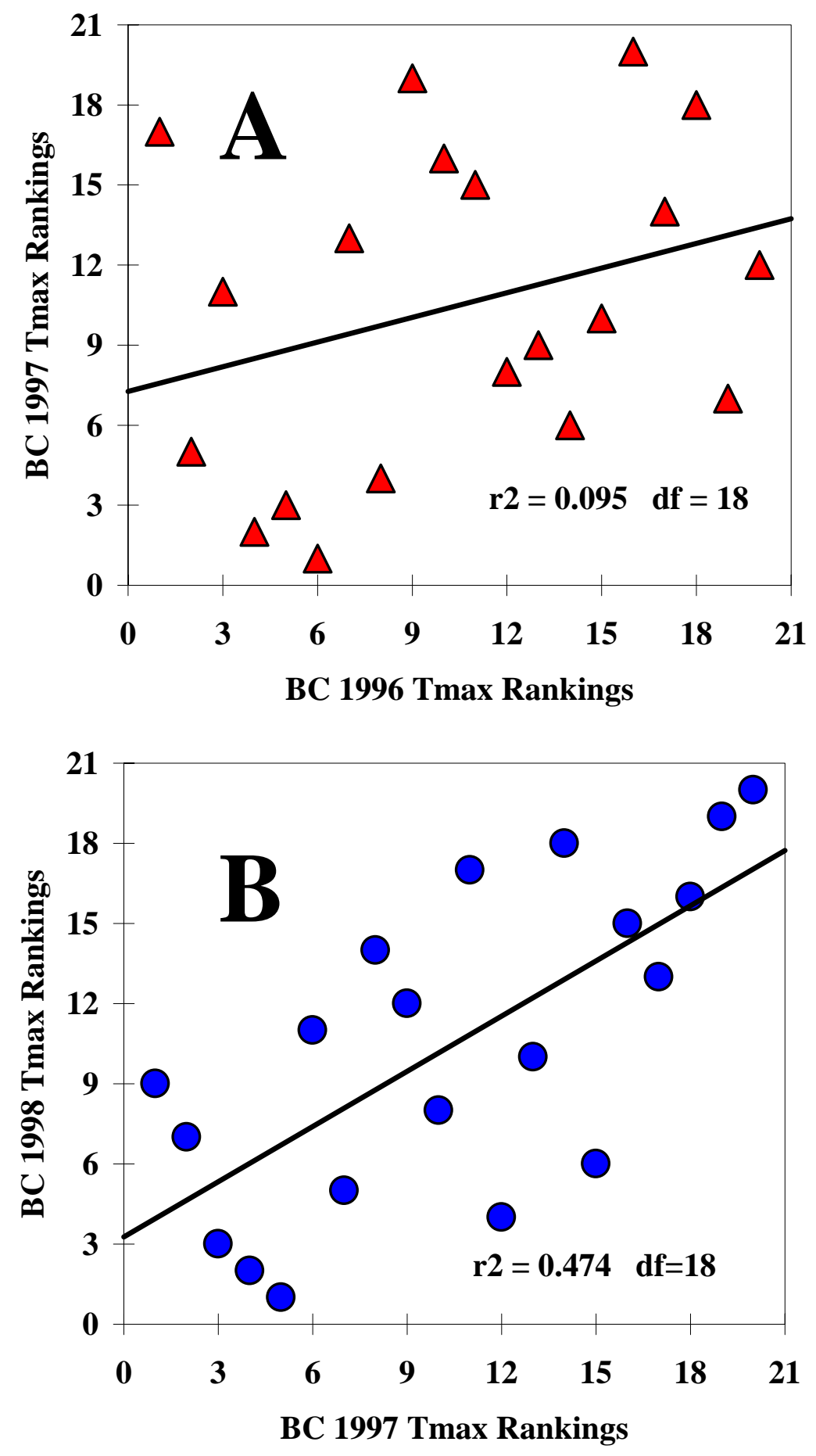


\section{CHAPTER SIX \\ DETECTING MOLECULAR MARKERS FOR COLD \\ HARDINESS IN RHODODENDRON POPULATIONS BY \\ BULKED SEGREGANT ANALYSIS}

\section{INTRODUCTION}

Leaf freezing-tolerance (LFT) is an important trait that should be incorporated into breeding programs for Rhododendron. However, considerable efforts are needed to generate the LFT data. The laboratory assays are costly, time consuming and labor intensive. Furthermore, other factors (such as juvenility as indicated in earlier chapter 5) may influence the outcome of the seedlings' cold hardiness $(\mathrm{CH})$ evaluation. Therefore, it would be useful to identify genetic markers that are closely linked to the $\mathrm{CH}$ trait for rapid selection of suitable germplasm.

The search for quantitative trait (like $\mathrm{CH}$ ) markers can be rather complicated. However, the identification of these markers might be facilitated by utilizing a procedure called bulk segregant analysis. Bulk segregant analysis allows for the rapid screening of many loci and identification of segregating markers (Michelmore et al. 1991). The analytical basis of this technique is the creation of bulk samples of DNA by pooling DNA from similar individuals within a population segregating for the trait. Each of the bulk DNA samples will contain a random sample of all the loci in the genome, with the exception of the region of the gene of interest and any linked, flanking regions. The two phenotypic bulks can be screened for polymorphisms using randomly amplified polymorphic DNA (RAPD) markers. RAPD techniques rely on the differential enzymatic amplification of small DNA fragments in polymerase chain reaction (PCR) with arbitrary oligonucleotide primers (Williams et al. 1990). RAPD markers provide an efficient way of identifying new loci because they require only small amounts of DNA, involve no radioactivity, and can be generated in abundance. Any difference 
in RAPD pattern between two phenotypic represents a potential linkage to the locus of interest, assuming there are no complex linkages.

Using bulk segregant analysis and RAPD method, Penner et al. (1993) found a RAPD marker for the crown rust resistance gene in oat while Poulsen et al. (1995) found a RAPD marker linked to leaf rust resistance in barley. In this study, we utilized bulked segregant analysis and RAPD analysis for screening of two bulks (low and high cold-tolerance) of Rhododendron $\mathrm{F}_{2}$ progenies segregating for the $\mathrm{CH}$ trait, in an attempt to identify molecular markers linked with LFT. A marker for $\mathrm{CH}$ would be of great benefit to Rhododendron breeders and researchers in screening young plants at an early age without having to wait for a test winter in the field or for flower buds to develop.

\section{MATERIAL AND METHODS}

Plant material. The experiment involved 15 different $\mathrm{F}_{2}$ Rhododendron progenies derived from the self-pollination of $R$. 'Ceylon' $\left(-43{ }^{\circ} \mathrm{C}\right) . R$. 'Ceylon' is the $\mathrm{F}_{1}$ hybrid cultivar derived from the cross between a super cold-hardy parent $\left(R\right.$. catawbiense, $\left.-52{ }^{\circ} \mathrm{C}\right)$ and a moderately-hardy parent $\left(R\right.$. fortunei, $-32{ }^{\circ} \mathrm{C}$ ). The LFT of these $\mathrm{F}_{2}$ progenies (3-to 4-year-old seedlings) were estimated in December 1996 and 1997. The LFT methodology and $\mathrm{T}_{\max }$ values (temperature causing maximum injury, used synonymously with LFT as indicators of $\mathrm{CH}$ ) have been previously reported (Lim et al. 1998). The $\mathrm{F}_{2}$ population as a whole segregated for $\mathrm{CH}$ and 10 progeny from high and low 'tails' of the $\mathrm{CH}$ distribution were selected for RAPD analysis. Each group of 10 plants differed in mean $\mathrm{T}_{\max }$ by $\sim 15^{\circ} \mathrm{C}$. All of the field-grown plants are maintained at the Holden Arboretum's Leach Research Station in Madison, $\mathrm{OH}$.

DNA isolation. Newly emerging leaves $(1.3 \mathrm{~g})$ were collected from selected plants in June 1998, ground finely in $\mathrm{LN}_{2}$ and stored in a $-80{ }^{\circ} \mathrm{C}$ freezer until used. DNA was extracted using the CTAB (Hexadecyltrimetryl-ammomium bromide) method according to Marquard et al. (1997). Extraction buffer [10 ml CTAB buffer (2\% CTAB, $100 \mathrm{mM}$ Tris-HCl pH 8, $20 \mathrm{mM}$ 
EDTA pH 8, 1.4 M NaCl) $+20 \mu \mathrm{l} \beta$-mercapthoethanol in 15-ml Corning tubes] was pre-warmed at $65^{\circ} \mathrm{C}$ for 30 to 45 minutes. Warmed extraction buffer was poured into $50-\mathrm{ml}$ Corning tubes containing $1.3 \mathrm{~g}$ of frozen samples. Extraction buffer and samples were quickly mixed with a sterile glass stir rod, then incubated in water bath at $65{ }^{\circ} \mathrm{C}$ for $1 \mathrm{~h}$ with occasional gentle swirling. After $1 \mathrm{~h}$ of incubation in a water bath, samples were transferred into 50-ml Oak Ridge tubes. An equal volume $(\sim 12 \mathrm{ml})$ of freshly made chloroform:isoamyl alcohol (24:1) mixture was added to each sample. Samples were gently mixed by inversion and the lids were cracked to let pressure escape 3 to 4 times. Tubes were balanced with extraction buffer and centrifuged at $6000 g_{\mathrm{n}}$ at room temperature for 12 minutes, carefully removed from centrifuge and placed on a slant rack. The aqueous (upper) phase was removed from each tube with slant-cut pipet tips and placed into cold 15-ml Corning tubes sitting in ice. DNA is precipitated from the sample by adding 0.6 volumes of cold isopropanol (about $6 \mathrm{ml}$ ) and gently inverted. Samples were then chilled at $-20^{\circ} \mathrm{C}$ for $2 \mathrm{~h}$ with gentle inversion occasionally. After chilling, samples were balanced with isopropanol and centrifuged at $1,400 g_{\mathrm{n}}$ for 12 minutes at $4{ }^{\circ} \mathrm{C}$. The supernatant was carefully removed and the DNA pellet was washed with DNA wash buffer (76\% alcohol, $10 \mathrm{mM}$ ammonium acetate) for $2 \mathrm{~h}$ at $4{ }^{\circ} \mathrm{C}$ (or longer). After washing, samples were centrifuged at 1,800 $g_{\mathrm{n}}$ for 12 minutes at $4{ }^{\circ} \mathrm{C}$. The DNA wash buffer was removed and the DNA pellet was air-dried by placing tubes in an inverted and slanted position overnight at room temperature. DNA was resuspended in $400 \mu \mathrm{TE}$ buffer $(10 \mathrm{mM}$ Tris- $\mathrm{HCl} \mathrm{pH} 8,0.2 \mathrm{mM}$ EDTA $\mathrm{pH}$ 8). To facilitate faster resuspension of the DNA pellet, tubes containing samples were placed in a water bath at $37^{\circ} \mathrm{C}$ (for 1-2 h) and gently agitated until the pellet dissolved (or left overnight at $4{ }^{\circ} \mathrm{C}$ ).

DNA Quantification Protocol. DNA was quantified by running known standards of genomic DNA along with samples. A $6 \mathrm{~mm}$ thick $0.8 \%$ agarose gel was prepared on 0.5X TBE buffer (45 mM Tris base, $45 \mathrm{mM}$ Boric acid, $1 \mathrm{mM}$ EDTA, adjusted to $\mathrm{pH} 8$ ). Agarose plus buffer was placed in a microwave and heated at high for $30 \mathrm{~s}$, then taken out and swirled. Heating was repeated until it boiled (twice). Agarose was cooled for 20 min before adding ethidium bromide ( $5 \mu \mathrm{l}$ of $10 \mathrm{mg} / \mathrm{ml}$ per $100 \mathrm{ml}$ gel). It was quickly swirled and poured onto a gel rig, left at room temperature for at least $1 \mathrm{~h}$. Two liters of gel running buffer $(0.5 \mathrm{X}$ TBE) were prepared. Standards were prepared from a 4:1 (v/v) ratio of DNA Mass Ladder: $6 X$ 
loading dye $(0.25 \%$ Bromophenol blue, $30 \%$ glycerol). Five or $10 \mu \mathrm{l}$ of genomic and sample DNA were loaded onto an agarose gel. The gel was run for $3.5 \mathrm{~h}$ at 140 constant volts. After running, the gel was placed on UV illuminator and documented with Polaroid instant black and white film. Sample concentration was estimated by comparing ethidium bromide staining intensity of the samples with that of known standards. Low and high cold-tolerance bulks were made by pooling equal amounts of DNA ( 810 ng DNA from each progeny).

PCR reaction and RAPD primers. All reactions were performed in $0.5 \mathrm{ml}$ microcentrifuge tubes with $25 \mu \mathrm{l}$ reaction mix (1X PCR buffer, $2 \mathrm{mM} \mathrm{MgCl}_{2}, 0.1 \mathrm{mM} \mathrm{dNTPs}$, $0.2 \mathrm{mM}$ Primer, 1 unit of Taq and $5 \mu \mathrm{l}$ sample DNA [approximately $25 \mathrm{ng}$ DNA]). Preliminary experiments showed that $6.25 \mathrm{ng}$ of DNA template provided the best resolution on the gels and this amount was used as a DNA template for all reactions unless otherwise specified. For primers, 200 high GC content 10-mer oligonucleotides (commercially available from UBC, Canada) were used in this study. High GC primers were selected due to their relatively higher likelihood of amplifying distinct DNA bands when used with other woody plants (Rowland LJ, personal communication). Once reaction mixtures were put together, microfuge tubes were loaded into a thermal cycler programmed to denature DNA at $94{ }^{\circ} \mathrm{C}$ for $1 \mathrm{~min}$, anneal primers at $35^{\circ} \mathrm{C}$ for $1 \mathrm{~min}$ and extend DNA template with dNTPs at $72{ }^{\circ} \mathrm{C}$ for $2 \mathrm{~min}$. The amplification continued for 44 cycles before cooling-down to $4{ }^{\circ} \mathrm{C}$.

Gels were prepared essentially as in DNA quantification experiments, except for containing $1.2 \%$ agarose. Commercially available 100 base pair standards (GibcoBRL, NY) for PCR products were mixed in a 1:1:5 (v: v: v) ratio of base pair standard: $6 \mathrm{X}$ dye: $\mathrm{H}_{2} 0$. Entire PCR products were loaded onto the gel. Gel running conditions and visualization of bands were done as in DNA quantification. DNA bands between bulks were compared. The primary screen involved all 200 primers with bulked DNA samples. Potential primers from the primary screen were used in a second screen of DNA bulks (varying in DNA concentration). Potential markers from the second screen were selected for a third screen of individual progeny DNA samples. 


\section{RESULTS}

Leaf freezing-tolerance. Due, presumably, to inbreeding depression and low vigor, some progeny selected for bulking were not available and were excluded. Therefore, the low bulk consisted of eight progenies while the high bulk was comprised of seven progenies. The individual and bulked $\mathrm{T}_{\max }$ values are presented in Table 1. The low and high bulks differed by mean $\mathrm{T}_{\max }$ of $14.7^{\circ} \mathrm{C}$.

RAPD analysis. After the initial screen of 200 primers, 18 appeared to show banding differences between the "low" and "high" bulks. A more stringent second screen (different amount of DNA templates, repeated at least once) of bulked DNA samples revealed that only 4 primers were potential markers. However after the third screen (of individual progenies, repeated 3-4 times), only one primer showed differences between "low" and "high" progenies. After PCR, the potential marker (UBC primer \#29 - CCGGCCTTAC) amplified a 800-bp long band in more of the "low" CH progenies than "high" $\mathrm{CH}$ progenies tested (Fig. 1). The 800-bp band was observed in six of the eight "low" progenies while only three of the seven "high" progenies showed a similar band.

\section{DISCUSSION}

The great advantage in using bulked segregant analysis and RAPD primers are the requirement for small amount of DNA (5-25 ng) and no prior need for knowledge of target sequences. However, the main drawbacks of this methodology are the poor reliability and reproducibility of the results (Jones et al. 1997). The experiments are subject to sensitive experimental and reaction conditions. Due to the short length of the primers, identical primers and reaction solution batches may work one day and may fail the following day. Therefore the relatively simple approach of RAPD experiments may be complicated by having to do the identical assay repeatedly before results can be confirmed. As a result, the fast and relatively simple approach of RAPD experiments can often turn out to be costly and time consuming. 
The intention of this study was to find RAPD primers that are associated with superhardy phenotypes. An earlier protein study on these Rhododendron progenies revealed a 25-kDa dehydrin that is closely associated with super CH trait (Lim et al. 1999). We had also suggested in Lim et al. (1998) that as few as 3 genes may be controlling the $\mathrm{CH}$ trait among the progenies used in this study. Therefore, the likelihood of finding some genetic markers was promising. However, no primers were found in this study to be associated with the "high" cold-tolerance bulk. It was somewhat surprising that we found a RAPD primer that is loosely associated with the "low" cold-tolerance bulk. Interestingly, in the second screen the "high" bulk lacked the 800bp band that UBC primer \#29 amplified in the "low" bulk (figure not shown), however, three of the seven "high" bulk progenies contained this band in the third screen. Also, a majority (six out of eight) of the "low" bulk progenies had the 800-bp band. Following are some explanations to partially address these nebulous results.

First, the 200 primers screened may not have been enough to detect genetic differences linked to $\mathrm{CH}$ genes. Theoretically, there are 1,048,576 different primers of 10 oligonucleotides (4 nucleotides per base). Therefore, we merely screened $0.02 \%$ of all the possible primers. It is likely, on the basis of random probability, that we did not screen enough primers to pick up the difference between low $\mathrm{CH}$ and high $\mathrm{CH}$ bulk. Although there is on average $\sim 15^{\circ} \mathrm{C}$ difference in LFT between the bulks, all progenies have the capacity to cold acclimate (to some degree); the main difference between the bulks is the degree to which they acclimate (as exhibited by superhardy parent, $R$. catawbiense vs. moderate-hardy parent, $R$. fortunei). Hence, there may not be great genomic differences between the loci governing super-and moderate- $\mathrm{CH}$ trait. Therefore, it is not surprising that markers associated with super $\mathrm{CH}$ are difficult to find. Maybe a larger number of different primers used in a primary screen would have generated better results.

Second, the bulking may have had a diluting or concentrating effect on DNA composition of the samples to be amplified. For example, a stronger band observed in the third screen (individual progenies) than in the second screen (bulks) can be explained by a 7-8 X dilution of individual genomes in the second screen. On the other hand, a relatively stronger band in the second screen than the third may also be due to contribution from other progenies having the similar bands with, perhaps, some progenies not having the 800-bp band at all. Although the bulking method may help in locating the loci of interest, it also provides complicated molecular representations. Most successful bulked-segregant analysis reports have dealt with a single 
(dominance) gene and it is more difficult to implement this methodology when dealing with quantitative traits such $\mathrm{CH}$. Therefore, it is necessary to verify each result with repeated experiments or to alter methodology completely.

Lastly, the most probable reason for the difficulty in finding markers in this study, is the basis on which the bulks were formed. Earlier studies (Lim et al. 1998 and Lim et al. 1999) have shown that there is a significant increase in the $\mathrm{CH}$ as the plant matures and the increase is nonuniform among progenies (Chapter 5). Since these plants are bulked based on their $3^{\text {rd }}$ and $4^{\text {th }}$ year $\mathrm{T}_{\max }$, it is likely that the current bulking was premature and it might be prudent to create the bulks when progeny hardiness stabilizes (i.e., plants are matured).

However, in spite of the juvenility effect, what would be the function of a gene that (when present) is associated with lower $\mathrm{CH}$ (as is the case with 800-bp DNA marker)? It seems that evolutionary retainment of this gene would reduce the chances of the plant's survival when faced with a test winter. What would be the remuneration of the plant in doing so? There is a possibility that this gene might not be associated with the less cold-hardy trait at all because it is also represented in high bulk. The fact that some 800-bp band appeared in the high bulk indicates that the linkage between 800-bp band and the gene governing degree of $\mathrm{T}_{\max }$ is not a close one. It is probable that this gene is linked to some other trait that is inversely co-segregating with the $\mathrm{CH}$ trait. It is important to note however, that the original goal of this cross $(R$. catawbiense $\mathrm{x} R$. fortunei) was not to improve $\mathrm{CH}$ but incorporate ornamental attributes into hardy background; Rhododendron breeders have always tried to breed for yellow flowers in hardy phenotypes. Although the literature provided no indication of what trait may be inversely related to $\mathrm{CH}$ in Rhododendron, it may be hypothesized that other important ornamental traits, such as flower color, leaf shape or size could be the likely candidate for this marker. The super $\mathrm{CH}$ genes are elusive and may need more screening in order to find a suitable marker or a different molecular approach may be needed. 


\section{ACKNOWLEDGEMENTS}

We thank Robert Marquard and Eric Davis of Holden Arboretum, OH for their help with the DNA isolation and RAPD protocol. We also thank Stephen L. Krebs and the Holden Arboretum for hosting us at the Lantern Court facility during our visit to learn these techniques. 


\section{LITERATURE CITED}

Jones N, Ougham H, Thomas H (1997) Markers and mapping: we are all geneticists now. New Phytologist 137:165-177

Lim CC, Krebs SL, Arora R (1998) Genetic study of freezing tolerance in Rhododendron populations: Implications for cold hardiness breeding. J Amer Rhododendron Soc 52:143148

Lim CC, Krebs SL, Arora R (1999) A 25-kDa Dehydrin associated with genotype-and agedependent leaf freezing-tolerance in Rhododendron: A genetic marker for cold hardiness? Theor Appl Genet 99:910-918

Marquard RD, Davis EP, Stowe EL (1997) Genetic diversity among Witchhazel cultivars based on randomly amplified polymorphic DNA markers. J Amer Soc Hort Sci 122:529-535

Michelmore RW, Paran I, Kesseli RV (1991) Identification of markers linked to diseaseresistance genes by bulked segregant analysis: a rapid method to detect markers in specific genomic regions by using segregating populations. Proc of the Natl Acad Sci USA 88:98289832

Penner GA, Chong J, Wight CP, Molnar SJ, Fedak G (1993) Identification of an RAPD marker for the crown rust resistance gene Pc68 in oats. Genome 36:818-820

Williams JGK, Kubelik AR, Livak KJ, Rafalski JA, Tingey SV (1990) DNA polymorphisms amplified by arbitrary primers are useful as genetic markers. Nucl Acid Res 18:6531-6535

Poulsen DME, Henry RJ, Johnston RP, Irwin JAG, Rees RG (1995) The use of bulk segregant analysis to identify a RAPD marker linked to leaf rust resistance in barley. Theor Appl Genet 91:270-273 
Table 1. Leaf freezing-tolerance $\left(\mathrm{T}_{\max },{ }^{\circ} \mathrm{C}\right)$ of Rhododendron progenies used for bulking

\begin{tabular}{|c|c|c|}
\hline$R$. 'Ceylon' x $R$. 'Ceylon', $\mathrm{F}_{2}$ progenies & $\mathrm{N}^{\mathrm{z}}$ & Mean $\mathrm{T}_{\max } \pm$ s.e. ${ }^{\mathrm{y}}$ \\
\hline $\mathrm{L}_{1}(93-22 / 008)$ & 2 & $-21.0 \pm 0.5$ \\
\hline $\mathrm{L}_{2}(93-22 / 033)$ & 2 & $-25.6 \pm 0.1$ \\
\hline $\mathrm{L}_{3}(93-22 / 036)$ & 2 & $-23.5 \pm 0.6$ \\
\hline $\mathrm{L}_{4}(93-22 / 040)$ & 2 & $-22.3 \pm 2.7$ \\
\hline $\mathrm{L}_{5}(93-22 / 064)$ & 2 & $-21.9 \pm 2.1$ \\
\hline $\mathrm{L}_{6}(93-22 / 070)$ & 2 & $-26.3 \pm 0.5$ \\
\hline $\mathrm{L}_{7}(93-22 / 090)$ & 2 & $-18.0 \pm 1.6$ \\
\hline $\mathrm{L}_{8}(93-22 / 099)$ & 2 & $-23.3 \pm 0.3$ \\
\hline $\mathrm{F}_{2}$-Low bulk & 8 & $-22.7 \pm 0.9$ \\
\hline $\mathrm{H}_{1}(93-22 / 005)$ & 2 & $-41.7 \pm 2.7$ \\
\hline $\mathrm{H}_{2}(93-22 / 023)$ & 2 & $-39.3 \pm 1.1$ \\
\hline $\mathrm{H}_{3}(93-22 / 037)$ & 2 & $-41.5 \pm 0.9$ \\
\hline $\mathrm{H}_{4}(93-22 / 076)$ & 2 & $-33.7 \pm 1.4$ \\
\hline $\mathrm{H}_{5}(93-22 / 077)$ & 2 & $-34.0 \pm 1.0$ \\
\hline $\mathrm{H}_{6}(93-22 / 146)$ & 2 & $-32.4 \pm 1.5$ \\
\hline $\mathrm{H}_{7}(93-22 / 157)$ & 2 & $-39.5 \pm 3.2$ \\
\hline $\mathrm{F}_{2}$-High bulk & 7 & $-37.4 \pm 1.5$ \\
\hline mean $T_{\max }$ difference between the two bulks & & $14.7^{\circ} \mathrm{C}$ \\
\hline
\end{tabular}

${ }^{\mathrm{z}}$ Similar progeny evaluated in December of 1996 and 1997.

${ }^{\mathrm{y}}$ Estimated by using Gompertz function fitted to leakage data (24 discs). Mean and standard error estimated from 2 years data for individual progenies and from all progenies for bulks 
Fig. 1. DNA profiles of individual $F_{2}$ progenies after PCR amplification with primer No. 29. Lane 9 was loaded with a 100 base pair (bp) ladder. L and H correspond to the "low" and "high" freeze-tolerant progenies. $\mathrm{T}_{\max }=$ quantitative measure of leaf freezing-tolerance

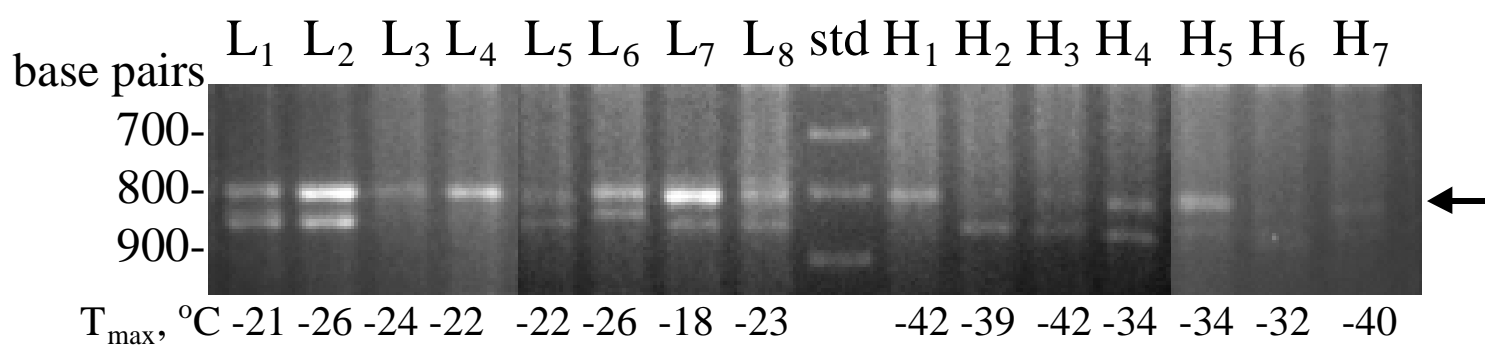




\section{CHAPTER SEVEN \\ LEAF FREEZING-TOLERANCE OF RHODODENDRON AND ITS RELATION TO TISSUE NUTRIENT STATUS}

\section{INTRODUCTION}

Healthy plants contain predictable concentrations of essential elements. These elements are required for normal growth and development. Plants require major elements (N, P, and K) in greatest quantities while secondary elements $(\mathrm{Ca}, \mathrm{Mg}$, and $\mathrm{S})$ are required in lesser quantities. Micronutrients ( $\mathrm{Fe}, \mathrm{Mn}, \mathrm{Zn}, \mathrm{Cu}, \mathrm{B}, \mathrm{Mo}, \mathrm{Cl}$, etc.) are required in very small amounts and can become toxic if present in excess. Leaf analyses provide a way to monitor the nutritional status of a particular plant. Since plants require nutrients in order to grow, develop and complete their life cycle, any nutrient shortages can adversely affect the overall function of the plant and may influence adaptive traits such as stress tolerance. It may be speculated that increased nutrition increases the total soluble salts in the plant cells, which then lowers the freezing point a few degrees and helps protect the plant during a freezing event.

Some nutrients have been known to be associated with plant cold hardiness $(\mathrm{CH})$, particularly calcium. Calcium has been shown to protect plant membranes in the event of cold stress. The injury caused to tissues by freeze-thaw was alleviated by extracellular calcium (Arora and Palta 1988). Calcium chloride $\left(\mathrm{CaCl}_{2}\right)$ and calcium nitrate $\left[\mathrm{Ca}\left(\mathrm{NO}_{3}\right)_{2}\right]$ fertilizer increased CH of 'Anjou' pear trees, and reduced the incidence of fruit disorders (Raese 1996). Also, Durner and Gianfagna (1988) have shown that fall calcium cyanamide application increases peach flower bud resistance to low-temperature stress. DeHayes et al. (1997) reported a significant decline of membrane- $\mathrm{Ca}^{2+}$ of current-year red spruce needles following a severe frost whereas this decline was much less pronounced in one-year-old needles. An earlier study (DeHayes et al. 1990) reported that one-year-old needles were typically $8-12^{\circ} \mathrm{C}$ more freezetolerant than the current-year needles from red spruce trees. Although there are reports on Rhododendron leaf nutrient content (Monk et al. 1985, Karlsson 1994), no studies have been 
found that correlate levels of nutrients with $\mathrm{CH}$ in Rhododendron.

This study investigated the relationship of the macronutrient $(\mathrm{P}, \mathrm{K}, \mathrm{Ca}, \mathrm{Mg}$ ) and micronutrient ( $\mathrm{Fe}, \mathrm{Mn}, \mathrm{Zn}, \mathrm{Cu}$, and $\mathrm{B}$ ) content of the leaves with seasonal changes in $\mathrm{CH}$ of Rhododendron cultivars and mid-winter hardiness of Rhododendron species.

\section{MATERIAL AND METHODS}

Plant material. Rhododendron cultivars ('Grumpy Yellow', 'Vulcan's Flame' and 'Chionoides') were obtained as 2-year-old rooted cuttings and maintained as described in Lim et al 1998. Current-year leaves from three Rhododendron cultivars were collected monthly from September 1996 until May 1997. Similarly, current-year leaves were collected from two species (R. catawbiense and $R$. fortunei, both $~ 40$-year-old), and its hybrid ( $R$. 'Ceylon', 30 -year-old) in February 1998. This group of field-grown plants is maintained at the Holden Arboretum's Leach Research Station in Madison, OH. LFTs of these plants have previously been reported (Lim et al. 1998a, Lim et al. 1998b).

Sample preparation. Leaves were randomly collected from plants, weighed, placed in an oven at $70{ }^{\circ} \mathrm{C}$ and dried to a constant weight. The dried samples were manually crushed (mortar and pestle) and passed through a 35-mesh sieve. The crushed and sieved samples were placed back into the oven $\left(70{ }^{\circ} \mathrm{C}\right)$ until use for nutrition analysis. Leaf samples were pre-weighed $(0.2-0.5 \mathrm{~g})$ into acid-bathed $(0.1 \mathrm{~N} \mathrm{HCl})$ crucibles before being ashed in a 500 ${ }^{\circ} \mathrm{C}$ oven for 4 hours. After ashing, samples were dissolved in $10 \mathrm{ml}$ of Nitric - perchloric acid destruction mixture (30\% of $12 \mathrm{~N}$ hydrochloric acid, $10 \%$ of $6 \mathrm{~N}$ nitric acid, $60 \%$ distilled deionized $\mathrm{H}_{2} \mathrm{O}$ ) and diluted to $25 \mathrm{ml}$ with distilled deionized $\mathrm{H}_{2} \mathrm{O}$. The acid mixture was heated to $40{ }^{\circ} \mathrm{C}$ on a hot plate to facilitate ash dissolution. The solution was then filtered (Whatmann 42 ashless filter paper) and stored at $-20{ }^{\circ} \mathrm{C}$ until nutrient determination. 
Nutrient determination. Leaf nutrient concentrations were determined on all samples. Potassium and sodium concentrations were obtained by atomic-absorption (AA) spectrophotometer while $\mathrm{P}, \mathrm{Ca}, \mathrm{Mg}, \mathrm{Fe}, \mathrm{Mn}, \mathrm{Zn}, \mathrm{Cu}$, and boron measurement were obtained by ICP (inductively-coupled plasma atomic emission spectrometer) which detects the characteristic wavelength of light emitted from a sample when heated to extreme temperatures within an argon plasma. Results from the spectrophotometer readings were multiplied by 125 (the dilution factor) to obtain $\mathrm{mg} / \mathrm{L}$ (or $\mathrm{mg} / \mathrm{Kg}$ ) and divided by 10,000 to obtain \% dry weight (only for macronutrients).

Statistical analysis. Leaf samples from each Rhododendron cultivar were pooled from a group of 10-15 plants at each sampling date to provide a representative sample. However, this leaf collection method render Duncan, Dunnett or any other multiple statistical comparisons method futile because it violates the assumption of leaf sample being independent from each other. Therefore, LSD (least significant difference) was used to identify differences among cultivar samples. The species and its hybrid were evaluated only once in February 1998 and differences between them were estimated by multiple $t$-test.

\section{RESULTS}

Macronutrients. There were no dramatic fluctuations in the cultivars' seasonal cycling of macronutrients that correspond with their $\mathrm{CH}$ fluctuation. However, it is interesting to note that $R$. 'Grumpy Yellow' had significantly higher amounts of phosphorus and potassium but a lower amount of calcium at the end of the season (Table 1). $R$. 'Grumpy Yellow' overall had a lower amount of magnesium than other cultivars, which was significantly lower during midwinter. $R$. 'Vulcan's Flame' had intermediate macronutrient concentrations throughout the entire season. $R$. 'Chionoides' on the other hand, had significantly lower potassium in mid-winter but significantly higher magnesium in the first three sampling dates. $R$. 'Chionoides' also had significantly higher amount of calcium in November 1996 (Table 1). 
The Rhododendron species and their hybrid exhibited rather unusual results. The hardier parent, $R$. catawbiense, had significantly lower amounts of all macronutrients evaluated than the moderately-hardy parent, $R$. fortunei in February 1998 (Table 2). The hybrid $R$. 'Ceylon' had intermediate macronutrients levels. Overall, both $R$. fortunei and $R$. 'Ceylon' had higher amounts of macronutrients than $R$. catawbiense.

Micronutrients. There was more variance in the micronutrient content of the leaves. Overall there were higher micronutrient concentrations in the leaves of $R$. 'Grumpy Yellow' and $R$. 'Vulcan's Flame' than in $R$. 'Chionoides'.

Iron. The amount of iron remained essentially constant in all cultivars throughout the season with the exception of the last sampling date of $R$. 'Grumpy Yellow'. There were no significant differences between Rhododendron species and hybrid group in February 1998.

Manganese. There were overall higher levels of manganese in $R$. 'Vulcan's Flame' and these levels were significantly higher in January and May 1997. All samples of $R$. 'Chionoides' exhibited significantly lower amounts of manganese while $R$. 'Grumpy Yellow' was mostly in intermediate range. In the Rhododendron species and hybrid group, R. fortune $i$ was significantly higher in manganese than $R$. 'Ceylon' and $R$. catawbiense. $R$. 'Ceylon' was also significantly higher than $R$. catawbiense. The concentration of manganese in February 1998 is inversely related to the $\mathrm{CH}$ rankings of these Rhododendron species and their hybrid.

Zinc. At the end of the season, $R$. 'Grumpy Yellow' and $R$. 'Vulcan's Flame' had significantly higher concentrations of zinc than $R$. 'Chionoides'. While exhibiting significantly higher zinc levels at the beginning of the season, $R$. 'Chionoides' had generally lower levels throughout the rest of the samplings dates with significantly lower amounts in November 1996, March 1997 and May 1997. There were no significant differences between Rhododendron species and the hybrid group in February 1998. 
Copper. R. 'Grumpy Yellow' had a significantly higher amount of copper at the beginning and the end of the sampling period. $R$. 'Vulcan's Flame' and $R$. 'Chionoides' exhibited significantly lower copper concentrations in March 1997 and May 1997, respectively. It was interesting to note that the trend of copper cycling was similar in $R$. 'Grumpy Yellow' and $R$. 'Vulcan's Flame' but was reversed for $R$. 'Chionoides'. There were no significant differences between the Rhododendron species and the hybrid group in February 1998.

Boron. Generally, $R$. 'Grumpy Yellow' leaves contained more boron, with significantly higher amounts in first 3 sampling dates, than $R$. 'Chionoides', which contained significantly lower amounts in March and May 1997. R. 'Vulcan's Flame' had intermediate levels of boron. The average concentration of boron is inversely related to the $\mathrm{CH}$ rankings of these cultivars. In the Rhododendron species and the hybrid group, $R$. fortunei and $R$. 'Ceylon' contained significantly more boron than did $R$. catawbiense.

\section{DISCUSSION}

The concentrations of marconutrients found in this study were comparable with those that were reported by Monk et al. (1985). The last sampling of leaves in the cultivars was made after the plants had been fertilized and this was reflected, in part, by the least-hardy cultivar, $R$. 'Grumpy Yellow', having significantly higher amount in overall nutrients. There was no significant correlation of macronutrient level to $\mathrm{CH}$ within a season or to the $\mathrm{CH}$ rankings of these cultivars. Other attempts to correlate frost hardiness with nutrient status were also unsuccessful (Rothwell and Robinson 1986). It was rather surprising that the hardiest plant, $R$. catawbiense had the lowest overall concentration of macronutrients.

As for the micronutrients, manganese levels in species and boron levels in cultivars were inversely correlated with $\mathrm{CH}$ rankings. Manganese is involved in the oxidation-reduction process in the photosynthetic electron transport system and plays a structural role in the chloroplast membrane system. While the biochemical functions of boron are unknown, it may be involved in some cellular activities such as division, differentiation, maturation and respiration. Thus, why 
are these two elements associated inversely with leaf $\mathrm{CH}$ of Rhododendron? Both elements are associated with actively growing process. In mid-winter however, these processes are likely to be in a somewhat less active or even close to dormant stage, therefore plants need not accumulate manganese or boron to high levels.

The supply of nutrients to the plants should be balanced in order to maximize the efficiency of the individual nutrients so that these meet the needs of the particular plant. It is important to note that not one of the mineral elements tested here positively correlates with $\mathrm{CH}$ of Rhododendron. Since no reports have been found to associate manganese and boron inversely with $\mathrm{CH}$ of plants, the results in this study could be coincidental rather than factual.

Our results seem to indicate that the lower the Rhododendron leaf nutrient content, the hardier the plant. This is the opposite of what one would hypothesize. From the plant point of view, the low nutrient assimilation might cause some stress, which results in the overall plant defense mechanisms being turned on and thus protecting the plant. However, it is not possible to depict any other reasoning for the association of lower nutrient assimilation with higher cold tolerances. Further studies of these cultivars and species, particularly at the anatomical level, will be required to determine whether leaf nutrient content has any significant impact on average $\mathrm{CH}$ performance.

\section{ACKNOWLEDGEMENTS}

We sincerely thank Dr. Devinder K. Bhumbla for his technical advice on nutrient analysis and, Elizabeth Joan Wright and Marlene Cross for their assistance in performing the nutrient determination. 


\section{LITERATURE CITED}

Arora R, Palta JP (1988) In vivo perturbation of membrane-associated calcium by freeze-thaw stress in onion bulb cell: Simulation of this perturbation in extra-cellular $\mathrm{KCl}$ and alleviation by calcium. Plant Physiol 85:622-628

Dehayes DH, Waite CE, Ingle MA, Williams MW (1990) Winter injury susceptibility and cold tolerance of current and year-old needles of red spruce trees from several provenances. For Sci 36: $982-994$

DeHayes DH, Schaberg PG, Hawley GJ, Borer CH, Cumming JR, Strimbeck GR (1997) Physiological implications of seasonal variation in membrane-associated calcium in red spruce mesophyll cells. Tree Physiol 17: 687-695

Durner EF, Gianfagna TJ (1988) Fall ethephon application increases peach flower bud resistance to low-temperature stress. J Amer Soc Hort Sci 113:404-406

Karlsson PS (1994) Photosynthetic capacity and photosynthetic nutrient-use efficiency of Rhododendron lapponicum leaves as related to leaf nutrient status, leaf age and branch reproductive status. Functional Ecol 8:694-700

Lim CC, Arora R, Townsend ED (1998a) Comparing Gompertz and Richards functions to estimate freezing injury in Rhododendron using electrolyte leakage. J Am Soc Hort Sci $123: 246-252$

Lim CC, Krebs SL, Arora R (1998 b) Genetic study of freezing tolerance in Rhododendron populations: Implications for cold hardiness breeding. J Am Rhododendron Soc 52:143-148

Monk CD, McGinty DT, Day FP Jr. (1985) The ecological importance of Kalmia latifolia and Rhododendron maximum in the deciduous forest of the southern Appalachians. Bull Torrey Bot Club 112:187-193

Raese JT (1996) Calcium nutrition affects cold hardiness, yield, and fruit disorders of apple and pear trees. J Plant Nutr 19:1131-1151

Rothwell SD, Robinson LW (1986) Cold acclimation potential of watercress in relation to growing season and nutrient status. J Horticultural Sci 61:373-378 


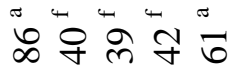
$0 \dot{0} 0000$ $+1+1+1+1+1$ a 9 \% त 눅둥

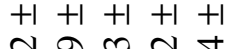
늠

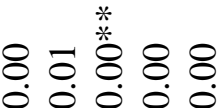
$+1+1+1+1+1$

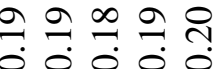

용 00000 $+1+1+1+1+1$ กิ กิ กิ กิ กิ

₹

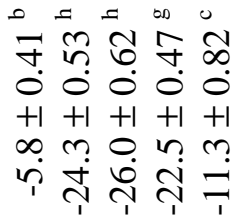

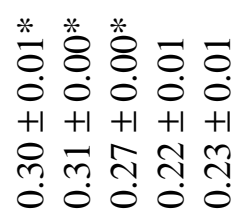

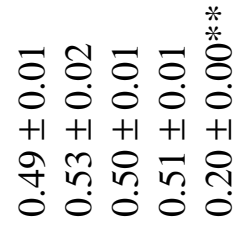
O 0000

응ㅎㅇㅇㅇ 00000 $+1+1+1+1+1$

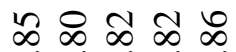

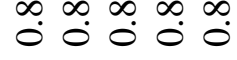

$\begin{array}{lllll}n & * & 8 & 0 & 8 \\ 0 & 0 & 0 & 0 & 0 \\ 0 & 0 & 0 & 0 & 0 \\ +1 & +1 & +1 & +1 & +1 \\ + & 0 & n & 0 & \infty \\ \infty & 9 & 0 \\ 0 & 0 & 0 & 0 & 0 \\ 0 & 0 & 0 & 0\end{array}$

$8888 \%$

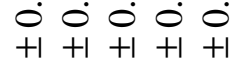
กి nి m

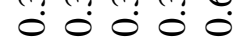

웅 8 $+1+1+1+1+1$

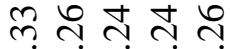
กำ ถุ

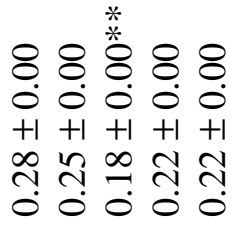

๑ \& \& \& \% 00000 $+1+1+1+1+1$ I느의 : $: \overrightarrow{0}: 0$ ?

৪8৪8৪ 00000 $+1+1+1+1+1$ $=n=0 \mathrm{I}$ $\overrightarrow{0} \overrightarrow{0} \overrightarrow{0} \overrightarrow{0} \overrightarrow{0}$

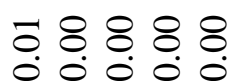
$+1+1+1+1+1$ 긍 $=0$.

$\operatorname{sandu~}$ $4 \operatorname{chn}$

nN n n

ㅇํํ솟

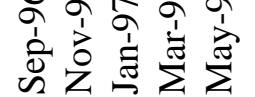

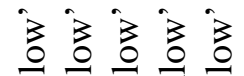

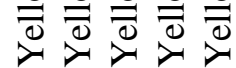

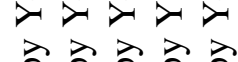

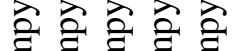

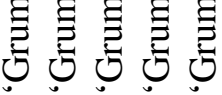
वن

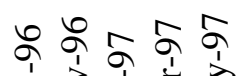

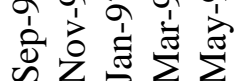

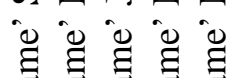
言壱壱壱吉 สี สี สี สี $\frac{0}{3} \frac{0}{3} \frac{0}{3} \frac{0}{3}$ ن

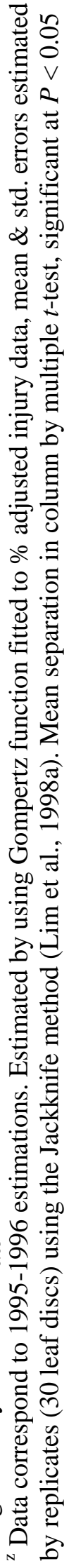


Table 2. Macronutrient concentrations (\% dry weight) in leaves of $R$. catawbiense, $R$. fortunei and $R$. 'Ceylon' in February 1998 and corresponding leaf freezing-tolerance levels $\left(\mathrm{T}_{\max }\right)$ in January 1997

\begin{tabular}{|c|c|c|c|c|c|c|}
\hline Plant & $\mathrm{N}^{\mathrm{y}}$ & $\begin{array}{c}\mathrm{P} \\
\text { means } \pm \text { s.e. }\end{array}$ & $\begin{array}{c}\mathrm{K} \\
\text { means } \pm \text { s.e. }\end{array}$ & $\begin{array}{c}\mathrm{Ca} \\
\text { means } \pm \text { s.e. }\end{array}$ & $\begin{array}{c}\mathrm{Mg} \\
\text { means } \pm \text { s.e. }\end{array}$ & $\begin{array}{c}\mathrm{T}_{\max }{ }^{\mathrm{z}} \\
\text { means } \pm \text { s.e. }\end{array}$ \\
\hline R. catawbiense & 2 & $0.10 \pm 0.0018^{\mathrm{a}}$ & $0.18 \pm 0.0004^{\mathrm{a}}$ & $0.47 \pm 0.0211^{\mathrm{a}}$ & $0.13 \pm 0.0004^{\mathrm{a}}$ & $-51.2 \pm 0.2^{\mathrm{k}}$ \\
\hline R. fortunei & 2 & $0.13 \pm 0.0008^{b}$ & $0.24 \pm 0.0013^{b}$ & $0.74 \pm 0.0051^{b}$ & $0.17 \pm 0.0019^{b}$ & $-32.4 \pm 0.9^{i}$ \\
\hline$R$. 'Ceylon' & 2 & $0.12 \pm 0.0015^{\mathrm{ab}}$ & $\mathrm{b} 0.17 \pm 0.0007^{\mathrm{a}}$ & $0.74 \pm 0.0009^{b}$ & $0.19 \pm 0.0006^{b}$ & $-43.2 \pm 1.3^{j}$ \\
\hline
\end{tabular}

Mean separation in column by multiple $t$-test, significant at $P<0.05$

z Estimated by using Gompertz function fitted to $\%$ adjusted injury data, mean \& std. errors estimated by replicates (24 leaf discs) using the Jackknife method (Lim et al., 1998a).

${ }^{\mathrm{y}} \mathrm{N}=$ number of samples 


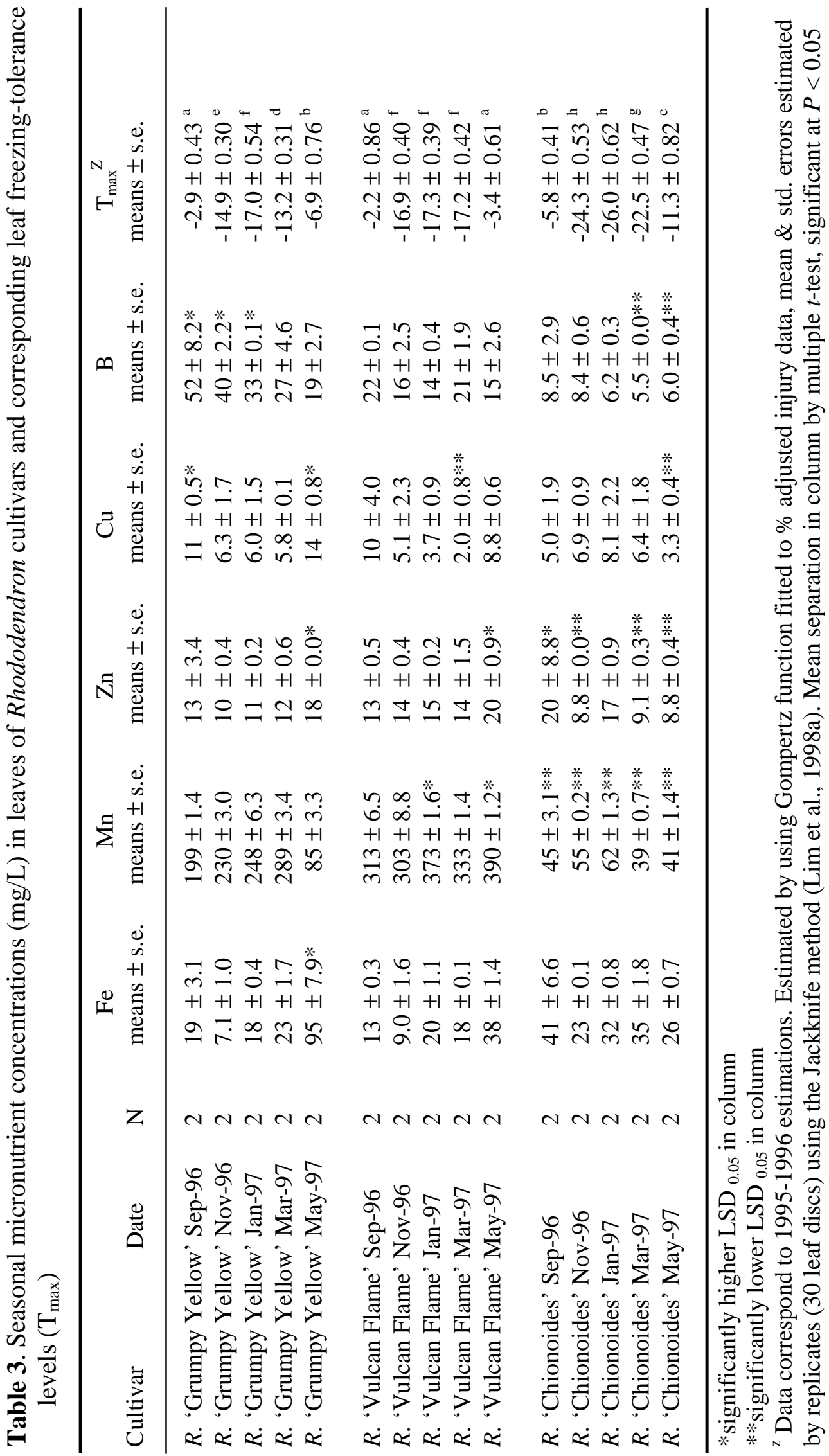




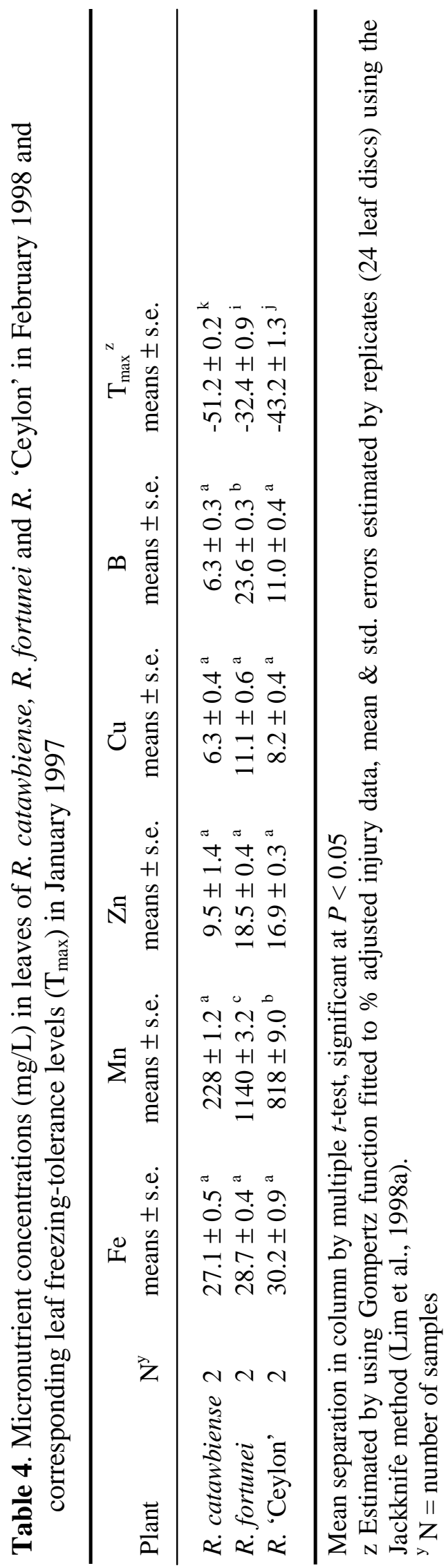




\section{CHAPTER EIGHT \\ SUMMARY AND CONCLUSIONS}

\section{SUMMARY}

A reliable and reproducible method of measuring cold hardiness $(\mathrm{CH})$ in Rhododendron was developed and reported in Chapter 2. The subsequent chapters contain the results of our work on the physiological and genetic aspects of Rhododendron $\mathrm{CH}$. A summary of the results obtained and conclusions drawn in this thesis is presented below.

Chapter 2. We developed a reliable in vitro laboratory protocol for assessing $\mathrm{CH}$ in rhododendrons based on leaf freezing-tolerance (LFT). In this method, the raw ion-leakage data is first transformed into percent-adjusted injury by taking into account the $0 \%$ and $100 \%$ injury. The $\%$ adjusted injury data was then fitted with asymmetric sigmoidal curves generated by a grid search of starting parameters. The slope of the sigmoidal curves represented the rate of injury and we selected the inflection point (equivalent to the highest rate of injury) as the quantitative measure of $\mathrm{CH}\left(\mathrm{T}_{\max }\right)$. The uniqueness of this study lies with the regeneration of data sets by the Jackknife method. This method allowed the generation of multiple data sets from a single timepoint measurement, which allowed for the computation of means and standard errors that can be statistically analyzed. The method was able to provide relative freezing tolerance information on five Rhododendron cultivars under naturally non- acclimated and cold-acclimated conditions. LFT values determined by this protocol based on ion-leakage tests corresponded well with visual assessments of LFT, and correlated well with USDA hardiness zone rankings of various Rhododendron cultivars.

Chapter 3. Utilizing our in vitro laboratory protocol for assessing $\mathrm{CH}$, we were able to screen $\mathrm{F}_{2}$ and $\mathrm{BC}$ Rhododendron populations segregating for the $\mathrm{CH}$ trait. LFT distribution in $\mathrm{F}_{2}$ and backcross populations derived from a $R$. catawbiense $\mathrm{x} R$. fortunei cross suggested that as. 
few as three genes with strong additive effects were controlling LFT variation in these progenies The prospect of a few major genes controlling $\mathrm{CH}$ makes genetic mapping and 'tagging' of $\mathrm{CH}$ genes a feasible objective in these Rhododendron populations. Differences in mid-winter freezing tolerance were primarily due to differences in acclimating ability among the segregants and were independent of non-acclimated freezing tolerance.

Chapter 4. This study examined whether dehydrin expression in leaves was associated with freezing-tolerance among $\mathrm{F}_{2}$ segregants, species, and cultivars of evergreen Rhododendron. Experiments were also conducted to determine whether physiological and chronological aging affects freezing-tolerance and dehydrin accumulation in Rhododendron leaf tissues. We found levels of a $25-\mathrm{kDa}$ dehydrin were closely associated with differences in LFT among segregants of cold-acclimated $\mathrm{F}_{2}$ populations. Levels of this dehydrin increased as LFT increased with both chronological age and developmental phase-change of wild and cultivated plants. It was suggested that presence or absence of the $25-\mathrm{kDa}$ dehydrin could serve as a genetic marker to distinguish between super cold-hardy and less cold-hardy rhododendron genotypes.

Chapter 5. Stemming from our results from Chapter 2, we investigated the yearly $\mathrm{CH}$ changes in several Rhododendron seedling populations and examined the relationship between LFT and aging. A yearly average increases in LFT of about $5-6^{\circ} \mathrm{C}$ during the juvenile period of Rhododendron seedling growth was observed in $\mathrm{F}_{1}, \mathrm{~F}_{2}$ and $\mathrm{BC}$ populations segregating for $\mathrm{T}_{\max }$. This shift in $\mathrm{CH}$ is likely the reflection of an increased ability to cold acclimate. However, there were varying degrees of $\mathrm{CH}$ increment in individual progenies from year to year. Therefore, the maximum cold acclimation (CA) potential of these populations could not be realized or estimated until they reached reproductive maturity.

Chapter 6. This chapter investigated the feasibility of finding DNA markers that are closely linked to the $\mathrm{CH}$ trait. We utilized bulked segregant analysis (a PCR-RAPD-based method) for a rapid screening of two bulks (low and high cold tolerance) of Rhododendron progenies segregating for the $\mathrm{CH}$ trait in search of molecular markers. Although, no primers were found to be associated with the high cold-tolerance bulk, a RAPD primer that is loosely 
associated with the low cold-tolerance bulk was identified. A possibility that the "bulk" used in this study might not have been appropriate for these experiments (since the ultimate CA ability of these progenies is not known yet) is discussed. We suggest that this study should be conducted again when progenies have reached reproductive maturity and their cold acclimated LFT has stabilized.

Chapter 7. This chapter attempts to correlate macronutrient and micronutrient concentrations with $\mathrm{CH}$ of Rhododendron cultivars and species. No significant correlation between macronutrients concentrations and Rhododendron $\mathrm{CH}$ was detected. Levels of boron in cultivars and manganese levels in species were inversely comparable to $\mathrm{CH}$ rankings. These findings are likely more coincidental than factual since no other nutrient report was found to have an inverse relationship with plant $\mathrm{CH}$.

\section{CONCLUSIONS}

The following conclusions can be drawn from the results presented in this thesis.

1. The in vitro laboratory protocol for assessing $\mathrm{CH}$ in rhododendrons based on LFT is nondestructive, reliable, repeatable and statistically sound.

2. The continuous and bell-shaped distributions of LFTs in $F_{2}$ and backcross populations of Rhododendron suggest that genetic control of $\mathrm{CH}$ is multigenic (as few as three genes).

3. A significant $\mathrm{CH}$ reduction of $\mathrm{BC}$ populations (in comparison to $\mathrm{F}_{2}$ populations) is indicative of an additive gene action of the $\mathrm{CH}$ genes.

4. The non-acclimated LFT of Rhododendron populations is not correlated with CA ability and is under independent genetic control from cold-acclimated LFT.

5. The presence or absence of the $25-\mathrm{kDa}$ dehydrin may serve as a genetic marker to distinguish between super cold-hardy and less cold-hardy rhododendron genotypes.

6. Studies of wild and cultivated plants indicated that LFT increased with both chronological age and developmental phase-change (juvenile to mature plants) and that this trend was accompanied by increased accumulation of the 25-kDa dehydrin. 
7. There is a yearly increase in the ability to cold acclimate by Rhododendron seedlings during the juvenile period but increments of $\mathrm{CH}$ varied from year to year.

8. The maximum CA ability of juvenile Rhododendron populations should stabilize once they reached reproductive maturity.

9. A DNA marker was found to be associated with genes for moderate-cold hardiness genes in Rhododendron but none were found to be associated with super cold-hardy genes.

10. No correlations were found between nutrient status and seasonal patterns of LFT in Rhododendron. 


\section{A 27-KILODALTON LEAF PROTEIN IN NON-ACCLIMATED AND DEACCLIMATED TISSUES OF RHODODENDRON IS RELATED TO A FAMILY OF ABA STRESS RIPENING/ WATER DEFICIT STRESS INDUCIBLE PROTEINS}

\section{INTRODUCTION}

In nature, a remarkable transition occurs in plant species adapted to cold climates. During periods of active growth a few degrees of frost will kill most plant tissues, but in mid-winter, non-supercooling tissues of many temperate zone woody plants can survive $-30^{\circ} \mathrm{C}$ or lower. Subsequently in spring, these tissues lose the acquired freezing tolerance, a process known as deacclimation. Many physiological and biochemical studies have shown accumulation of unique biochemical products that are strongly associated with the cold hardy state (Arora and Wisniewski 1994, Guy 1990). Scientists are exploring the nature and roles of these products in increasing freezing-tolerance (cold acclimation). However, there is a scarcity of reports on physiological and/or biochemical changes associated with deacclimation process. This is an integral part of plant cold hardiness $(\mathrm{CH})$ since the spring frost can cause severe crop damages.

In this study, we present evidence of a $27-\mathrm{kDa}$ Rhododendron deacclimation protein that accumulates during the deacclimated and non-acclimated stage but disappears or does not accumulate during cold-acclimated conditions. 


\section{MATERIAL AND METHODS}

Plant materials. Current-year leaves were collected from three Rhododendron cultivars ('Chionoides', 'Grumpy Yellow', and 'Vulcan's Flame'; 4-year-old rooted cuttings) during natural non-acclimated, cold-acclimated and deacclimated conditions. The maintenance of these plants has been previously described in Lim et al. (1998a).

Protein extractions, measurement, SDS-PAGE and preparative free-solution iso-electric-focusing. Extractions and quantification of protein from Rhododendron leaf tissues, and their analysis by SDS-PAGE were done according to Lim et al. (1999). Preliminary results showed that non-acclimated plant proteins were most abundant in $R$. 'Vulcan's Flame'. Therefore $R$. 'Vulcan's Flame' plant proteins were concentrated (from $120 \mathrm{~g}$ of tissue) and partially purified by fractionating borate buffer-protein extracts in preparative, free-solution IEF (iso-electric-focusing) using Rotofor (Bio-Rad) as described by Arora and Wisniewski (1994).

Amino acid composition and protein sequencing. To determine total amino acid composition of 27-kDa protein, $5-\mu \mathrm{L}$ aliquots of fraction 13 (highly enriched in 27$\mathrm{kDa}$ protein) were separated by SDS-PAGE and electroblotted onto a $0.2-\mu \mathrm{m}$ polyvinylidene difluoride protein-sequencing membrane (Bio-Rad) as described in Arora and Wisniewski (1994). The bands corresponding to the $27-\mathrm{kDa}$ protein were excised and sent to Harvard Microchemistry Facility for amino acids composition analysis. Protein sequencing analyses were also performed by Harvard Microchemistry Facility using gel bands corresponding to $27-\mathrm{kDa}$ polypeptide that were excised from one dimensional SDS-PAGE profiles of Rotofor fraction \#13. 


\section{RESULTS}

\section{Rhododendron protein variation throughout the season. Protein} extraction from Rhododendron leaves presented a real challenge and was rather difficult technically. Although all effort was made to optimize the extraction and measurement protocols, there were always variations in overall protein band intensity when fractionated by discontinuous SDS-PAGE. After numerous attempts, acceptable SDS-PAGE profiles (almost equivalent lane intensities) of Rhododendron proteins from non-acclimated, cold-acclimated and deacclimated leaves were finally obtained (Fig. 1). The profiles exhibited a striking variation of a particular 27-kDa protein. We labeled this protein RhDA27 for Rhododendron deacclimation protein of 27$\mathrm{kD}$, because it accumulates in deacclimated tissues. At the deacclimated stage, $R$. 'Vulcan's Flame' had a higher amount of RhDA27 than the other cultivars based on visual estimates. Protein extracts from deacclimated $R$. 'Vulcan's Flame' were fractionated by free-solution IEF in a Rotofor apparatus. SDS-PAGE profiles of fractions 3 through 20 are presented in Figure 2. Fraction 13 was highly enriched in RhDA27, having an isoelectric point of 6.5. RhDA27 was also found to a lesser extent in fraction 11 and 12 .

\section{Amino acid composition and partial microsequencing of}

RhDA27. Amino acid analysis of RhDA27 indicated that it had a compositional bias for Glu/Gln (13.9\%), His (11.4\%), Gly (11\%), Ala (10\%), Lys (8.3\%) and Asp/Asn (8.1\%) (Table 1). These six amino acids represent about $63 \%$ of the total. The amino acid analysis process used in this study did not recover cystine and tryptophan. Hydrophilic amino acids constituted about $54 \%$ of the total amino acids while $40 \%$ were nonpolar, aliphatic amino acids (Gly, Ala, Val, Leu, Ile, Pro) and only 6\% were aromatic amino acids (Phe and Tyr). Partial clevage of excised RhDA27 protein produced four peptides. A search in the protein sequence database by BLAST revealed that two proteins contain sequences similarities with all four RhDA27 peptides (Table 2). Based on these similar proteins, the order of the RhDA27 protein was established. According to this order, one peptide segment occurs near the $\mathrm{N}$-terminus of the protein while the other three 
segments are almost continuous, close to the C-terminus. The two proteins homologous to RhDA27 protein are part of the family of ABA stress ripening/ water deficit stress inducible proteins (Table 3).

\section{DISCUSSION}

Abiotic stress can significantly reduce crop yields and restrict the latitudes and soils on which commercially important species can be cultivated. Understanding how plants tolerate freezing and desiccation may significantly impact food and ornamental products. Research has shown that apparently diverse abiotic stresses can inflict very similar injury on plant cells at the biochemical level (Guy 1990). This is reflected in the similarity of plant responses to different abiotic stresses, in the fact that exposure of a plant to one stress will induce resistance to another stress, and in the complex signaling network involved in stress-regulation of gene expression. Plant stresses like ABA, drought, salinity and cold are often cross-induced in plant defense mechanisms because all of them contain a dehydrative component. Therefore, it was rather unexpected when the RhDA27 polypeptide which accumulates to high levels during nonacclimated and deacclimated stage, showed homology with a family of ABA stress ripening/ water deficit stress inducible proteins. Accumulation of RhDA27 in non-acclimating and deacclimating conditions instead of the cold-acclimating stage is rather perplexing. Why a plant protein that resembles (based on limited sequences) those proteins that might be more linked with cold acclimation, accumulates during deacclimation process?

We have earlier reported that Rhododendron $\mathrm{CH}$ in non-acclimating and cold-acclimating conditions are independent of each other (Lim et al. 1998b). Since the mechanisms for $\mathrm{CH}$ in mid-winter is different from non-acclimating conditions, it may be postulated that RhDA27 may be associated closer with non-acclimated $\mathrm{CH}$ or to any other stress or growth developmental process that occurs in non-acclimating and deacclimating conditions. More research is needed to verify the functionality of the RhDA27 protein and its association with deacclimation. 


\section{LITERATURE CITED}

Arora R, Wisniewski ME (1994) Cold acclimation in genetically related (sibling) deciduous and evergreen peach (Prunus persica [L.] Batsch). II. A 60-kilodalton bark protein in coldacclimated tissues of peach is heat stable and related to the dehydrin family of proteins. Plant Physiol 105:95-101

Guy CL (1990) Cold acclimation and freezing stress tolerance: role of protein metabolism. Annu Rev Plant Physiol Plant Mol Biol 41: 187-223

Lim CC, Arora R, Townsend ED (1998 a) Comparing Gompertz and Richards functions to estimate freezing injury in Rhododendron using electrolyte leakage. J Amer Soc Hort Sci $123: 246-252$

Lim CC, Krebs SL, Arora R (1998 b) Genetic study of freezing tolerance in Rhododendron populations: Implications for cold hardiness breeding. J Amer Rhododendron Soc 52:143148

Lim CC, Krebs SL, Arora R (1999) A 25 kDa Dehydrin Associated with Genotype-and AgeDependent Leaf Freezing-Tolerance in Rhododendron: A genetic marker for cold hardiness? Theor Appl Genet 99:910-918 
Table 1. Total amino acid composition of RhDA27

\begin{tabular}{ccc}
\hline Amino Acid \& Abbreviations & Mol (\%) \\
\hline Ala & A & 10.0 \\
Arg & R & 2.5 \\
Asx & B & 8.1 \\
Cys & C & --- \\
Glx & Z & 13.9 \\
Gly & G & 11.0 \\
His & H & 11.4 \\
Ile & I & 4.2 \\
Leu & L & 6.1 \\
Lys & K & 8.3 \\
Met & M & 1.8 \\
Phe & F & 3.4 \\
Pro & P & 3.6 \\
Ser & S & 3.6 \\
Thr & T & 3.9 \\
Trp & W & --- \\
Tyr & Y & 2.8 \\
Val & V & 5.4 \\
\hline
\end{tabular}

Asx and Glx are used because amino acid analysis was not able to distinguish between Asp and Asn, Glu and Gl respectively. The amino acid analysis process used in this study did not recover cystine and tryptophan. 
Table 2. Partial amino acid sequence of RhDA27 and its comparison with two closely related proteins

\begin{tabular}{|c|c|c|c|c|}
\hline Plant & Polypeptide & Part & ial sequences & Accession No. \\
\hline Rhododendron & RhDA27 & $\begin{array}{l}1 \\
1 \\
1 \\
1\end{array}$ & $\begin{array}{l}\text { HHFFHHHK } 8 \\
\text { EHLGELGAVAAGAFALHEK } 19 \\
\text { SQKDPEHAH } 9 \\
\text { HKLEEEIAAAAAVGAGGYAFHEHHEK }\end{array}$ & 26 \\
\hline $\begin{array}{l}\text { Mesembryanthemum } \\
\text { crystallinum }\end{array}$ & $\begin{array}{l}\text { ABA stress } \\
\text { ripening } \\
\text { protein } \\
(143 \mathrm{bp})\end{array}$ & $\begin{array}{l}9 \\
68 \\
89 \\
99\end{array}$ & $\begin{array}{l}\text { HHLFHHHK } 16 \\
\text { EHMGELGAVAAGAFALHEK } 86 \\
\text { IEKDPEHAH } 97 \\
\text { HKIEEEIAAAARVGAGGYVFHEHHEK }\end{array}$ & gi|3064035 \\
\hline Pinus taeda & $\begin{array}{l}\text { LP3-1 water } \\
\text { stress } \\
\text { inducible } \\
(126 \mathrm{bp})\end{array}$ & $\begin{array}{l}8 \\
51 \\
72 \\
82\end{array}$ & $\begin{array}{l}\text { HHLFHHHK } 15 \\
\text { EHLGEMGTVAAGAFALHEK } 69 \\
\text { DKKDPEHAH } 80 \\
\text { HKIEEEVAAAAAVGAGGYVFHEHHEK }\end{array}$ & gi|1297089 \\
\hline Consensus sequences & $\begin{array}{l}1 \\
2 \\
3 \\
4\end{array}$ & & $\begin{array}{l}\text { HH FHHHK } \\
\text { EH+GE+G VAAGAFALHEK } \\
+ \text { KDPEHAH } \\
\text { HK+EEE+ }\end{array}$ & \\
\hline
\end{tabular}


Table 3. Three partial amino acid sequences of Rhododendron RhDA27 when arranged with other closely related proteins

Partial seqs. 1 EHLGELGAVAAGAFALHEK--SQKDPEHAH-HKLEEEIAAAAAVGAGGYAFHEHHEK 57

Accession No.

gi|1297089: 51 EHLGEMGTVAAGAFALHEKHADKKDPEHAHRHKIEEEVAAAAAVGAGGYVFHEHHEK 107

pir||S53488:187 EEIGGLGAVAAGAFALHEKHKAEKDPENAHKHKIEEGIAAAAAIGAGGFAFHEHHEK 243

gi|3064035 : 68 EHMGELGAVAAGAFALHEKHKIEKDPEHAHRHKIEEEIAAAARVGAGGYVFHEHHEK 124

gi|1519370:73 EELGGLGTVAAGAFALHEKHASKKDPENAHRHKIEEEIAAAAAVGAGGYVFHEHHEK 129

gi|4098250:36 EKIGELGAVAAGAFALHEKHKAKKDPENAHKHKIEEEIAAVAAVGAGGFAFHEHHQK 92

gi|4098248: 35 EQIGKLGTVAAGAYALHEKHEAKKDPEHAHKHKIEEEIAAAAAVGAGGFALHEHHEK 91

gi|3661618: 36 EQIGKLGTVAAGAYALHEKHEAKKDPEHAHKHKIEEEIAAAAAVGAGGFAFHEHHEK 92

sp|Q08655 : 36 EQIGKLGTVAAGAYALHEKHEAKKDPEHAHKHKIEEEIAAAAAVGAGGFAFHEHHEK 92

gi|2773154: 62 QHLGEAGALAAGAFALYEKHEAKKDPENAHRHKITEEIAATAAVGAGGYAFHEHHEK 118

gi|310940 : 38 EKIGELGAVAAGALALHEKHKAKKDPEHAHKHKIEEEIAAVAAVGAGGFAFHEHHQK 94

sp|P37219 : 38 EKIGELGAVAAGALALHEKHKAKKDPEHAHKHKIEEEIMAVAAVGAGGFAFHEHHQK 94

gi|2677824:125 EHLSEPGAAAAGVFALHEKHESKKDPEHAHKHKIEEEIAAAAAVGSGGFAFHEHHEK 181 
Fig. 1. SDS-PAGE profile of soluble leaf proteins from non-acclimated, cold-acclimated and deacclimated tissues of Rhododendron cultivars. Protein $(30 \mu \mathrm{g})$ was loaded in each lane. Molecular masses $(\mathrm{kDa})$ of protein standards are indicated to the left. NA=non-acclimated, $\mathrm{CA}=$ cold-acclimated and $\mathrm{DA}=$ deacclimated.

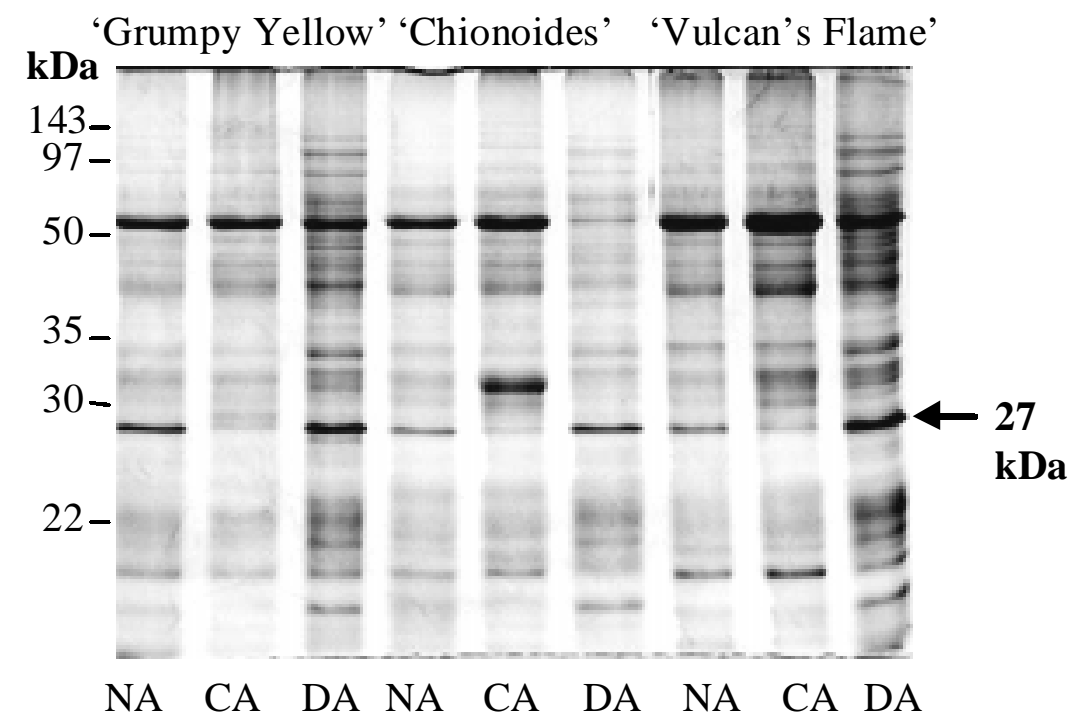


Fig. 2. SDS-PAGE analysis of Rotofor fractions $(3-20)$ containing soluble leaf proteins from deacclimated tissues of R. 'Vulcan's Flame'. Fractions were obtained by free-solution IEF as described in M\&M. Ten microliters of sample was loaded in each lane. Fraction 13 was highly enriched with 27-kDa protein (arrow). The $\mathrm{pH}$ of each fraction, which corresponds to the isoelectric point of the proteins in that fraction, is indicated at the bottom. Molecular masses $(\mathrm{kDa})$ of protein standards are indicated to the left.

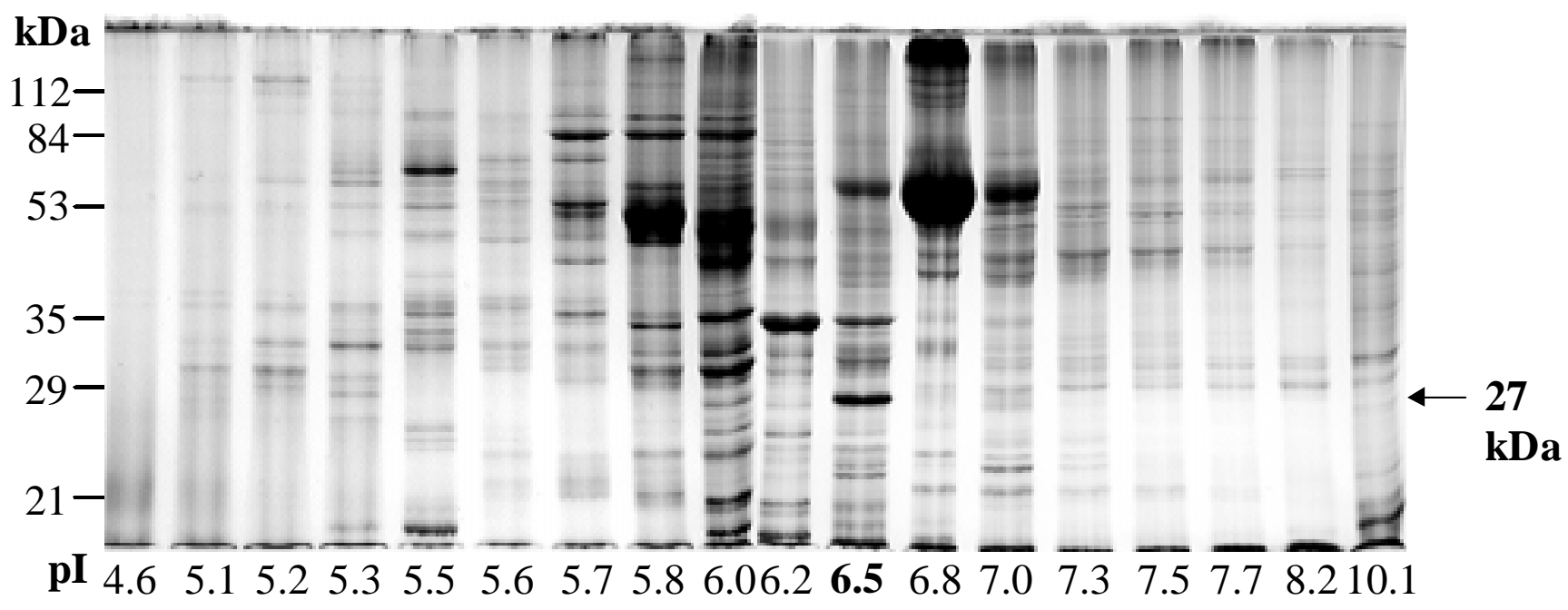




\section{APPENDIX B \\ LIST OF OTHER RELATED ARTICLES}

Arora R, Rowland LJ, Panta GR, Lim CC, Lehman JS, Vorsa N (1998) Genetic control of cold hardiness in blueberry. In: Li PH, Chen THH (eds) Plant cold hardiness: molecular biology, biochemistry, and physiology. Plenum Press, New York, pp 99

Rowland LJ, Arora R, Lehman JS, Levi A., Ogden EL, Panta GR, Lim CC (submitted) Use of blueberry to study genetic control of chilling requirement and cold hardiness in woody perennials. HortSci in press

Arora R, Rowland LJ, Lehman JS, Lim CC, Panta GR, Vorsa N (submitted) Genetic Analysis of Freezing Tolerance in Blueberry (Vaccinium section Cyanococcus). Theor Appl Genet in press 


\section{VITA}

\section{CHON CHONG (KENNY) LIM}

140 JALAN SS22/32 • 47400 PETALING JAYA • SELANGOR D. E. MALAYSIA

PHONE1-603-717-3399.E-MAILchonlim@hotmail.com

EDUCATION

- 1993 - $1995 \quad$ University of Delaware Newark, Delaware

M. Sc. in Plant Improvement (Plant Tissue Culture)

Micropropagation of Aconitum uncinatum and Helleborus orientalis

- 1991 - $1993 \quad$ Oklahoma State University Stillwater, Oklahoma

B. S. in Agriculture (Horticulture and Landscape Architecture)

WORK EXPERIENCE

- 1995-1999 West Virginia University

Graduate Research Assistant - Stress Physiology Lab

- 1993 - $1995 \quad$ University of Delaware

Teaching Assistant - Botany I and Botany II

- Summer $1994 \quad$ University of Delaware

Research Assistant - Corn Breeding Program

- Spring $1993 \quad$ Oklahoma State University

Greenhouse Staff

- 1988 - 1990 Orchid Breeder
Morgantown, West Virginia

Newark, Delaware

Newark, Delaware

Stillwater, Oklahoma

Selangor, MALAYSIA

SCHOLARSHIPS AND GRANTS

- Research Assistantships (West Virginia U) 1995-1999

- Henry Miller Scholarship (Pittsburgh Foundation) 1997

- Teaching Assistantships (U of Delaware) 1993-1995

- Ester Henry Memorial Scholarship (Tulsa Garden Club) 1992-1993

- Student Travel Grant (American Society for Horticulture Science) 1996-1999

- Doctoral Student Travel Grant (Office of Academic Affairs, WVU) 1996, 1998 
AWARDS RECEIVED

- Sigma Xi's Graduate Student Award for Research Excellence 1999

- WVU International Student Service Award 1998

- Who's Who Among Students in American Universities and Colleges 1993

- ASHS Outstanding Undergraduate Student in Horticulture 1993

- Transfer Scholar Award (Gamma Sigma Delta) 1993

- Exceptional Leadership Achievement Certificate (OSU Minority Programs and Services) 1992

- President's Honor Roll (OSU) Fall 1992 - Spring 1993

- Dean's Honor List (OSU) Fall 1991 - Spring 1993

POSTER COMPETITION \& FLORAL CROPS JUDGING CONTEST

- $1^{\text {st }}$ place ASHS $4^{\text {th }}$ Annual Graduate Student Poster Competition 1998

- $1^{\text {st }}$ place WVU 2nd Annual CAFCS Graduate Student Poster Session 1997

- $1^{\text {st }}$ place ASHS 2nd Annual Graduate Student Poster Competition 1996

- 52nd. National Intercollegiate Floral Crops Judging Contest in River Falls, Wisconsin, 1993

Team rank (Oklahoma State University) - 3rd overall

Individual $\quad-5^{\text {th }}$ overall

Potted plants category $\quad-2^{\text {nd }}$ place

PROFESSIONAL MEMBERSHIPS

- American Society for Horticulture Science

HONORARY ORGANIZATIONS

- WVU Chapter of Sigma Xi (The Scientific Research Society) 1999

- Gamma Sigma Delta (Honorary Society for Agriculture) 1993 (OSU), 1999 (WVU)

- Phi Kappa Phi (Honorary Society for University Top Ten seniors) 1993

- Alpha-Delta Chapter of Pi Alpha Xi (Honorary Society for Floriculture) 1992-1993

- Golden Key National Honor Society 1992

UNIVERSITY ORGANIZATIONS

- WVU Graduate Student Task Force (International Student Representative) 1998

- WVU Student Affairs Visiting Committee (Graduate Student Representative) 1996

- WVU Malaysian Student Association (President) 1996-1997

- UD Annual Conference for Graduate Teaching Assistants (Panelist) 1994

- OSU College of Agr. Effective Teaching Committee (Student Representative) 1992-1993

- OSU Malaysian Student Society (Assistant Secretary) 1991-1992 


\section{INTERNATIONAL AND NATIONAL ACTIVITIES}

- Poster presentation on Juvenility influences cold acclimation ability in Rhododendron populations at $96^{\text {th }}$ ASHS International Conference, Minneapolis, Minnesota, July 1999

- Poster presentation on Freezing tolerances in Rhododendron and its association with dehydrin expression at $95^{\text {th }}$ ASHS International Conference, Charlotte, North Carolina, July 1998

- Poster presentation on Genetic study of cold hardiness in Rhododendron populations at 94th ASHS International Conference, Salt Lake City, Utah, July 1997

- Poster presentation on Seasonal fluctuations in cold hardiness and protein profiles of five Rhododendron cultivars at 93 ${ }^{\text {rd }}$ ASHS National Meeting, Lexington, Kentucky, October 1996

- Poster presentation on Micropropagation of Helleborus orientalis Lam. and Aconitum uncinatum Linn. at $92^{\text {nd }}$ ASHS National Meeting, Montreal, Canada, July 1995

- Oral presentation on Micropropagation of Aconitum uncinatumr. growth regulators and antioxidants screening by surface-response analysis method at Northeast Regional ASHS Meeting, USDA Beltsville, Maryland, January 1995

\section{UNIVERSITY ACTIVITIES}

- Poster presentation on A $25-\mathrm{kD}$ dehydrin associated with genotype-and age-dependent leaf freezing-tolerance in Rhododendron : a genetic marker for cold hardiness at $3^{\text {rd }}$ Annual CAFCS Graduate Student Paper/ Poster Session, WVU, Morgantown, March 1999

- Poster presentation on Genetic study of cold hardiness in Rhododendron populations at $2^{\text {nd }}$ Annual CAFCS Graduate Student Paper/ Poster Session, WVU, Morgantown, April 1998

- Poster presentation on A comparison of analytical approaches for estimating freezing injury in Rhododendron using electrolyte leakage method at $1^{\text {st }}$ Annual CAFCS Graduate Student Paper/ Poster Session, WVU, Morgantown, March 1997

- UD International Teaching Assistants Training Program (Participant) 1993

- OSU Flower Judging Team (Team Captain) 1993

- OSU International Cultural Night (Performer) 1991-1992

- OSU International Expo (Malaysia booth Display Curator) 1991

- OSU Annual Madrigal Dinner and Concert (Floral decorator) 1992.

\section{OTHER ACTIVITIES}

- WVU International Student Society \& Malaysian Student Association 1995-1999

- Designed Tropical Landscape in OSU Teaching Greenhouses 1991

- Volunteer in various fund-raising activities for OSU Flower Judging Team 1992

- OSU Horticulture Club \& Malaysian Student Society 1991-1993 